by

C. Neumeyer, P. Heitzenroeder, J. Spitzer, J. Chrzanowski, A. Brooks, J. Bialek, H.M. Fan, G. Barnes, M. Viola, B. Nelson, P. Goranson, R. Wilson, E. Fredd, L. Dudek, R. Parsells, M. Kalish, W. Blanchard, R. Kaita, H. Kugel, B. McCormack, S. Ramakrishnan, R. Hatcher, G. Oliaro, E. Perry, T. Egebo, A. Von Halle, M. Williams, and M. Ono.

May 2000

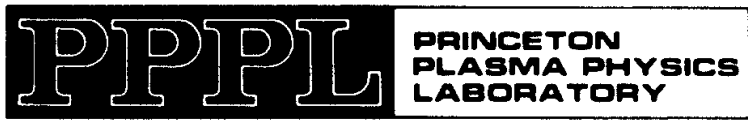

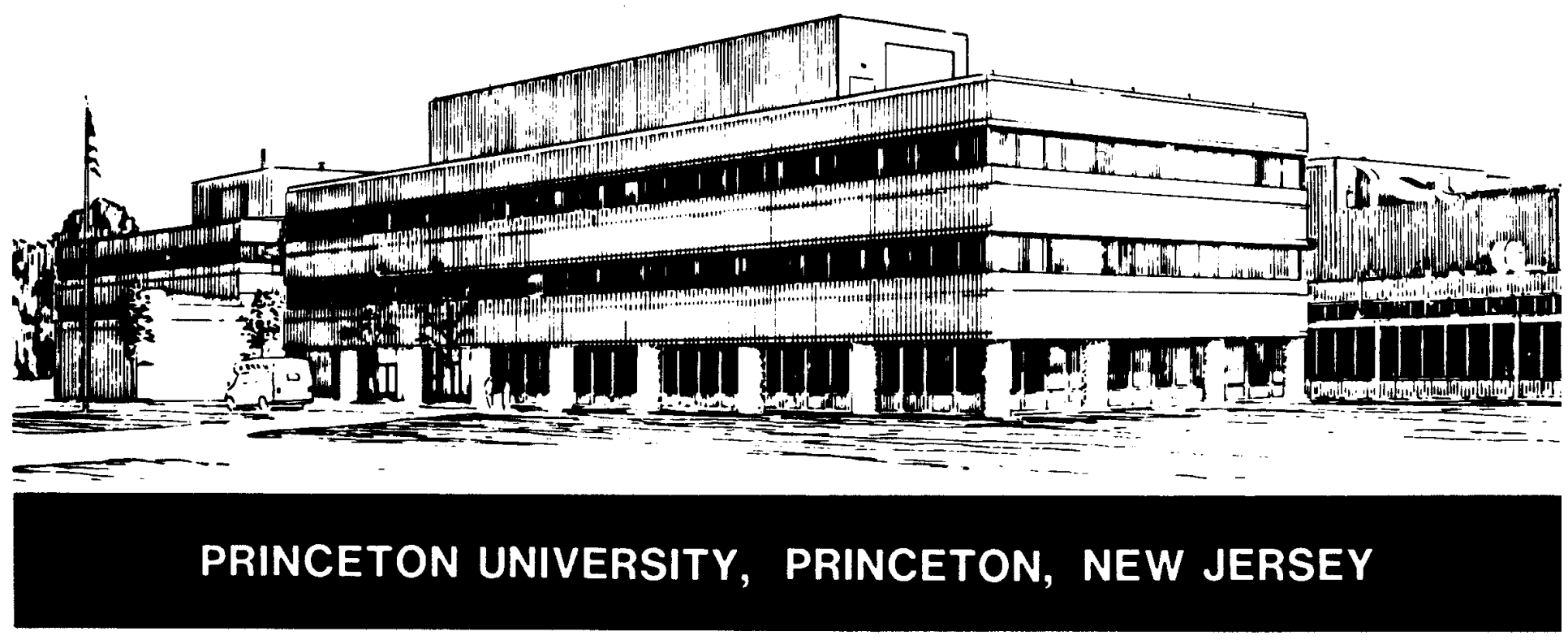




\section{PPPL Reports Disclaimer}

This report was prepared as an account of work sponsored by an agency of the United States Government. Neither the United States Government nor any agency thereof, nor any of their employees, makes any warranty, express or implied, or assumes any legal liability or responsibility for the accuracy, completeness, or usefulness of any information, apparatus, product, or process disclosed, or represents that its use would not infringe privately owned rights. Reference herein to any specific commercial product, process, or service by trade name, trademark, manufacturer, or otherwise, does not necessarily constitute or imply its endorsement, recommendation, or favoring by the United States Government or any agency thereof. The views and opinions of authors expressed herein do not necessarily state or reflect those of the United States Government or any agency thereof.

\section{Availability}

This report is posted on the U.S. Department of Energy's Princeton Plasma Physics Laboratory Publications and Reports web site in Calendar Year 2000. The home page for PPPL Reports and Publications is: http://www.pppl.gov/pub_report/

DOE and DOE Contractors can obtain copies of this report from:

U.S. Department of Energy

Office of Scientific and Technical Information

DOE Technical Information Services (DTIS)

P.O. Box 62

Oak Ridge, TN 37831

Telephone: (865) 576-8401

Fax: (865) 576-5728

Email: reports@adonis.osti.gov

This report is available to the general public from:

National Technical Information Service

U.S. Department of Commerce

5285 Port Royal Road

Springfield, VA 22161

Telephone: $1-800-553-6847$ or

(703) $605-6000$

Fax: (703) 321-8547

Internet: http://www.ntis.gov/ordering.htm 


\title{
ENGINEERING DESIGN OF THE NATIONAL SPHERICAL TORUS EXPERIMENT
}

C. Neumeyer ${ }^{\mathrm{a}}$, P. Heitzenroeder ${ }^{\mathrm{a}}$, J. Spitzer ${ }^{\mathrm{a}}, \mathrm{J}_{\text {. Chrzanowski }}$, A. Brooks ${ }^{\mathrm{a}}$, J. Bialek $^{\mathrm{b}}$, H. M. Fan ${ }^{\mathrm{a}}$, G. Barnes ${ }^{\mathrm{a}}$, M. Viola ${ }^{\mathrm{a}}$, B. Nelson ${ }^{\mathrm{c}}$, P. Goranson ${ }^{\mathrm{c}}$, R. Wilson $^{a}$, E. Fredd ${ }^{a}$, L. Dudek ${ }^{a}$, R. Parsells ${ }^{a}$, M. Kalish ${ }^{a}$, W. Blanchard ${ }^{a}$, R. Kaita $^{\mathrm{a}}$, H. Kugela ${ }^{\mathrm{a}}$, B. McCormack ${ }^{\mathrm{a}}$, S. Ramakrishnan ${ }^{\mathrm{a}}$, R. Hatcher ${ }^{\mathrm{a}}$, G. Oliaro $^{\text {a }}$, E. Perry ${ }^{\mathrm{a}}$, T. Egebo ${ }^{\mathrm{a}}$, A. Von Halle ${ }^{\mathrm{a}}$, M. Williams ${ }^{\mathrm{a}}$, M. Ono ${ }^{\mathrm{a}}$

aPrinceton Plasma Physics Laboratory, Princeton, NJ, USA

${ }^{\mathrm{b} C}$ Columbia University, New York, NY, USA

'Oak Ridge National Laboratory, Oak Ridge, TN, USA

\begin{abstract}
NSTX is a proof-of-principle experiment aimed at exploring the physics of the "spherical torus" (ST) configuration, which is predicted to exhibit more efficient magnetic confinement than conventional large aspect ratio tokamaks, amongst other advantages. The low aspect ratio (R/a, typically 1.2 $\sim 2$ in ST designs compared to $4 \sim 5$ in conventional tokamaks) decreases the available cross sectional area through the center of the torus for toroidal and poloidal field coil conductors, vacuum vessel wall, plasma facing components, etc., thus increasing the need to deploy all components within the so-called "center stack" in the most efficient manner possible. Several unique design features have been developed for the NSTX center stack, and careful engineering of this region of the machine, utilizing materials up to their engineering allowables, has been key to meeting the desired objectives. The design and construction of the machine has been accomplished in a rapid and cost effective manner thanks to the availability of extensive facilities, a strong experience base from the TFTR era, and good cooperation between institutions.
\end{abstract}

\section{Introduction}

The National Spherical Torus Experiment (NSTX) is a proof-of-principle "spherical torus" (ST) experiment, the development of which was motivated by promising results obtained by several small scale experiments, as well as encouraging theoretical predictions. 
The ST is an axi-symmetric toroidal device characterized by a low aspect ratio compared to that of traditional tokamak experimental devices. The primary factor leading to strong interest in the ST configuration is its ability to operate with relatively high ratio $(\beta)$ of plasma pressure to magnetic field. Since the power density in a fusion reactor is proportional to $\beta^{2}$, a significant increase in this factor over that obtainable in high aspect ratio devices could dramatically improve the prospects for realization of practical magnetic confinement fusion power. In addition to an increase in the $\beta$ limit, the ST configuration is predicted to be favorable for high pressure driven (bootstrap) currents. Its naturally elongated plasma shape leads to a reduction in shaping duty imposed on external poloidal field coils, and a reduction in density of power deposited on plasma facing surfaces as a result of flux tube expansion $[1,2]$.

The aim of the NSTX experiment is to assess and quantify the physics performance of the ST on a moderate scale and provide a database for the design of future machines based on the ST configuration.

While offering the advantages cited above, the low aspect ratio decreases the available cross sectional area through the center of the torus for toroidal and poloidal field coil conductors, vacuum vessel wall, plasma facing components, etc., thus increasing the need to deploy all components within the "center stack" in the most efficient manner possible. Therefore careful engineering of this region of the machine, utilizing materials up to their engineering allowables, is key to meeting the desired objectives.

In addition to the engineering challenges presented by the center stack, two additional aspects are especially important and noteworthy as significant design drivers on NSTX. First, the use of non-inductive current drive via Coaxial Helicity Injection (CHI) [3], which requires the ability to apply a high voltage between the inner and outer parts of the machine. Second, the use of high temperature $\left(350^{\circ} \mathrm{C}\right)$ bakeout to facilitate the removal of water from the graphite and carbon fiber composite Plasma Facing Components (PFCs), which requires provision of a high temperature heating system along with suitable structural design features to allow for the differential thermal expansion of the various machine components.

Construction of the basic NSTX machine culminated in first plasma in February 1999. Since then, the installation of all of the internal hardware, 
along with the High Harmonic Fast Wave RF heating system, as well several basic diagnostic systems, has been completed. The plasma control system has been commissioned, all fields have been operated at rated levels and 1MA plasma discharges have been obtained. It is planned to install Neutral Beam Injection (NBI) and commence operations of same by October 2000.

This article describes the engineering design of the NSTX device, with emphasis on those features which are unique to the ST configuration.

\section{Mission and Requirements}

\subsection{Background}

NSTX evolved from ST machine concepts (e.g. PSTX) originally conceived and developed by M. Ono, M. Peng, and S. Kaye et al beginning in the early 1990's. The design approach was strongly influenced by the objective of cost minimization via use of existing equipment and facilities. The original plan called for the use of the PPPL C-site facility which formerly supplied the Princeton Large Torus (PLT), as well as the vacuum vessel domes and outer poloidal field (PF) coils from the Spheromak-1 (S-1) machine. Given the constraints of the C-site facility, and the physical dimensions of the S-1 equipment, the basic size of the machine was to a large degree predetermined without extensive parametric analysis as would otherwise be the case.

Following the Physics Validation in June 1995, the engineering effort began in earnest. An "Engineering Cost \& Schedule Review" (ECSR, really a project-wide conceptual design) was held in July 1996. The ECSR Committee consisted of experts from various institutions not directly involved in NSTX. In April 1996 the Tokamak Fusion Test Reactor (TFTR), which operated at the PPPL D-site facility, was retired, and the decision was taken in December 1996 to install NSTX at D-site in the "Hot Cell" adjacent to the TFTR Test Cell, where the TFTR machine remains (its decommissioning has recently begun). Although the basic NSTX machine size and mission were not changed at that time, the availability of the D-site facility, in particular the power supply system, provided relief on significant design constraints associated with the toroidal field (TF) and PF coil systems. The eventual availability of the TFTR NBI system was an additional significant benefit to be realized by relocation to D-site. A "Checkpoint Review" was held in October 1996 at which time the ECSR 
Committee assessed progress against the action items raised at the ECSR. A Final Design Review (FDR) of the center stack components was held in February 1997, along with a review of the systems which had to be redesigned after the project relocated to D-site (Power Systems, Auxiliary Systems (vacuum, water, services, etc.) and Central I\&C). Following this review, procurement of long lead items (copper conductor extrusions) began.

All remaining elements were subject to Preliminary and Final Design Review, the last of which (the Data Acquisition System) was completed in November 1998, thus ending the engineering design phase of the original construction project.

Major project milestones are summarized in Table 1.

Table 1 - Major Project Milestones

\begin{tabular}{|l|l|}
\hline Physics validation & June 1995 \\
\hline Engineering Cost \& Schedule Review (CDR) & July 1996 \\
\hline Checkpoint Review & October 1996 \\
\hline Center Stack Final Design Review & February 1997 \\
\hline TF \& OH Conductor Procurement & May - September 1997 \\
\hline TF Coil Inner Leg Bundle Fabrication & June 1997 - March 1998 \\
\hline OH Coil Fabrication & August 1997 - June 1998 \\
\hline Vacuum Vessel Fabrication & March - August 1998 \\
\hline Plasma Facing Component (PFC) Tile Fabrication & February - November 1998 \\
\hline Center Stack Assembly & April - November 1998 \\
\hline Basic Machine Assembly & October - December 1998 \\
\hline Final Engineering FDR & November 1998 \\
\hline First Pump Down & November 1998 \\
\hline First Plasma & February 1999 \\
\hline Internal Hardware \& RF Antenna Assembly & March 1999 - July 1999 \\
\hline Completion of Baseline Project Scope & July 1999 \\
\hline
\end{tabular}

The Total Project Cost (TPC) was $\$ 23.6 \mathrm{M}$. Cost breakdown is given in Table 2. 
Table 2 - Cost Breakdown (\$M)

\begin{tabular}{|l|c|}
\hline Plasma Facing Components & 1.90 \\
\hline Vacuum Vessel & 1.44 \\
\hline Magnets & 5.41 \\
\hline HHFW RF and ECH Preionization & 1.67 \\
\hline Auxiliary Systems (Water, Vacuum, Gas, Bakeout) & 1.87 \\
\hline Initial Diagnostic Set & 0.92 \\
\hline Power Systems & 1.85 \\
\hline Central I\&C & 1.91 \\
\hline Facilities \& Machine Assembly & 2.40 \\
\hline Project Support and Integration \& Other & 4.22 \\
\hline TOTAL PROJECT COST & $\$ 23.6 \mathrm{M}$ \\
\hline
\end{tabular}

Thanks to the availability of D-site following TFTR retirement, a significant existing facility infrastructure was made available to the NSTX project. The estimated value of the site credits is given in Table 3, counting only that equipment used directly on NSTX, and excluding building costs, diagnostics, and NBI systems. With this in mind, to give a sense of scale of the entire undertaking, the total project cost in case of a "green field" site would have been of order $\$ 100 \mathrm{M}$.

Table 3 - Estimated Value of Site Credits (\$M)

\begin{tabular}{|l|c|}
\hline Electric Power Systems & 44.8 \\
\hline RF Systems & 30.9 \\
\hline Auxiliary Systems (Water, Vacuum, etc.) & 0.8 \\
\hline S-1 PF Coils & 0.3 \\
\hline Other & 0.35 \\
\hline TOTAL SITE CREDITS & $\$ 77.1 \mathrm{M}$ \\
\hline
\end{tabular}

\subsection{Mission}

The mission of NSTX is to perform a proof-of-principle experiment to assess the physics of the ST in terms of global confinement and transport, pressure $(\beta)$ limits, pressure driven (bootstrap) currents, scrape-off-layer and divertor physics, and stability and disruptions. The outcome will be an extension of the knowledge base already in hand for high aspect ratio devices, which can serve as a basis for future machines such as a Volumetric 
Neutron Source (VNS) or Deuterium-Tritium (DT) ST burning plasma experiment (DTST). In addition, because the ultimate ST reactor configuration would exclude the use of an $\mathrm{OH}$ coil in the center column, technologies for plasma non-inductive start up, current drive, sustainment, and profile control need to be developed as part of the NSTX mission. These include High Harmonic Fast Wave (HHFW) RF Injection and Coaxial Helicity Injection (CHI)

The mission strategy is to provide a low aspect ratio machine which aims to minimize center stack radial build but is still equipped with a modest Ohmic Heating $(\mathrm{OH})$ coil for limited inductive current drive. The initial phase of the research will be performed with fully inductive plasma discharges with plasma current $\mathrm{I}_{\mathrm{p}} \sim 1 \mathrm{MA}, 0.5$ second flat top and a bipolar $\mathrm{OH}$ current waveform to deliver the maximum possible flux swing. Capability is provided for operation over wide range of plasma configurations and shapes including double null, single null, and inboard limited plasmas with aspect ratio $\mathrm{R} / \mathrm{a} \sim 1.25$ to 2.5 , elongation $\kappa \sim 1.3$ to 2.1 and triangularity $\delta \sim 0.2$ to 0.6. This will allow for the characterization of basic ST physics over a wide range. Following the initial phase of the research, the focus will move toward the development of the $\mathrm{CHI}$ and HHFW current drive capability, first with partial inductive start-up and current drive in which the $\mathrm{OH}$ creates a target plasma with a single flux swing ending at or near zero current, after which CHI and HHFW are to sustain the plasma for up to 5 seconds. During the final phase of the research fully inductive startup and sustainment will be attempted.

\subsection{Requirements}

Engineering requirements, summarized in Table 4, were developed and formalized following the conceptual design phase. 
Table 4 - Summary of Engineering Requirements

\begin{tabular}{|l|l|l|}
\hline \multirow{5}{*}{ Plasma } & Major Radius (R0) & $85.4 \mathrm{~cm}$ \\
\cline { 2 - 3 } & Aspect Ratio (R/a) & 1.26 \\
\cline { 2 - 3 } & Current & $1.0 \mathrm{MA}$ \\
\cline { 2 - 3 } & Ramp Time & $0.2-0.4 \mathrm{sec}$ \\
\cline { 2 - 3 } & Flat Top (Inductive) & $0.5 \mathrm{sec}$ \\
\cline { 2 - 3 } & Repetition Period (Ind.) & $600.0 \mathrm{sec}$ \\
\cline { 2 - 3 } & Flat Top (non-Inductive) & $5.0 \mathrm{sec}$ \\
\cline { 2 - 3 } & Repetition Period (Partial \& Non-Ind.) & $300.0 \mathrm{sec}$ \\
\hline \multirow{3}{*}{ Toroidal Field } & Field @ R0 & $3.0(6.0 \mathrm{kG}$ option) \\
\hline \multirow{3}{*}{$\begin{array}{l}\text { Heating/ } \\
\text { Current Drive }\end{array}$} & Flux (double swing) & $2 \times 0.3 \mathrm{volt}-\mathrm{sec}$ \\
\cline { 2 - 3 } & Initiation Loop Voltage @ R0 & $5.0 \mathrm{volt} / \mathrm{turn}$ \\
\cline { 2 - 3 } & Coaxial Helicity Injection (CHI) & $6.0 \mathrm{MW}, 30 \mathrm{MHz}, 5 \mathrm{sec}$ \\
\cline { 2 - 3 } & Neutral Beam Injection Upgrade (NBI) & $5.0 \mathrm{MW}, 80 \mathrm{kV}, 5 \mathrm{sec}$ \\
\hline Pre-Ionization & Electron Cyclotron & $30 \mathrm{~kW}, 18 \mathrm{GHz}, 0.1 \mathrm{sec}$ \\
\hline Bakeout & Bakeout Temperature & $350 \mathrm{C} \mathrm{PFCs,} \mathrm{150C} \mathrm{VV}$ \\
\hline
\end{tabular}

\section{Machine Overview}

A photograph of the NSTX machine is shown in Figure 1, and a conceptual elevation view in Figure 2. A cross section of the center stack is given in Figure 3 . The main components of the machine are described in the paragraphs which follow. 


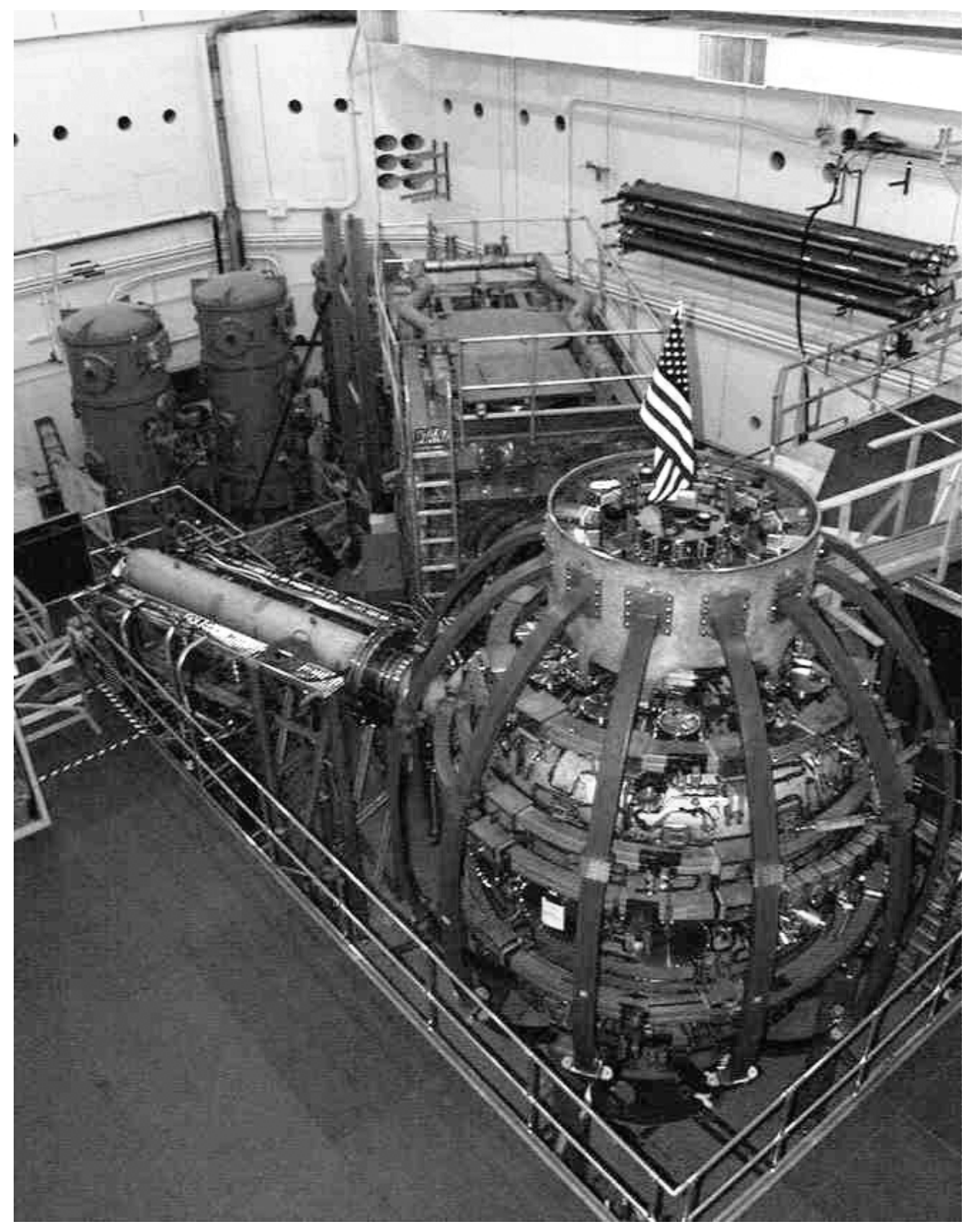

Figure 1 - NSTX In Test Cell 


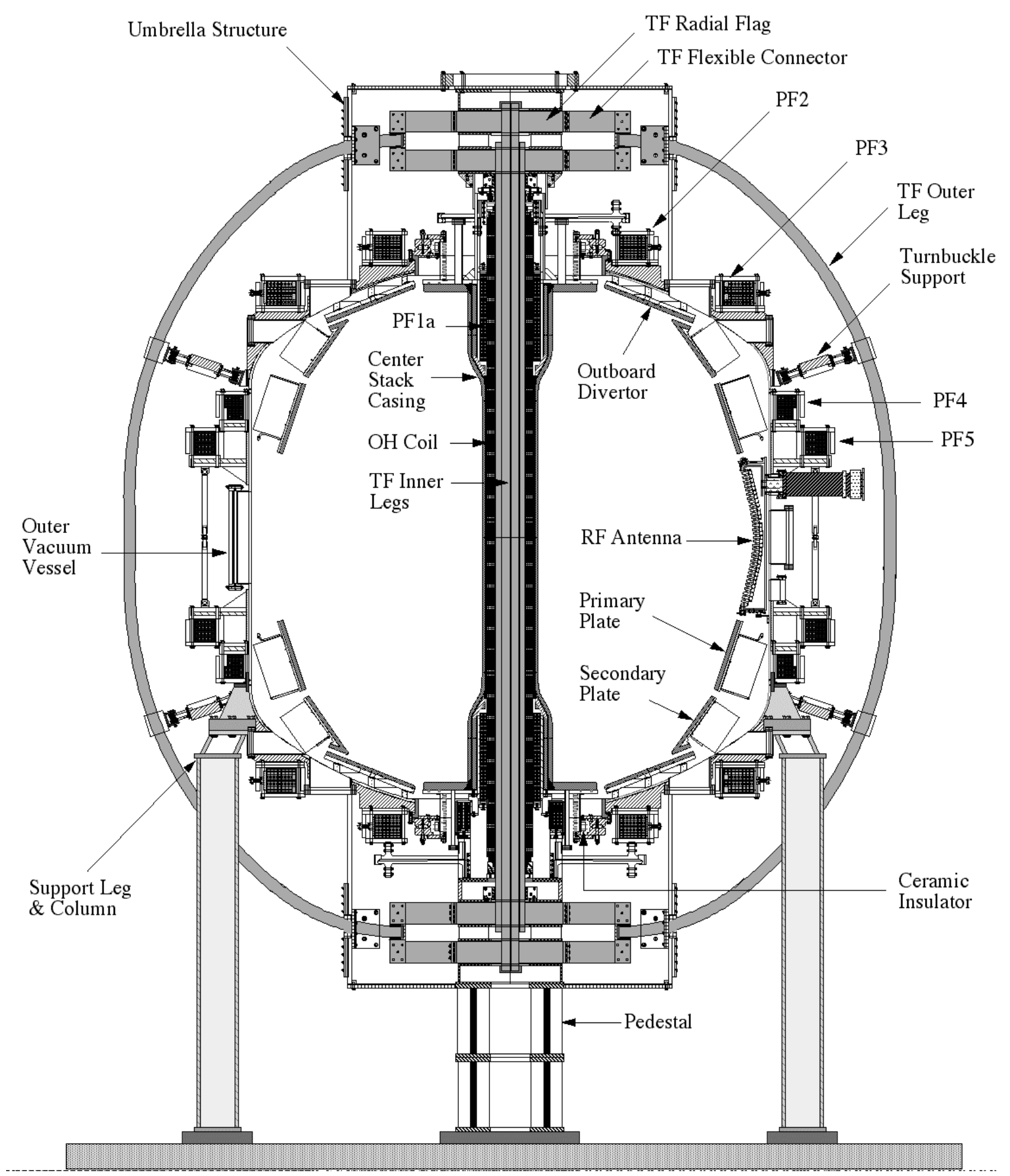

Figure 2 - Cross Section of NSTX Machine 


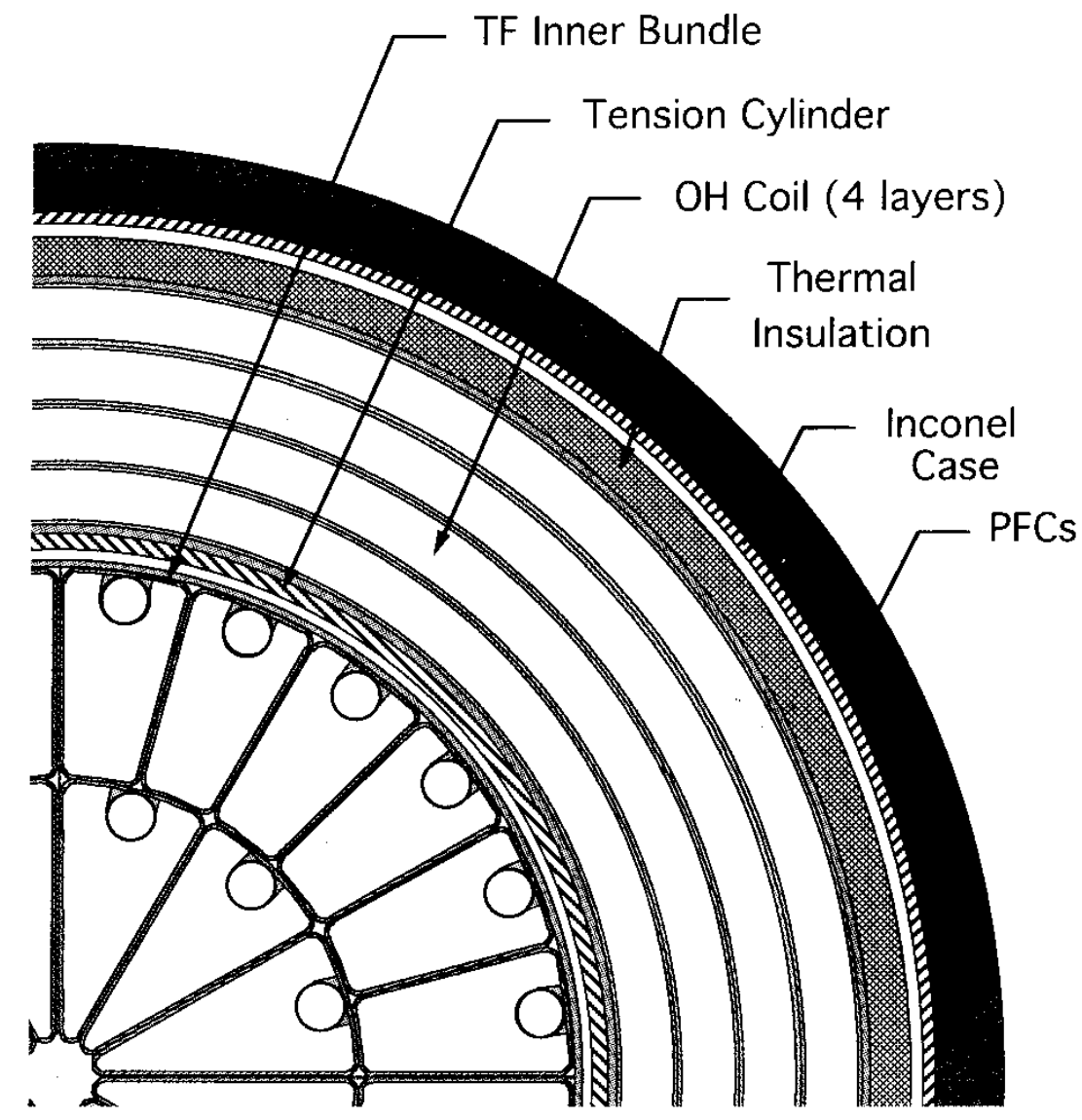

Figure 3 - Quarter Cross Section of Center Stack at Midplane

\subsection{Toroidal Field (TF) coil system}

The 36 turn "TF coil" system consists of the "inner legs", the "radial flags", the "flexible connectors", and the "outer legs". The inner legs consist of a bundle of extruded copper conductors. Each conductor is water cooled with cooling tubes soldered into milled slots on the outside edges. There are 12 turns on the inner layer and 24 turns on the outer, all of equal cross section, insulated with a B-staged epoxy glass system. Figure 4 shows the fabricated bundle prior to assembly. 


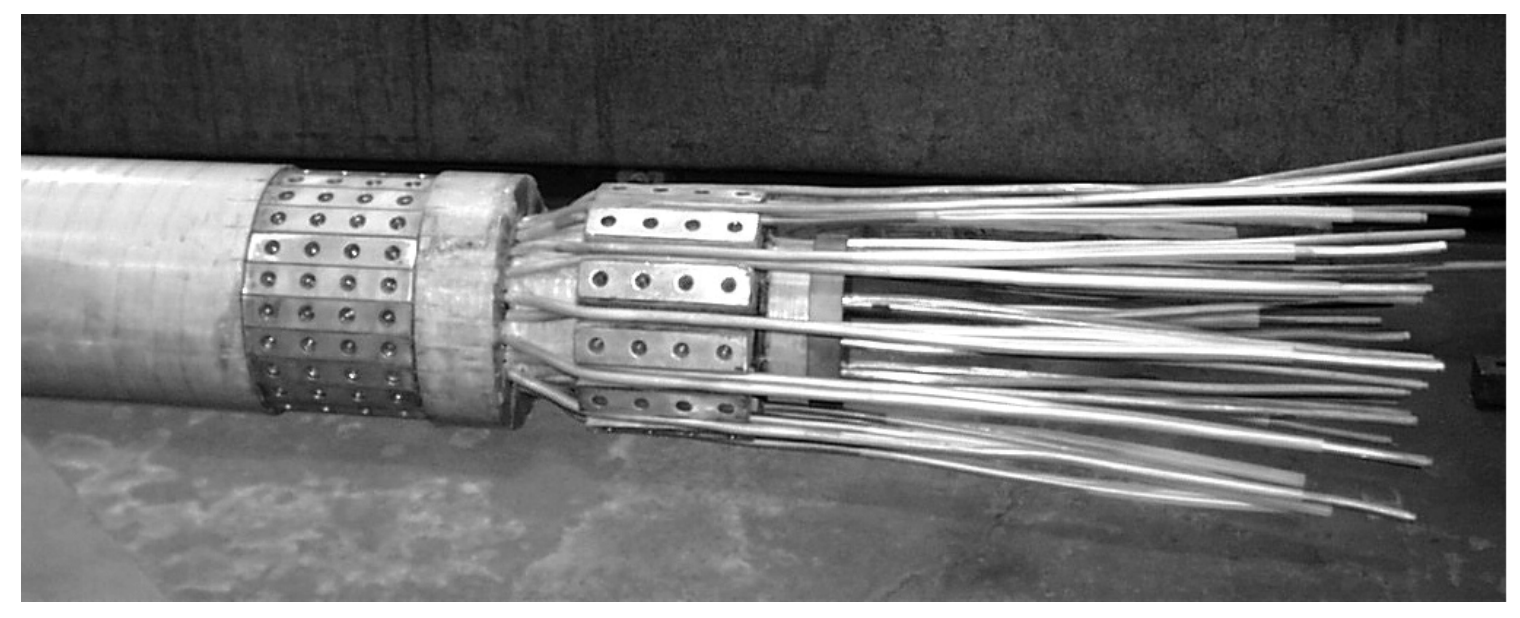

Figure 4 - End of TF Inner Leg Bundle After Fabrication, Prior to Assembly Showing Inner and Outer Leg Conductors and Water Cooling Tubes

Connections to the inner and outer layers are made at two elevations by the radial flags which are cooled mainly by thermal conduction to the water cooled inner legs, and which are supported by "hub assemblies" (Figure 5). The hub assemblies serve to lock the radial flags in place so the bolted joints to the inner legs do not experience any deformation and loss of contact pressure under electromagnetic load. 


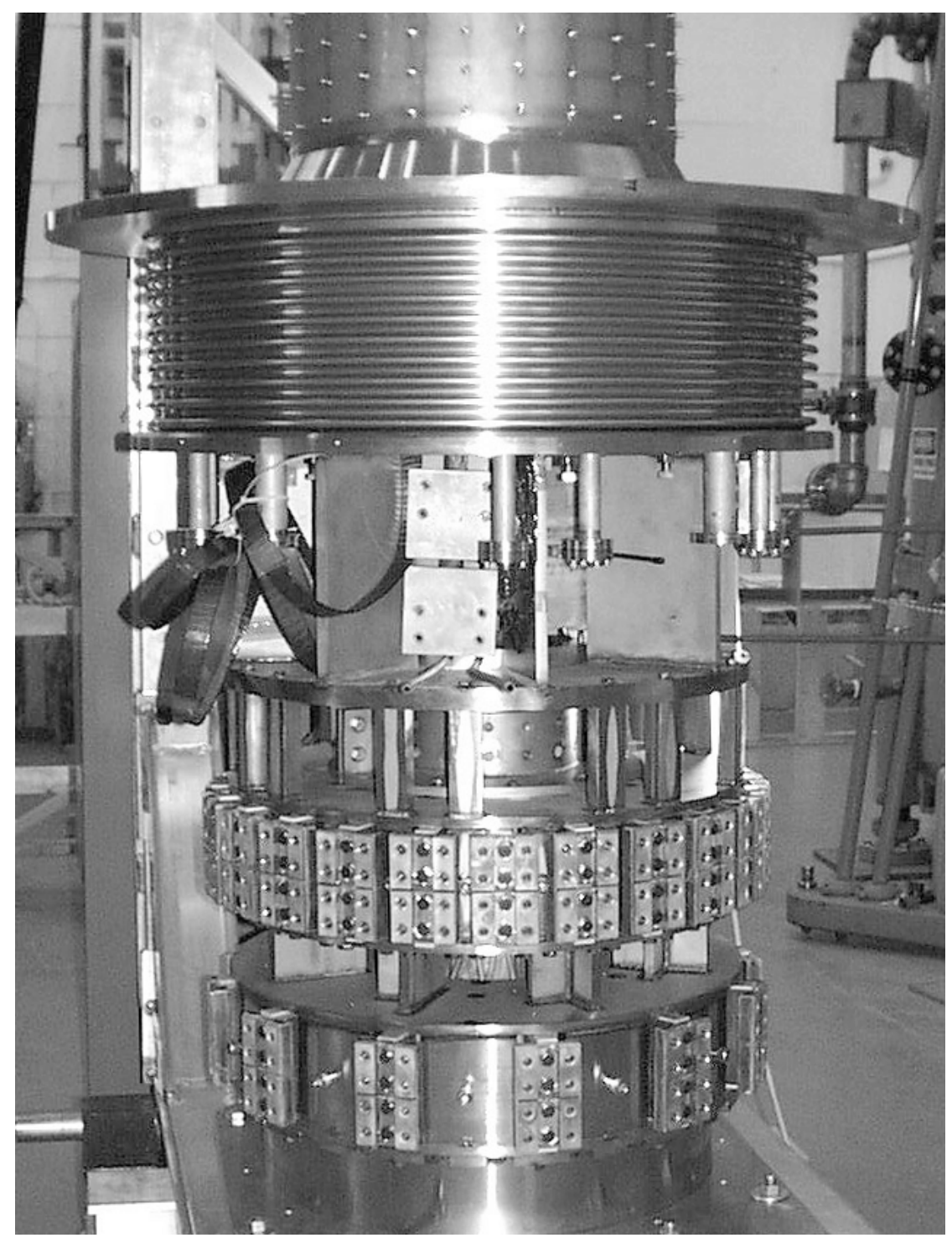

Figure 5 - Hub Assembly at End of Center Stack

The connection between the radial flags and the outer legs is accomplished via demountable flexible connectors, which are cooled mainly by conduction to the water cooled outer legs. The flexible connectors provide a mechanical decoupling of the inner leg/radial flag/hub assemblies from the outer legs for both axial and rotational modes. In addition when the are disconnected and removed the entire center stack can be removed from the machine for installation/assembly/maintenance. By careful arrangement of the turn to turn connections' angular progression in the two elevations top and bottom the net toroidal current apparent from a distance is nullified. Figure 6 shows a top view of the machine with the TF flexible connectors installed. 


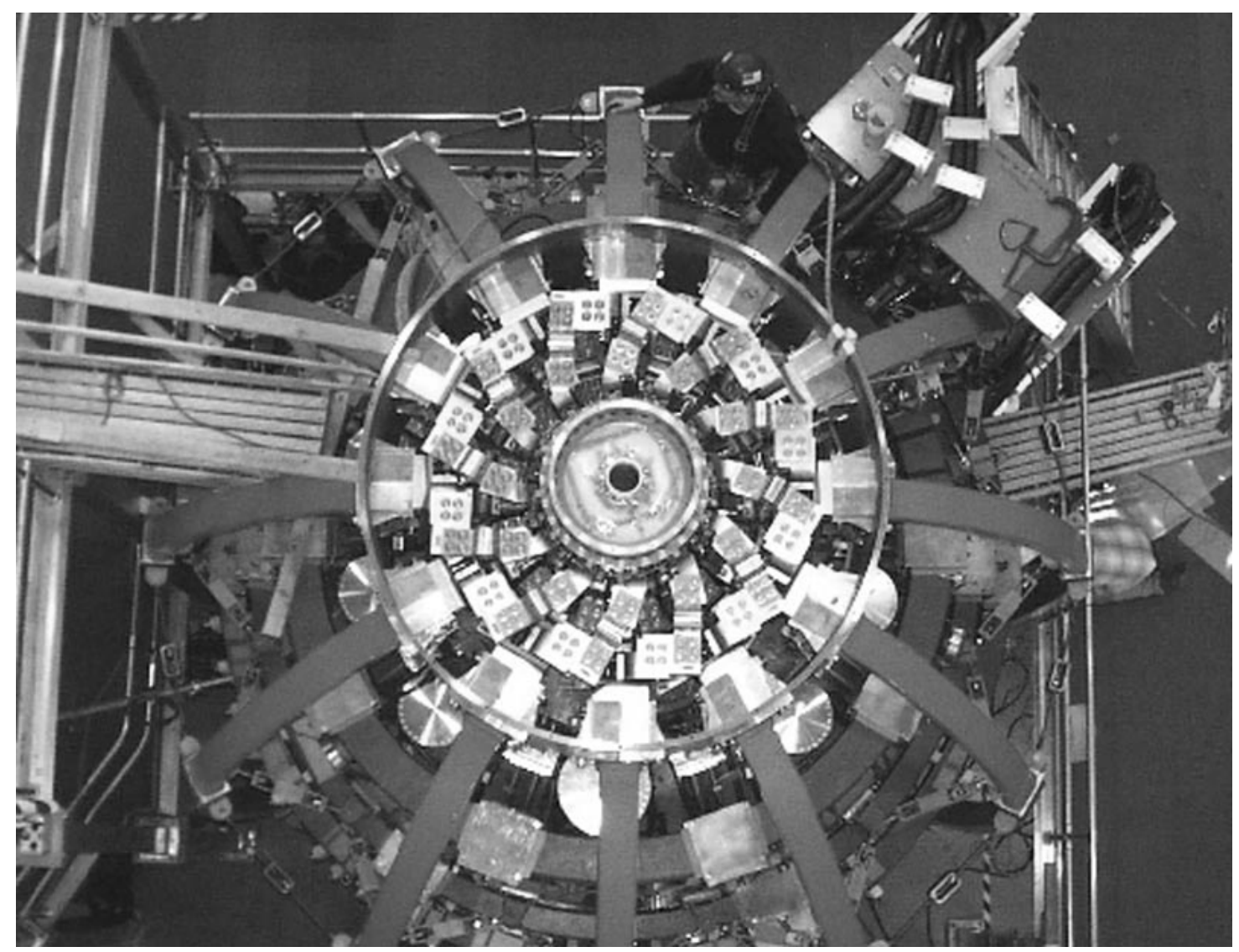

Figure 6 - Top View Showing TF Flexible Connections to Outer Legs

The TF outer legs consist of 12 bundles of three extruded copper conductors. Each conductor is water cooled with cooling tubes soldered into milled slots on the inside edges of the conductors, and insulated with a B-staged epoxy glass system. The outer legs receive their inlet cooling water from the outlet of the inner legs. The outer legs are supported as they pass through the "umbrella structure", and by a strut and "turnbuckle support" system which reacts dead weight and torsional electromagnetic loads back to the "outer vacuum vessel". Installation of TF Outer Legs is shown in Figure 7.

The TF inner leg assembly rests on the "pedestal" beneath the center stack such that all axial thermal growth is in the upward direction. 


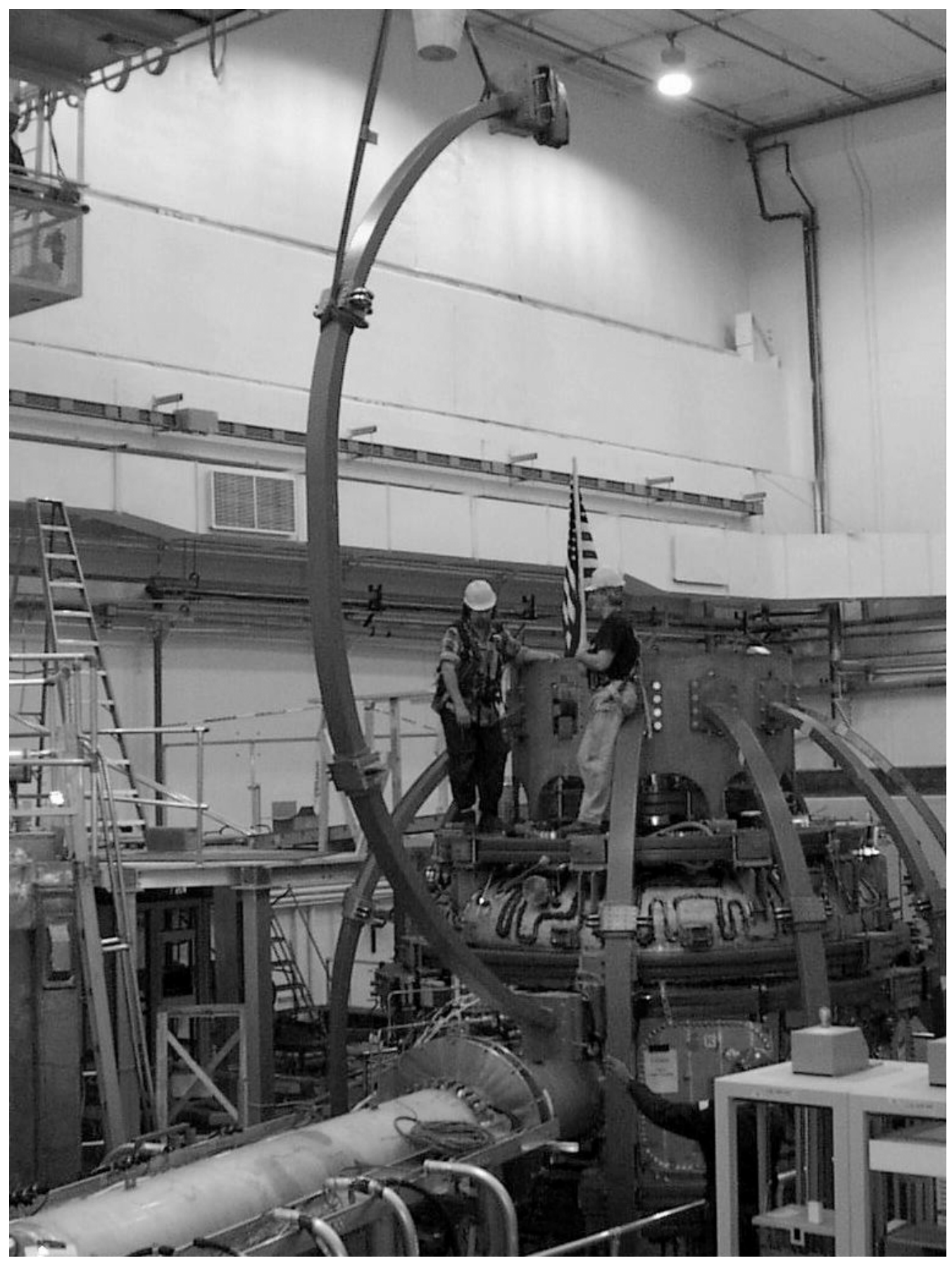

Figure 7 - TF Outer Leg Installation

3.2 Ohmic Heating $(\mathrm{OH})$ coil system

The 962 turn "OH coil" system consists of four layers which are wound "two-in-hand", forming a total of 8 sub-windings which are electrically 
connected in series, but which are water cooled in parallel by 8 individual cooling paths. Each winding is formed using extruded copper conductors with central passage for water cooling, and insulated using a B-staged kapton/epoxy glass composite. The conductor is extruded in a polygon shape such that it deforms during winding to a nearly square shape. The coil is wound over a stainless steel "tension tube", covered with a Teflon slip plane as shown in Figure 8. The tension tube serves as a winding form, and also as a means of support structure for the coil. The tension tube is affixed to the pedestal. A stack of compression washers between the top flange of the tension tube and the top of the coil body provides an axial pre-load, and axial thermal expansion of the coil body causes it to grow upward at the top while further compressing the washer stack. A sliding gap exists between the tension tube and the TF coil inner leg assembly within, allowing for the axial thermal expansion of the TF coil inner legs. A low resistance conducting paint layer forms an electrostatic shield ("ground plane") on the outside of the $\mathrm{OH}$ coil assembly. Various magnetic diagnostics (flux loops and Rogowski coils), as well as thermocouples are installed upon the $\mathrm{OH}$ coil ground plane.

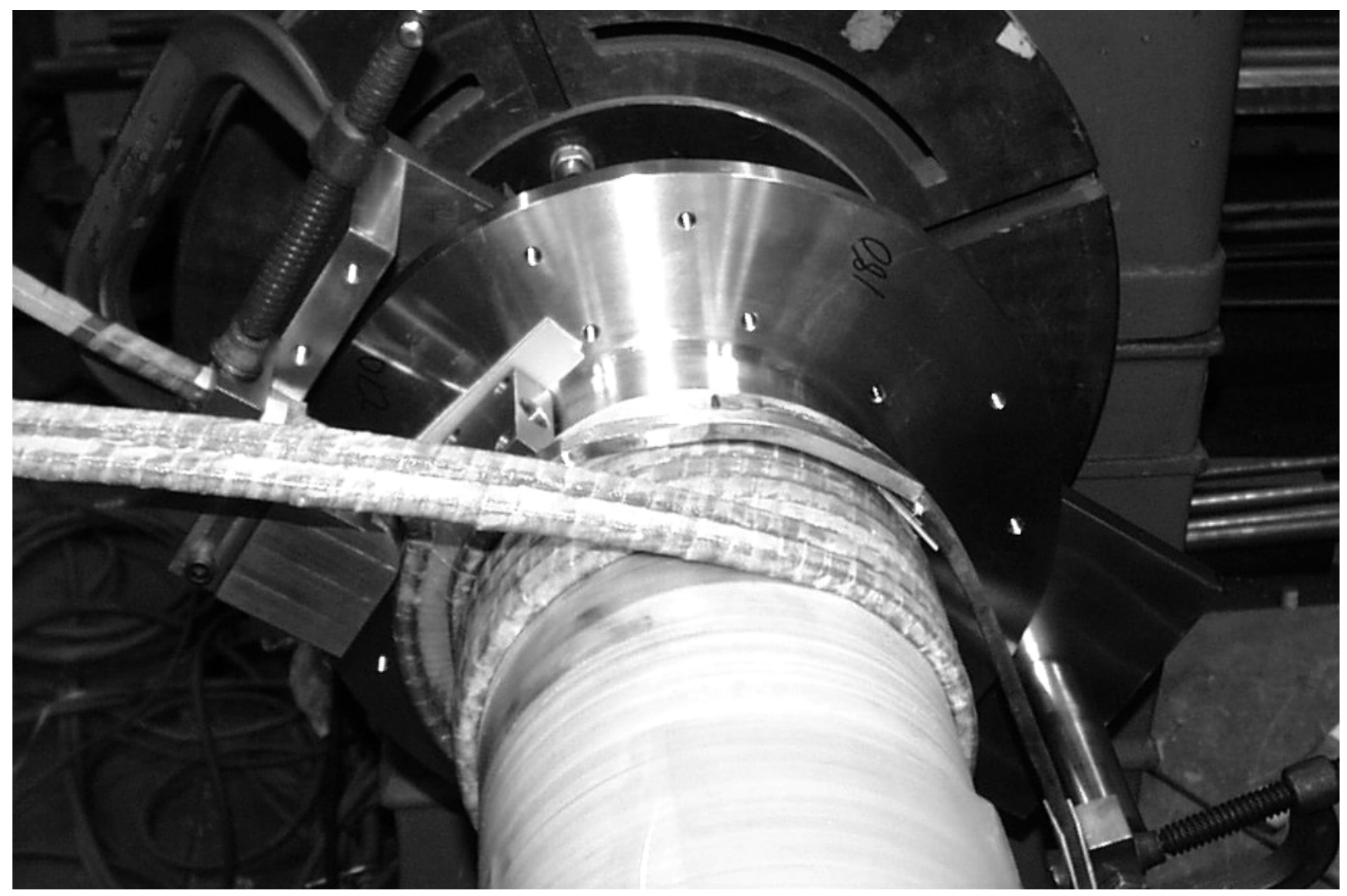

Figure 8 - OH Winding Two-In-Hand Over Teflon Layer on Tension Tube 
As shown in Figure 9 the surface of the $\mathrm{OH}$ and inner PF coils is are covered with an efficient thermal insulation ("Microtherm" by Microtherm Inc., Maryville, TN, thermal conductivity $\sim 0.025 \mathrm{~W} / \mathrm{m}-{ }^{\circ} \mathrm{K}$ ) to isolate the center stack coils from heat flowing inwards from the center stack casing during plasma operations and bakeout.

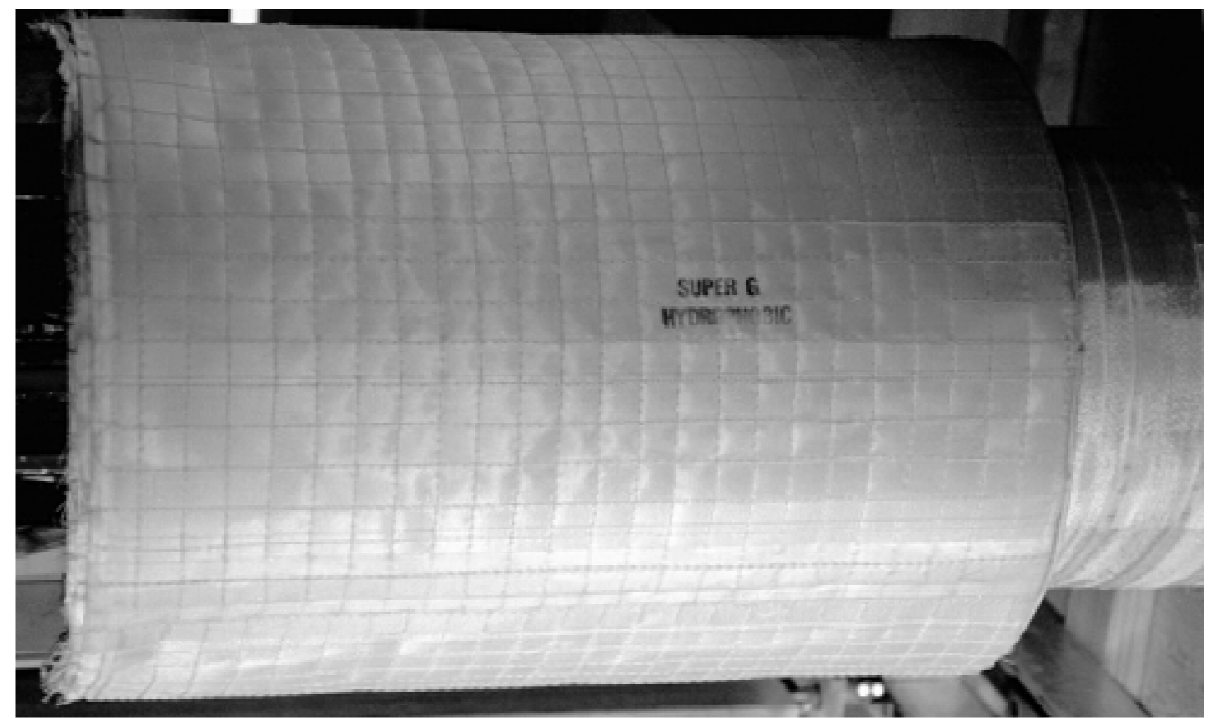

Figure 9 - Microtherm Blanket Covering OH and PF1a Coils

\subsection{Center Stack Casing}

The center stack casing (CSC) consists of a flanged inconel tube which serves as the inner wall of the vacuum vessel (Figure 10). Access for diagnostic wiring and gas injection from the air to the vacuum side of the casing is provided by the "organ pipe" tubes and conflats, approx.12 each on top and bottom flanges. In addition, four toroidally symmetric rods connect to the top and bottom flanges so as to provide an electrical connection point for the CHI bus bar, which is used both for $\mathrm{CHI}$ and for dc current injection for ohmic heating of the inconel tube during bakeout. The surface of the CSC is covered with a compact interlocking PFC tile system, consisting of alternating ATJ graphite tiles and Carbon Fiber Composite (CFC) tiles, the latter of which serve to lock in place the former (Figure 11). Cavities are provided in the rear of the tiles into which Mirnov coils and thermocouples are installed, with the sensor lead wiring exiting via channels formed at the 
borders of adjoining tiles. There is no active cooling of the CSC; it is cooled primarily by radiation to the outboard internal hardware. As a consequence it is designed for operation up to $600^{\circ} \mathrm{C}$. The CSC flanges are mechanically connected to the outer vacuum vessel (VV) via bellows and "ceramic insulator" assemblies. The bellows allow for relative displacement of the CSC and the outer VV due to thermal effects during operations and bakeout The ceramic insulator assemblies provide electrical insulation between the CSC and outer VV so as to allow application of the CHI voltage.

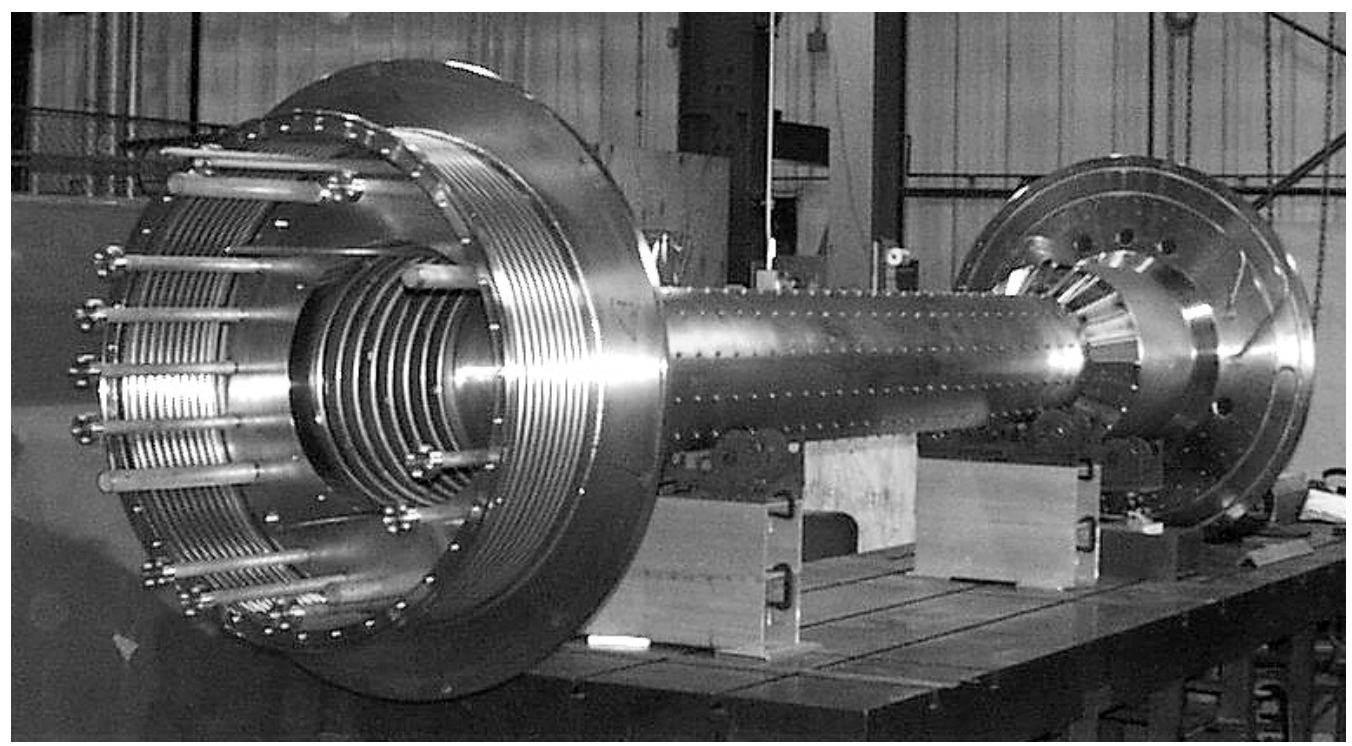

Figure 10 - Center Stack Casing 


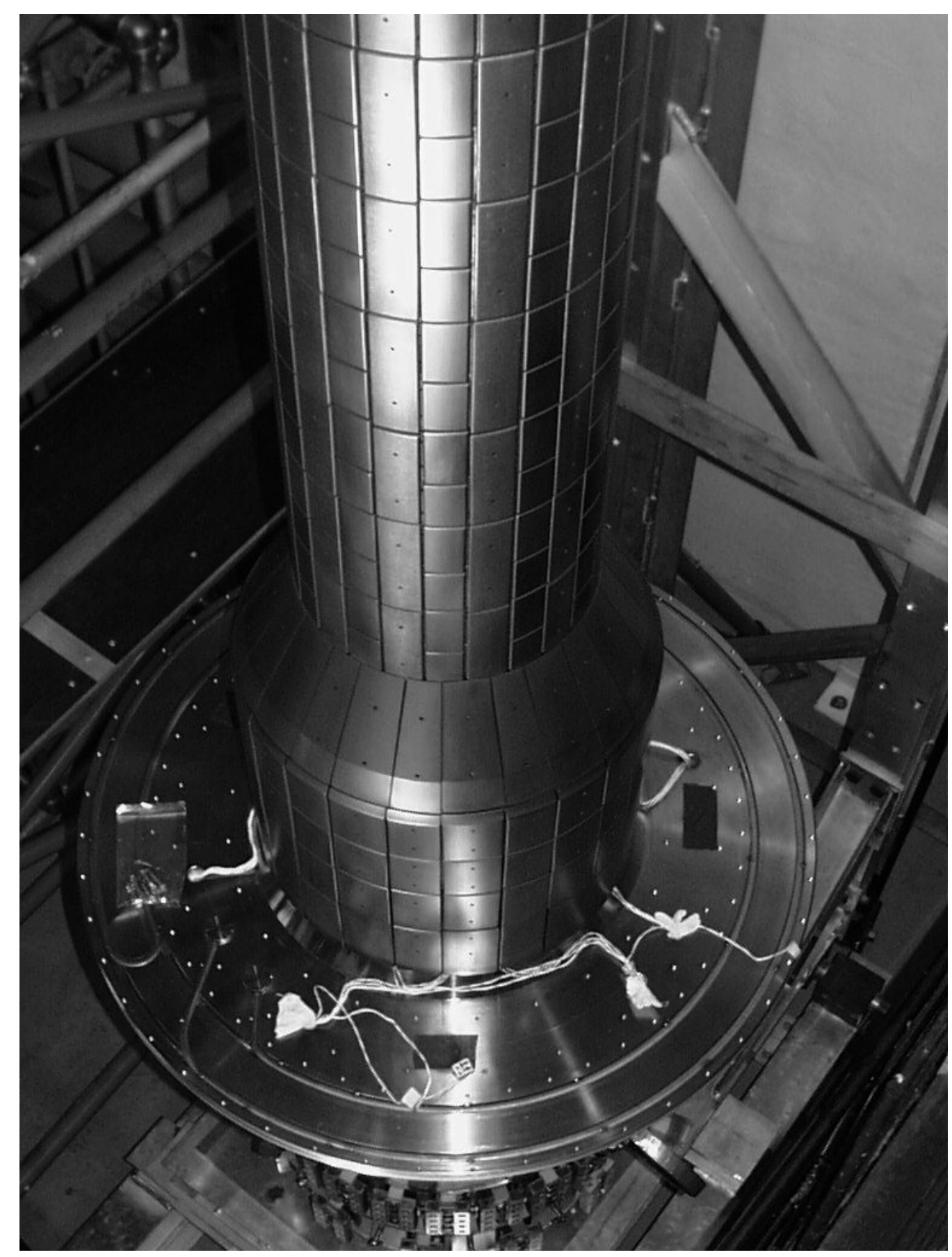

Figure 11 - Center Stack Casing with Interlocking Tiles on Central Column

\subsection{Internal Hardware}

The internal hardware consists of the Primary Passive Plates (PPP), Secondary Passive Plates (SPP), and Outboard Divertor (OBD). The OBD provides a target for energetic particles emanating from the plasma Scrape 
Off Layer (SOL), and also serves as the outer CHI electrode. It consists of 48 toroidally segmented copper backplates with ATJ graphite tiles, for a total of 96 segments above and below the midplane. The OBD is supported by a precision three ring assembly (Figure 12) which is mounted to the outer $\mathrm{VV}$ via pin and u-bracket fasteners. This mounting scheme is designed to accommodate the non-ideal shape of the dome. The OBD copper backplate centers are is fixed in position as they attach to the central support ring, whereas the inner and outer fasteners are attached via slotted holes, allowing for thermal expansion in the poloidal direction during bakeout.

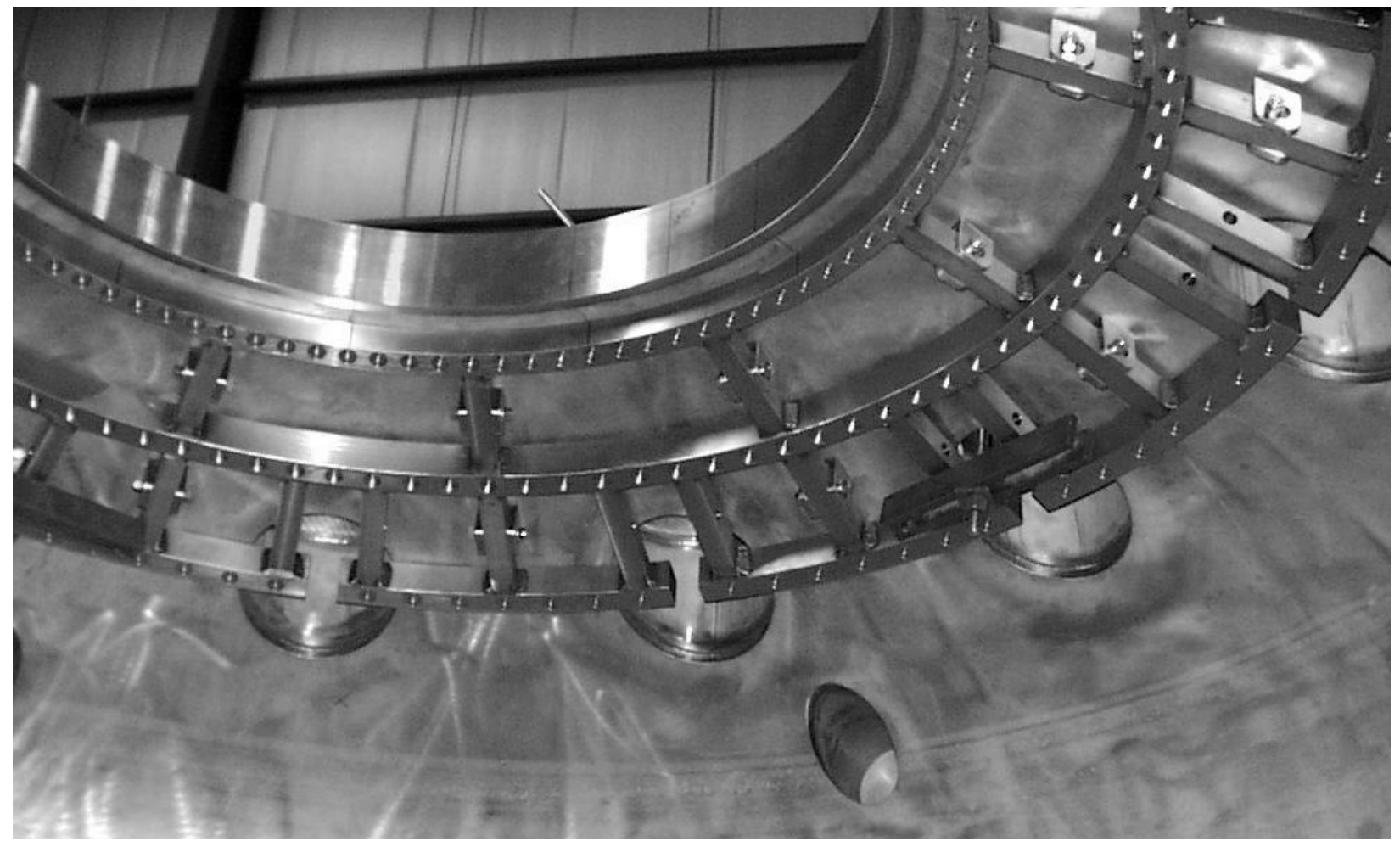

Figure 12 - Outboard Divertor Support Structure

The passive plates provide a close fitting conducting shell in which eddy currents are induced in response to plasma motion and deformation, such that a restoring force is generated which resists the motion and deformation. They consist of 12 toroidal segments, primary and secondary, above and below the midplane, total 48 pieces. The plates are constructed of a high strength copper alloy ( $\mathrm{Cu} \mathrm{Cr} \mathrm{Zr}$ ) which is able to withstand the high bakeout temperature without annealing. ATJ graphite tiles mounted to the copper 
plates provide the plasma facing surface. The passive plates are attached to the outer VV via support structures which include sliding pin fasteners which are designed to allow for thermal expansion in both the toroidal and poloidal directions during bakeout (Figure 13).

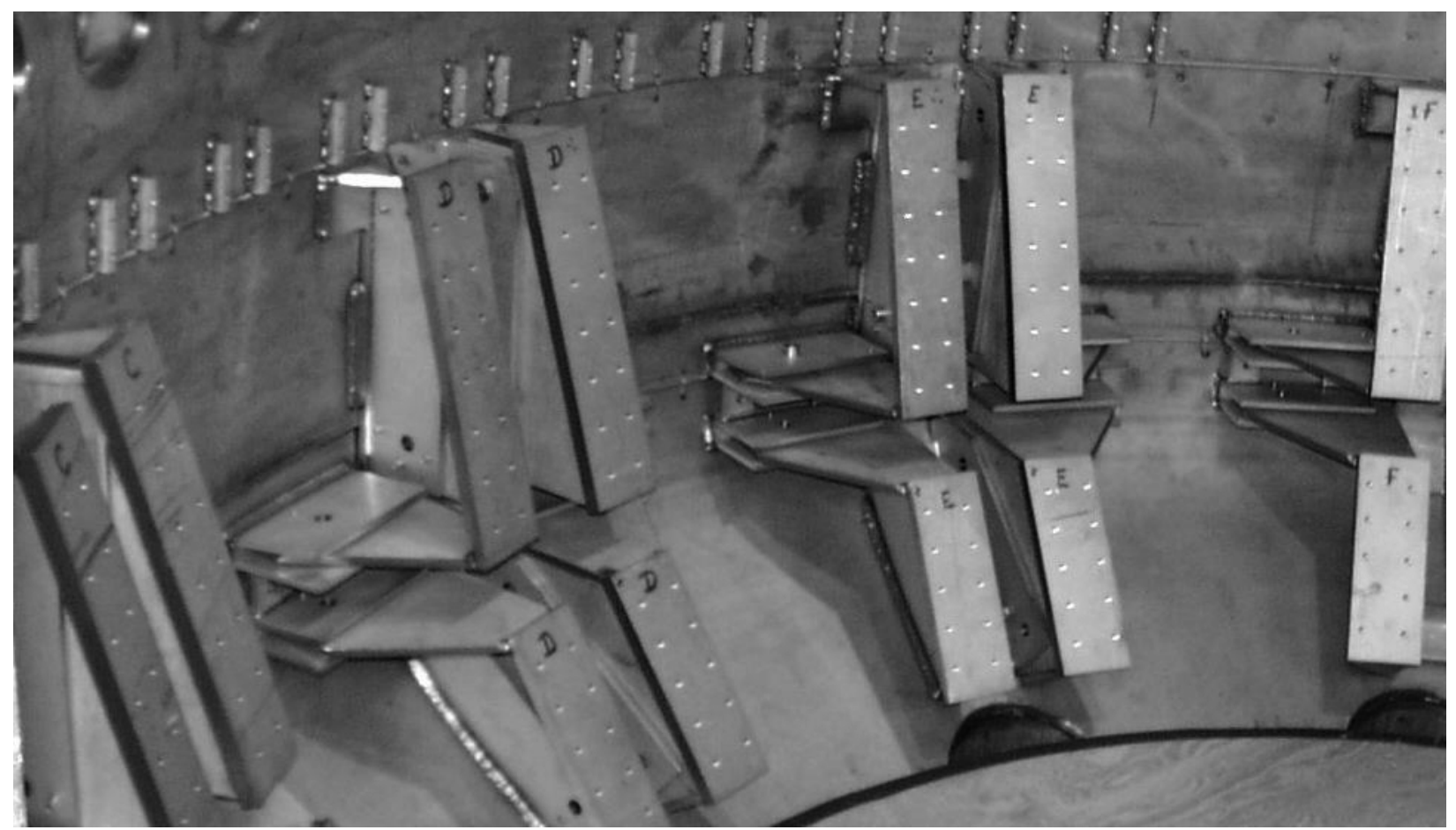

Figure 13 - Passive Plate Support Structure

A variety of diagnostics including Mirnov coils, Langmuir Probes, and thermcouples are mounted in cavities machined into the rear of the PPP, SPP, and OBD tiles. A stainless steel piping system is embedded and brazed into the PPP, SPP, and OBD copper backing plates to allow for transfer of heat into and out of the system using liquid and gaseous heat transfer during operations and bakeout. The system consist of 24 parallel circuits, 12 in each half plane, which passes through 4 OBD backing plates. Figure 14 shows the installed internal hardware below the midplane prior to installation of the PFC tiles on the edges of the passive plates. 


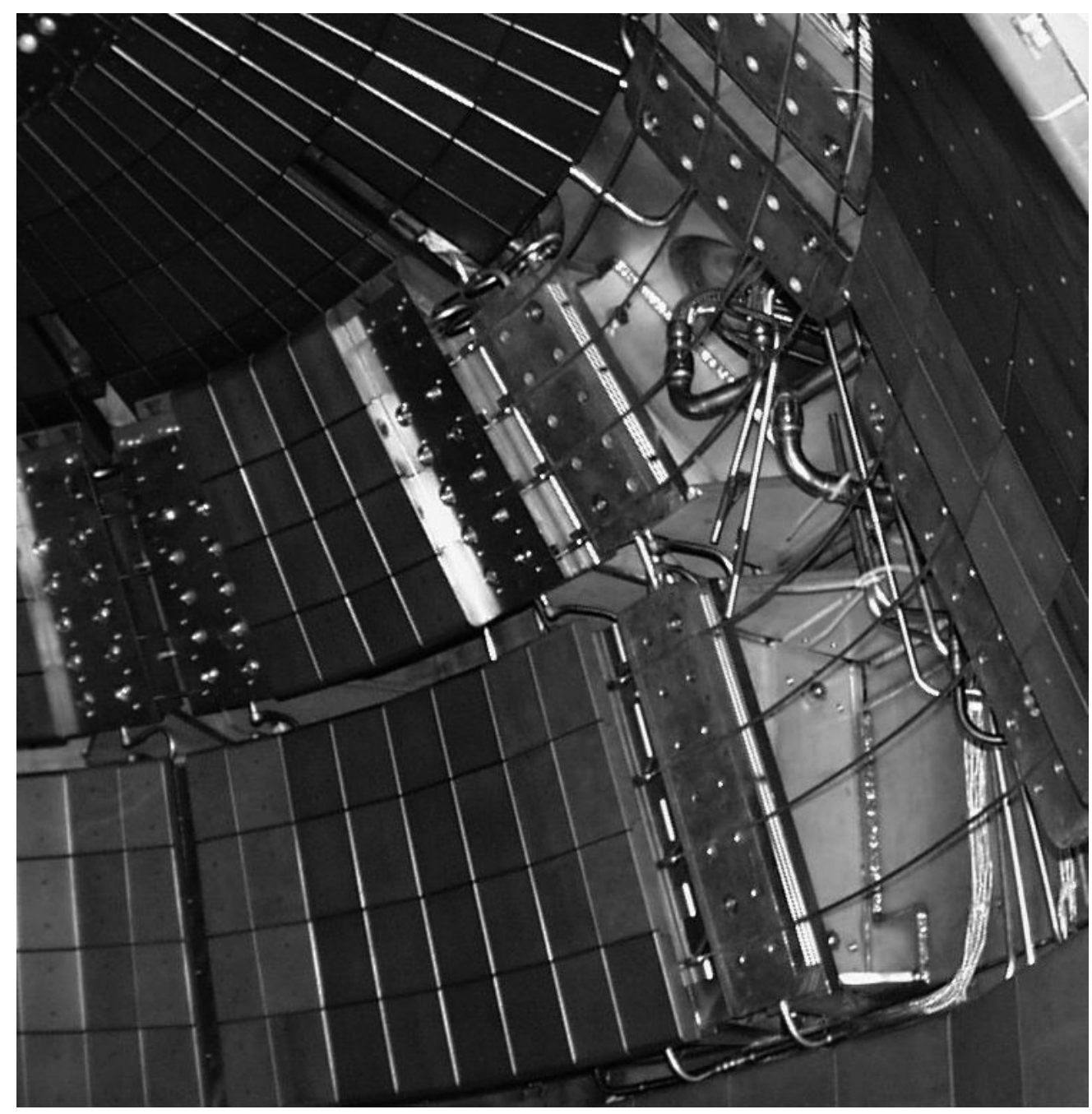

Figure 14 - Internal Hardware Above Midplane

\subsection{RF Antenna}

The RF antenna (Figure 15) delivers up to 6MW of "High Harmonic Fast Wave" (HHFW) RF power at $30 \mathrm{MHz}$, corresponding to the $15^{\text {th }}$ harmonic of the ion cyclotron resonant frequency at $\mathrm{B}_{\mathrm{T}}=3 \mathrm{kG}$. In this regime, which is especially important for the low field ST configuration, power is deposited primarily on the plasma electrons as a result of Landau damping. The antenna consists of 12 launchers which cover a toroidal angle of $90^{\circ}$, driven by six independent sources, allowing a wide spectral variety as required for the heating and current drive functions. Each copper antenna strap is fed on one end via the RF feedthru, and grounded to the outer VV via a sliding joint at the opposite end. Each strap is protected by a molybdenum faraday shield, 
and is contained in a stainless steel box structure, with boron nitride shields positioned on top and bottom and between adjacent boxes. The RF feedthrus are mounted to the outer VV RF port flanges with special spool pieces, custom machined for each of the 12 locations to accommodate variations in the position of the VV port flanges. Active cooling is provided on the lower strap terminal to remove the average dissipated power between pulses.

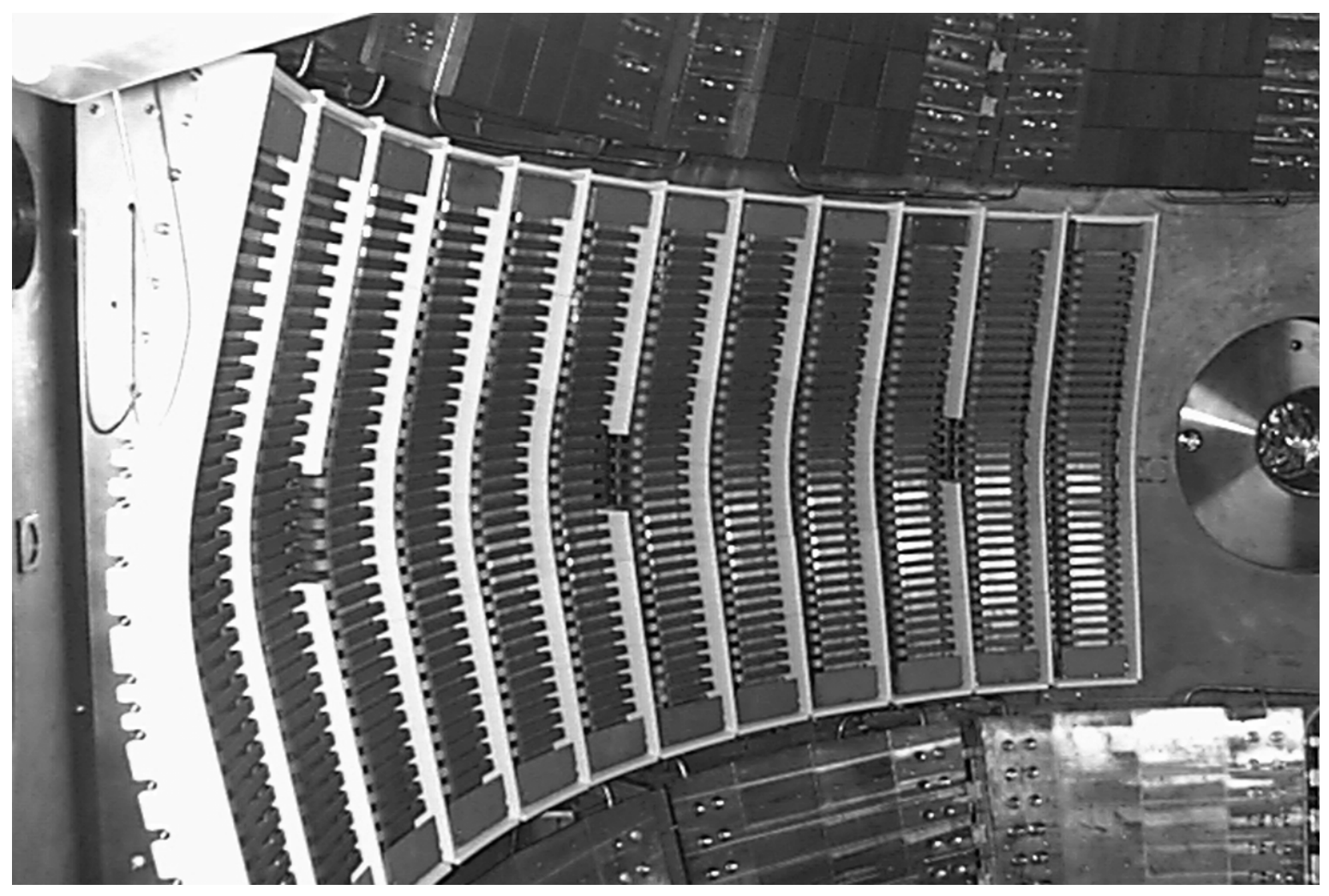

Figure 15 - High Harmonic Fast Wave RF Antenna

\subsection{Outer Vacuum Vessel}

The outer VV, fabricated by Process Systems International, Westboro, Ma., is constructed of 5/8" thick 304 stainless steel, and consists of upper and lower dome sections, and central cylindrical section, all welded together (Figure 16). The domes were spun from plates, and the cylindrical section roll-formed from plate (the original plan to use the S-1 domes had to be scrapped due to weld features which would not support the stresses associated with the $350^{\circ} \mathrm{C}$ bakeout). The upper and lower dome flanges were precision machined by placing the entire outer VV assembly on a large 
milling machine; these surfaces provided the primary fiducial position reference during subsequent machine assembly. Major horizontal ports consist of seven 24" diameter midplane ports, two non-circular midplane ports designed to mate to the TFTR NBI duct, three 16.5" midplane RF access ports, and twenty-six 4" diameter RF feedthru ports (to accommodate the 12 antenna straps, with possible tilting in the future).

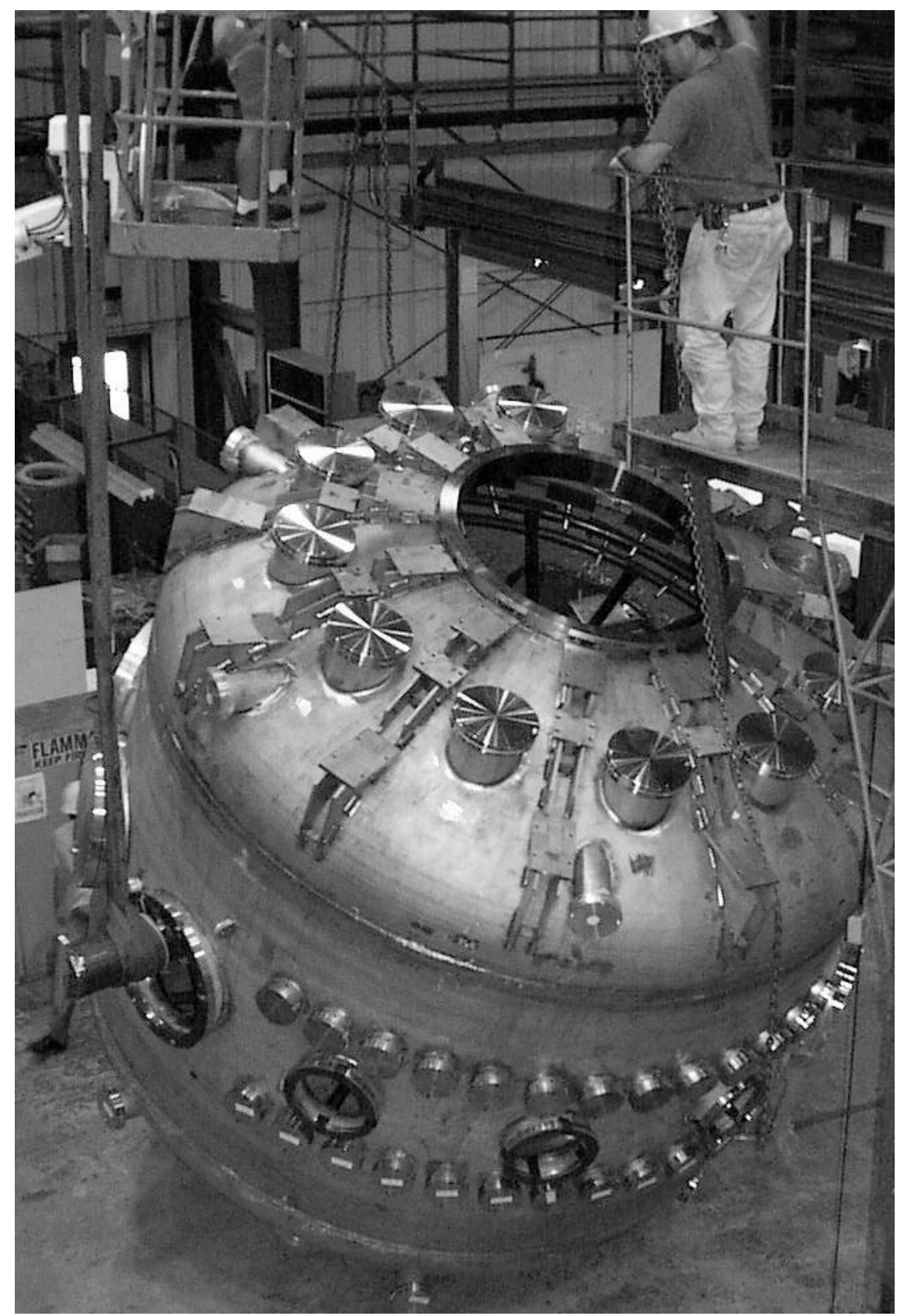

Figure 16 - Outer Vacuum Vessel 
Major vertical ports consist of ten 16.5" diameter ports on each of the domes. The outer $\mathrm{VV}$ serves as the attachment point for the internal hardware, and the support structure for the outer PF and TF coils. The outer PF coils are mounted on radial sliding supports which engage with plates welded on to external rib structures. These external rib structures are welded to tabs which are, in turn, welded to the outer VV. The tabs are provided to allow for the out-of-roundness of the outer VV. The radial slide supports are provided to allow for the axisymmetric radial expansion of the VV during bakeout without imparting significant load on the outer PF coils. The TF coil outer legs are restrained by the outer VV via a turnbuckle support system. The upper and lower "umbrella structures" (Figure 17) are attached to the outer VV using a radial slide support, similar to that used for the PF coil supports.

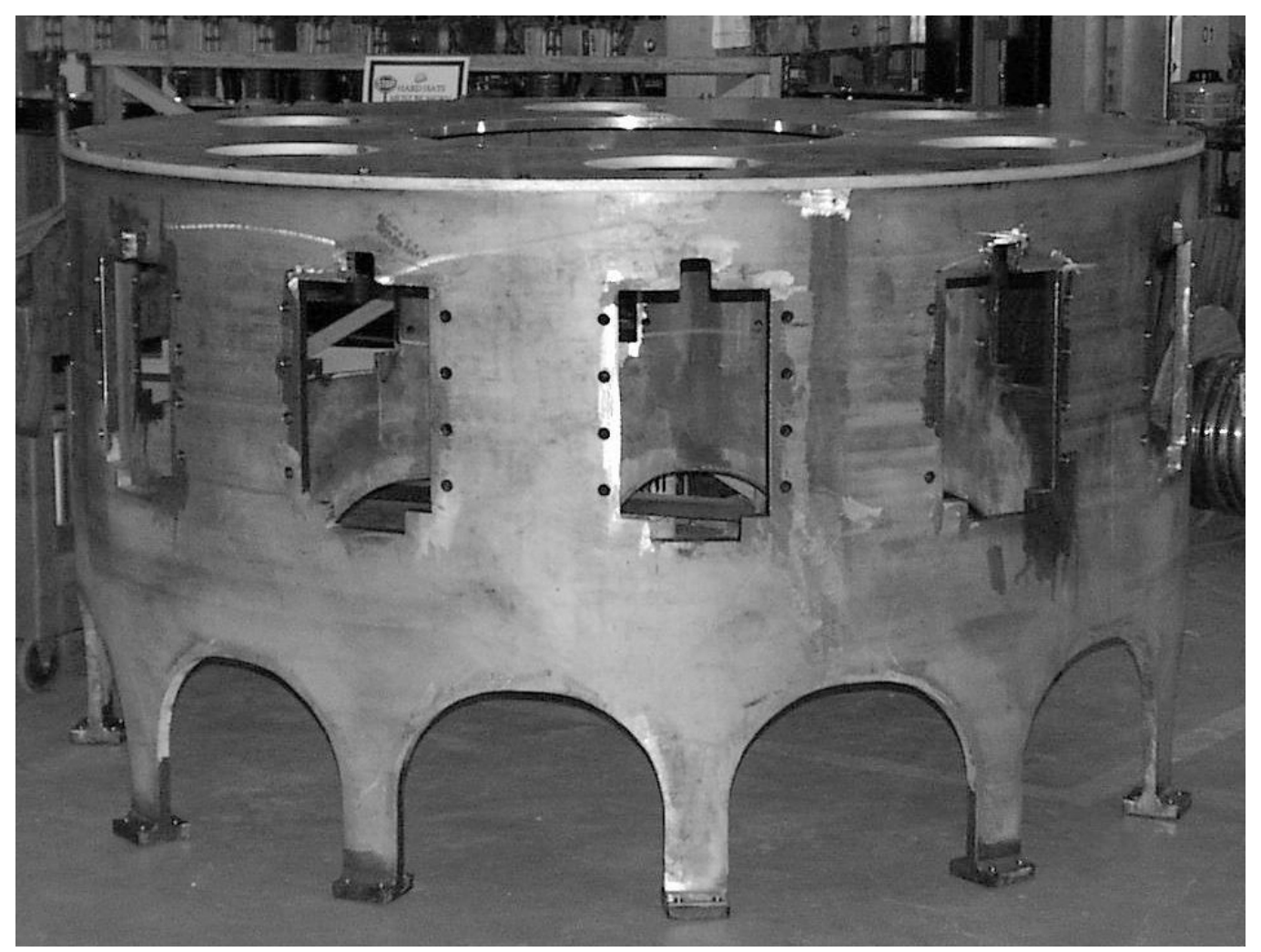

Figure 17 - Umbrella Structure 
The vacuum vessel and all components mounted thereto (total weight approximately 100,000 lbs.) is supported from the floor via four legs. The legs rest upon columns. The leg-to-column interface consists of a radial slide support, coated with a special low friction coefficient surface treatment ("Magnaplate"). This scheme allows for the axisymmetric radial expansion of the outer VV during bakeout. The outer VV is thermally insulated using a 2 " thick mineral wool covered with a $1 / 2$ " thick layer of silicone foam, total $\mathrm{R}$ value $\sim 16$.

\subsection{Outer PF Coils}

The outer PF coil set consist of PF-2, $-3,-4$, and -5 , the first three of which (Figure 18) were taken from the retired S-1 machine, and the last of which was built specifically for NSTX.

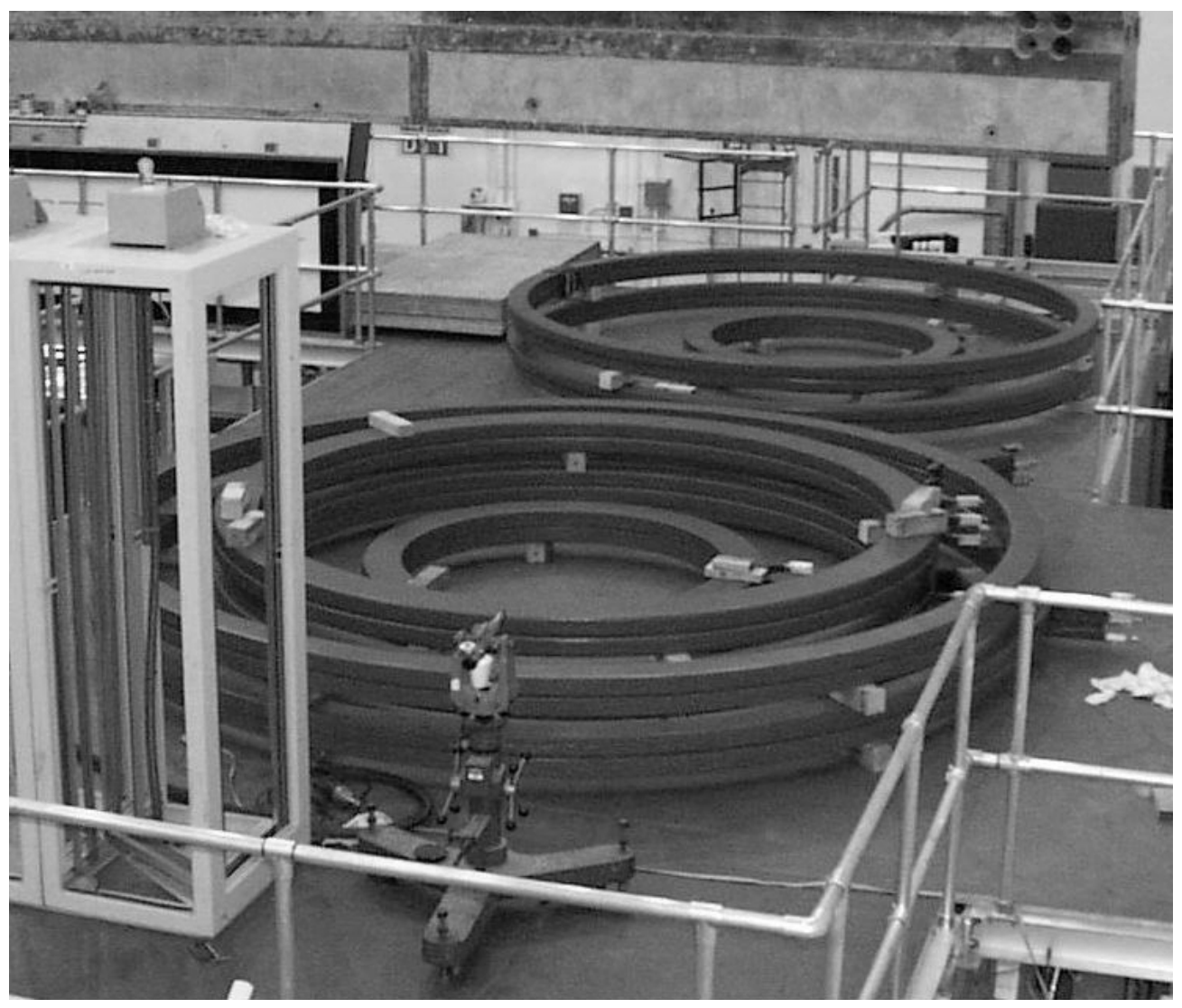

Figure 18 - Outer PF Coils from S-1 Machine

The early design of NSTX did not in fact include PF-5; however it was discovered during equilibria analysis that PF-5 was necessary to avoid a 
"dimple" in the plasma shape near the midplane. The outer PF coils from S1 are pancake wound water cooled copper coils, with a Mylar and Fusa-fab (B-staged epoxy glass) composite turn insulation, and a Fusa-fab (B-staged epoxy glass) ground wall. The PF-5 coil is similar in construction. The PF-2 coils are driven by a unipolar power supply which includes a midpoint tap such that the current may be different in the upper and lower coils. PF-2 is used mainly to "stretch" the plasma (elongation) and to form single and double null X-points. The PF-3 coils are are driven by a bipolar power

supply which includes a midpoint tap such that the current may be different in the upper and lower coils. PF-3 is biased initially to cancel the stray field from the $\mathrm{OH}$ to promote the formation of a null region for plasma initiation. Then later in the discharge in the opposite current direction a difference current in the upper and lower PF-3 coils is used to provide a radial field for vertical position control. The PF-4 coils are at present not used, but are reserved for future use. The PF-5 coils are connected directly in series (no midpoint tap) to a unipolar power supply. These coils are used to produce a vertical field for radial position control.

\section{Electrical and Electromagnetic Design and Performance}

\subsection{Constraints}

\subsubsection{D-site Power Supplies}

The availability of the D-site power supplies influenced the selection of current and voltage ratings for those coils built specifically for NSTX (TF, $\mathrm{OH}, \mathrm{PF}-1 \mathrm{a}, \mathrm{PF}-1 \mathrm{~b}$, and PF-5). These power supplies are modular with standard module rating $1 \mathrm{kV}, 24 \mathrm{kA}, 6$ second pulse, 300 second repetition period. Thus the NSTX voltage and current ratings were based on series connections of the modules (multiples of $1 \mathrm{kV}$ ) and parallel connections of the modules (multiples of $24 \mathrm{kA}$, after allowance for current imbalance).

\subsubsection{S-1 Outer PF Coils}

The S-1 coil peak currents were limited to 20kA per the S-1 design; S-1 voltage ratings were much higher (20kV DC hipot level) than required by NSTX to drive the coils, so voltage was not a constraint. 


\subsection{Physics Input}

\subsubsection{Equilibria and Scenarios}

The TF requirement was established based simply on the field and flat top duration. The $\mathrm{OH}$ requirement was based on 1) total flux swing, 2) Loop voltage during plasma initiation, 3) $\mathrm{I}_{\mathrm{p}}$ ramp times, flat top duration, and volt second consumption for various scenarios as predicted by the Tokamak Simulation Code (TSC), a time dependant free boundary predictive equilibrium and transport solver. [4]. The PF coil requirements were based on $\mathrm{I}_{\mathrm{p}}$ ramp times and PF coil currents for various equilibria over the range of triangularity and elongation. For the $\mathrm{OH}$ and $\mathrm{PF}$ systems these requirements translate to a set of linear breakpoint design basis waveforms. Those corresponding to the slow (400ms) plasma ramp time set the fi2(t)dt requirement, while those corresponding to the fast $(200 \mathrm{mS})$ ramp time set the driving voltage requirement. In addition to the above, a loop voltage and field null quality requirement was specified which influenced the height $(+/-$ $\mathrm{Z}$ ) of the $\mathrm{OH}$ coil (related to the stray leakage flux), along with the forcing voltage and bipolarity requirement for PF-3.

\subsubsection{Disruptions}

The TSC code was used to predict plasma disruption behavior. The result for a current and thermal quench beginning with a centered stationary plasma (but with vertical and radial control turned off) predicts an $I_{p}$ waveform which resembles an exponential decay with initial slope $1 \mathrm{MA} / 6 \mathrm{mS}$ [5]. Therefore subsequent engineering calculations followed this prescription and utilized a linear ramp from 1.0MA to zero in $6 \mathrm{mS}$ to estimate induced toroidal voltages and currents.

For halo currents, the prescription was set to $10 \%$ of the maximum plasma current prior to the disruption, with a toroidal peaking factor of $2: 1$. It is noted that this guidance is based on, but somewhat reduced from, the halo current data base from large aspect ratio tokamaks (typically $40 \%$ if initial plasma current) based on parametric scaling related to aspect ratio. An important feature of halo current flow is the polarity relative to the toroidal field, which determines whether the $\mathrm{J} \times \mathrm{B}$ forces will be inward or outward. Physics arguments [6] which apply consistently independent of the relative

polarity of $I_{p}$ and $B_{T}$, indicate that for most scenarios which generate halo current flow (vertical drift, radial drift, current quench) the forces generated 
are outward (and act to push the PFC tiles against their backplates). However it is predicted that changes in plasma shape and stored energy will give rise to poloidal current flow to conserve or increase toroidal flux, and that this poloidal current, when flowing in the halo, will result in inward forces (which act to pull the PFC tiles off of their backplates). Typically the many halo generating mechanisms are active simultaneously and vary in their strength, so it remains unclear as to which will dominate and under what circumstances. For NSTX it was concluded that some scenarios, at least, will result in the halo force pulling inward toward the plasma.

\subsection{Determination of Current per Turn in New NSTX Coils}

The current per turn in the TF coil was chosen based on the desire to 1) minimize number of turns for sake of simplicity and packing factor, 2) operate with no more than four parallel branches of the D-site power supplies (to minimize power supply reconfiguration costs).

The current per turn in the $\mathrm{OH}$ coil was chosen based on the 24kA rating of the D-site power supplies. It was decided to utilize a only a single power supply branch (for each current direction), because multiple parallels would significantly complicate the operation of the power supply system in the bipolar mode.

The inner PF coil currents per turn were set at 15kA (PF1a) and 20kA (PF1b) based on 1) the desire to utilize a simple square conductor cross section for the two new coils, which are rated for 5 and 1 second pulses, respectively, 2) the $24 \mathrm{kA}$ current limit of the single power supply branch, and 3) to fit the narrow radial space available for the PF1a coil.

\subsection{Conductor Sizing}

\subsubsection{Conductor Temperature}

The maximum conductor temperature allowable was set to $95^{\circ} \mathrm{C}$ to avoid the use of a pressurized water system and the degradation of insulation mechanical properties which occurs at higher temperatures. Operation at full ratings is constrained by this limit, including due consideration of the scenario requirements along with the prospective $\int \mathrm{i}^{2}(\mathrm{t}) \mathrm{dt}$ due to $\mathrm{L} / \mathrm{R}$ decay following a fault, as well as temperature ratcheting from one pulse to the next in a sequence. 


\subsubsection{Temperature Rise During a Pulse}

The most critical coils are the TF inner legs and $\mathrm{OH}$, which are located in the center stack region where cross sectional area is at a premium. Conductor cross sections for these coils were chosen based on the assumption of adiabatic conditions during a pulse, and full cool down between pulses to an inlet water temperature of $10^{\circ} \mathrm{C}$.

The properties given in Table 5 were used (100\% IACS Copper).

Table 5 - Conductor Properties

\begin{tabular}{|l|l|}
\hline $20^{\circ} \mathrm{C}$ Resistivity & $1.7241 \mu \Omega-\mathrm{cm}$ \\
\hline Temp Coeff of Resistance $(\alpha)$ & $0.0041 / \mathrm{deg} \mathrm{C}$ \\
\hline $27^{\circ} \mathrm{C}$ Specific Heat & $386 \mathrm{~J} / \mathrm{kg}-\mathrm{deg} \mathrm{C}$ \\
\hline Temp Coeff of Specific Heat $(\beta)$ & $0.105 \mathrm{~J} / \mathrm{kg}-\mathrm{deg} \mathrm{C} / \mathrm{deg} \mathrm{C}$ \\
\hline Density & $8.95 \mathrm{gm} / \mathrm{cc}$ \\
\hline
\end{tabular}

"G" (conductor heating) and " $\mathrm{H}$ " (conductor energy deposition) functions were derived as follows [7].

$\rho_{\mathrm{e}} \quad=$ electrical resistivity

$\rho_{\mathrm{e}} \mathrm{T}_{0 \mathrm{e}}=$ electrical resistivity at temperature $\mathrm{t}_{0 \mathrm{e}}$

$\mathrm{T}=$ temperature

$\rho_{\mathrm{e}} \quad=\rho_{\mathrm{e}} \mathrm{t}_{0 \mathrm{e}}\left(1+\alpha\left(\mathrm{T}-\mathrm{T}_{0 \mathrm{e}}\right)\right)$

$\mathrm{C}_{\mathrm{p}}=$ specific heat

$\mathrm{C}_{\mathrm{p}} \mathrm{t}_{0 \mathrm{c}}=$ specific heat at temperature $\mathrm{T}_{0 \mathrm{c}}$

$\mathrm{C}_{\mathrm{p}}=\mathrm{C}_{\mathrm{p}} \mathrm{t}_{0 \mathrm{c}}+\beta\left(\mathrm{T}-\mathrm{T}_{0 \mathrm{c}}\right)$

$\mathrm{J}=$ current density

$\rho_{\mathrm{d}} \quad=$ density

$\mathrm{t}=$ time

For an adiabatic conductor:

$$
\rho_{\mathrm{e}} \mathrm{J} 2 \mathrm{dt}=\rho_{\mathrm{d}} \mathrm{C}_{\mathrm{p}} \mathrm{dT}
$$


G Function:

$$
\begin{aligned}
& \mathrm{J} 2 \mathrm{dt}=\rho_{\mathrm{d}} \mathrm{C}_{\mathrm{p}} \mathrm{dT} / \rho_{\mathrm{e}}, \\
& \mathrm{J} 2 \mathrm{t}=\int \rho_{\mathrm{d}} \mathrm{C}_{\mathrm{p}} \mathrm{dT} / \rho_{\mathrm{e}} \equiv \mathrm{G}(\mathrm{t}) \quad\left[\left(\mathrm{A} / \mathrm{m}^{2}\right)^{2}-\mathrm{sec}\right]
\end{aligned}
$$

H Function:

$$
\mathrm{J}^{2} \rho_{\mathrm{e}} \mathrm{t}=\int \rho_{\mathrm{d}} \mathrm{C}_{\mathrm{p}} \mathrm{dT} \equiv \mathrm{H}(\mathrm{t}) \quad\left[\left(\mathrm{J} / \mathrm{m}^{3}\right)\right]
$$

Piecewise integration of $\mathrm{G} \& \mathrm{H}$ functions was performed over the range 0 to $120^{\circ} \mathrm{C}$ and the following curve fit functions derived.

$$
\begin{aligned}
& \mathrm{G}(\mathrm{T})=6.2949 \mathrm{e} 13+2.0934 \mathrm{e} 14 * \mathrm{~T}-2.8709 \mathrm{e} 11 * \mathrm{~T}^{2} \\
& \mathrm{~T}(\mathrm{G})=0.13608+4.5496 \mathrm{e}-15 * \mathrm{G}+5.3309 \mathrm{e}-32 * \mathrm{G}^{2} \\
& \mathrm{H}(\mathrm{T})=-1.1183 \mathrm{e} 6+3.4362 \mathrm{e} 6 * \mathrm{~T} \mathrm{~J} 2 \rho_{\mathrm{e}} \mathrm{dt}=\rho_{\mathrm{d}} \mathrm{C}_{\mathrm{p}} \mathrm{dT}
\end{aligned}
$$

Thus to calculate final temperature:
(1) Calculate $\mathrm{G}\left(\mathrm{T}_{0}\right)$
(2) Calculate $\Delta \mathrm{G}=\int \mathrm{J} 2 \mathrm{dt}$
(3) Calculate $\mathrm{G}_{\text {final }}=\mathrm{G}\left(\mathrm{T}_{0}\right)+\Delta \mathrm{G}$
(4) Calculate $T_{\text {final }}=T\left(G_{\text {final }}\right)$

To calculate energy dissipation and heat load to cooling water system:
(1) Calculate $\mathrm{H}\left(\mathrm{T}_{0}\right)$
(2) Calculate $\Delta \mathrm{H}=\mathrm{H}\left(\mathrm{T}_{\text {final }}\right)-\mathrm{H}\left(\mathrm{T}_{0}\right)$

\subsubsection{Cool-down Between Pulses}

Each of the 36 turns of the TF coil are individually cooled, with the water passing through the inner legs (high current density) and then through the outer legs (low current density). The cool-down after a pulse is rapid (bulk thermal time constant $\sim 25$ seconds) compared to minimum NSTX repetition period of 300 seconds. Therefore no temperature ratcheting will occur. 
The cool-down between pulses was a major issue in the design of the $\mathrm{OH}$ coil, due to the long length of the conductors paths. Cool-down time was minimized by 1) winding the coil two-in-hand to cut the maximum conductor path length in half and 2) increasing the pressure and flow of the water coolant via a special booster pump providing $400 \mathrm{psi}$ at the inlet. Cool-down of the $\mathrm{OH}$ coil was simulated using a FORTRAN code [8] which divides the conductor length in many sections through which a slug of water progresses over time and receives heat through the heat transfer film resistance. Figure 19 shows a typical result for the case of the fifth pulse in a sequence. During the pulse the conductor temperature rises to its maximum for a brief instant after which some of the heat flows into the body of water occupying the coolant passage and equilibrium is reached. Following this, the first turns of the coil at the inlet of the coil receive cool water and rapid cooling takes place. However the water heats up and is not effective in removing heat from the downstream conductor until the "cooling wave" passes through the coil. A period of 600 seconds is necessary to achieve complete cooling of the coil, including the turns at the end, near the outlet.

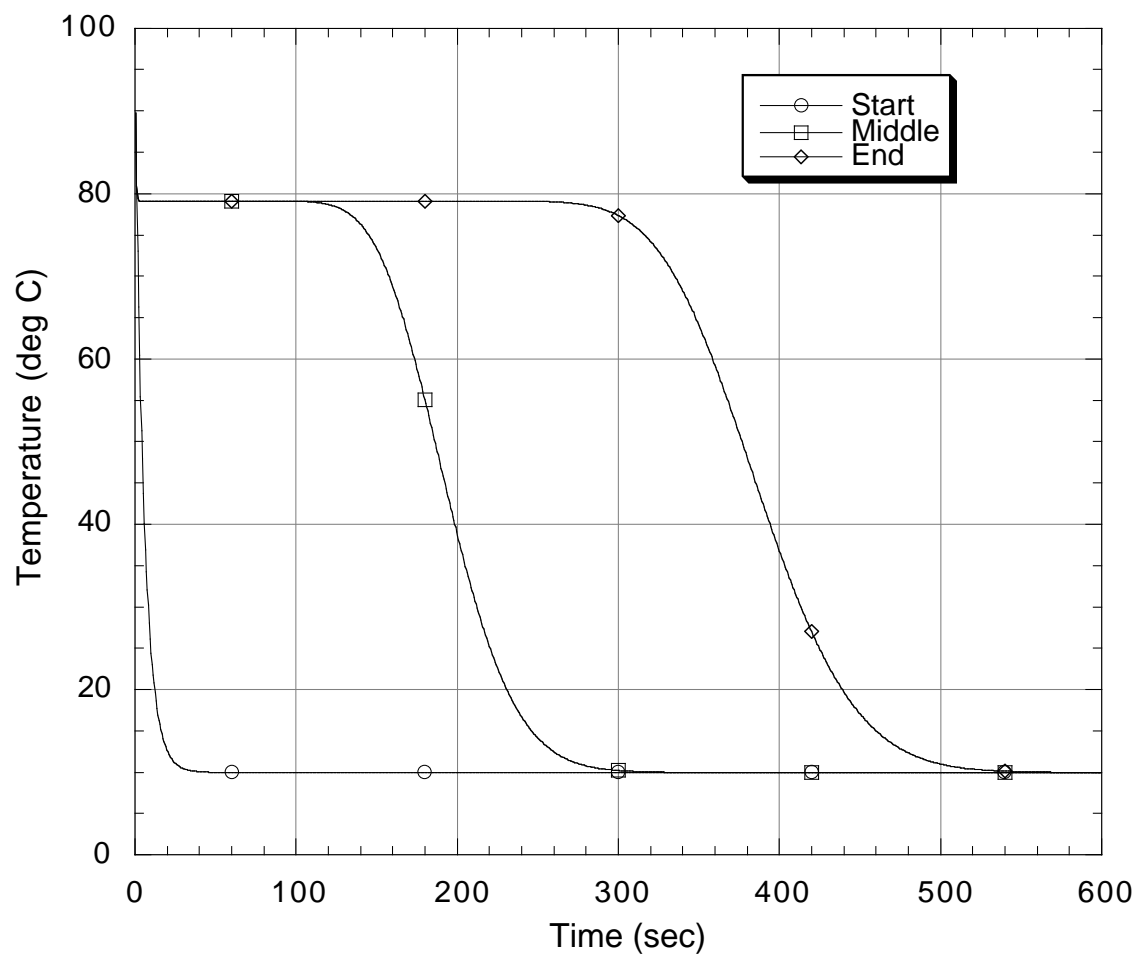

Figure 19 - OH Coil Temperature at Start, Middle, and End of Winding During and After Fifth Pulse, 600 Second Repetition Period 
The PF-4 and PF-5 coils, due to their large diameter, also have long cooldown times. The PF-5 coil includes a water tap midway through the winding so that the total cooling path length is cut in half.

\subsection{Coil System Impedance}

The TF coil inductance $(4.176 \mathrm{mH})$ was computed [7] using a simple piecewise integration $\phi=\int \mathrm{B}^{*} \mathrm{dA}$ across the bore of the TF coil system, with $B=\mu_{0} \mathrm{NI} / 2 \pi \mathrm{r}$ and $\mathrm{L}=\mathrm{N} \phi / \mathrm{I}$. TF coil resistance computation $(6.52 \mathrm{~m} \Omega)$ includes an allowance for the many joints in the circuit (six joints per turn).

The inductance matrix and resistance vector of PF coil set was calculated [9] using the ICC code from the PPPL magnetics library, based on the coil geometry given in Table 6. Results are given in Tables 7 and 8. Due to its unusual aspect ratio and critical function, the $\mathrm{OH}$ coil inductance was cross checked using two other techniques and good agreement was found. Measurements taken in the field during commissioning tests are in agreement with the calculated $\mathrm{L}$ and $\mathrm{R}$ values.

Table 6 - PF/OH Coil Geometry

\begin{tabular}{|l|c|c|c|c|c|c|c|}
\hline & $\begin{array}{c}\mathrm{R}_{\text {center }} \\
(\mathrm{m})\end{array}$ & $\begin{array}{c}\Delta \mathrm{R} \\
(\mathrm{m})\end{array}$ & $\begin{array}{c}\mathrm{Z}_{\text {center }} \\
(\mathrm{m})\end{array}$ & $\begin{array}{c}\Delta \mathrm{Z} \\
(\mathrm{m})\end{array}$ & turns & $\begin{array}{c}\text { Turn CSA } \\
\left(\mathrm{cm}^{2}\right)\end{array}$ & fill \\
\hline $\mathrm{OH}$ & 0.1319 & 0.0449 & 1.0657 & $+/-2.1313$ & 482 & 1.4139 & 0.712 \\
\hline PF1a & 0.1803 & 0.0416 & 1.4483 & $+/-0.5388$ & 48 & 3.3513 & 0.718 \\
\hline PF1b & 0.3048 & 0.0848 & -1.8188 & -0.1713 & 28 & 3.3513 & 0.646 \\
\hline PF2Ua & 0.7992 & 0.1627 & 1.9335 & $+/-0.068$ & 14 & 5.8528 & 0.741 \\
\hline PF2Ub & 0.7992 & 0.1627 & 1.8526 & $+/-0.068$ & 14 & 5.8528 & 0.741 \\
\hline PF3Ua & 1.4945 & 0.1864 & 1.6335 & $+/-0.068$ & 15 & 5.8528 & 0.693 \\
\hline PF3Ub & 1.4945 & 0.1864 & 1.5526 & $+/-0.068$ & 15 & 5.8528 & 0.693 \\
\hline PF4b & 1.7946 & 0.0915 & 0.8072 & $+/-0.068$ & 8 & 5.8528 & 0.753 \\
\hline PF4c & 1.8065 & 0.1153 & 0.8881 & $+/-0.068$ & 9 & 5.8528 & 0.672 \\
\hline PF5a & 1.9946 & 0.1359 & 0.6523 & $+/-0.0685$ & 12 & 5.9667 & 0.769 \\
\hline PF5b & 1.9946 & 0.1359 & 0.5777 & $+/-0.0685$ & 12 & 5.9667 & 0.769 \\
\hline
\end{tabular}

Note: \#Turns in above table are the number above and/or below the mid plane $(\mathrm{Z}=0)$ 
Table 7 - PF/OH Circuit 20C Resistances

\begin{tabular}{|l|c|}
\hline \multicolumn{1}{|c|}{ Circuit } & Resistance \\
\hline & $(\mathrm{m} \Omega)$ \\
\hline OH & 97.5 \\
\hline PF1au & 2.80 \\
\hline PF1al & 2.80 \\
\hline PF1b & 2.76 \\
\hline PF2u & 4.14 \\
\hline PF21 & 4.14 \\
\hline PF3u & 8.29 \\
\hline PF31 & 8.29 \\
\hline PF4 & 11.33 \\
\hline PF5 & 17.38 \\
\hline
\end{tabular}

Table 8 - PF/OH Mutual Inductance Matrix (mH)

\begin{tabular}{|l|r|r|r|l|l|l|l|l|l|l|r|}
\hline & OH & PF1aU & PF1aL & PF1b & PF2U & PF2L & PF3U & PF3L & PF4 & PF5 & $\begin{array}{l}\text { Plasma } \\
\text { (x1000) }\end{array}$ \\
\hline OH & 13.007 & 0.731 & 0.731 & 0.374 & 0.276 & 0.276 & 0.295 & 0.295 & 0.379 & 0.528 & 13.20 \\
\hline PF1aU & 0.731 & 0.376 & 0.000 & 0.000 & 0.072 & 0.001 & 0.060 & 0.005 & 0.032 & 0.042 & 0.487 \\
\hline PF1aL & 0.731 & 0.000 & 0.376 & 0.090 & 0.001 & 0.072 & 0.005 & 0.060 & 0.032 & 0.042 & 0.487 \\
\hline PF1b & 0.374 & 0.000 & 0.090 & 0.536 & 0.002 & 0.186 & 0.007 & 0.101 & 0.041 & 0.054 & 0.454 \\
\hline PF2U & 0.276 & 0.072 & 0.001 & 0.002 & 1.975 & 0.010 & 0.731 & 0.041 & 0.264 & 0.345 & 2.440 \\
\hline PF2L & 0.276 & 0.001 & 0.072 & 0.186 & 0.010 & 1.975 & 0.041 & 0.731 & 0.264 & 0.345 & 2.440 \\
\hline PF3U & 0.295 & 0.060 & 0.005 & 0.007 & 0.731 & 0.041 & 5.178 & 0.166 & 1.161 & 1.487 & 8.380 \\
\hline PF3L & 0.295 & 0.005 & 0.060 & 0.101 & 0.041 & 0.731 & 0.166 & 5.178 & 1.161 & 1.487 & 8.380 \\
\hline PF4 & 0.379 & 0.032 & 0.032 & 0.041 & 0.264 & 0.264 & 1.161 & 1.161 & 5.160 & 4.807 & 20.10 \\
\hline PF5 & 0.528 & 0.042 & 0.042 & 0.054 & 0.345 & 0.345 & 1.487 & 1.487 & 4.807 & 12.289 & 31.40 \\
\hline Plasma & 13.20 & 0.487 & 0.487 & 0.454 & 2.440 & 2.440 & 8.380 & 8.380 & 20.10 & 31.40 & 2.660 \\
(x & & & & & & & & & & & \\
1000) & & & & & & & & & & & \\
\hline
\end{tabular}

Note: Plasma modeled above is a filament at $\mathrm{R}_{\mathrm{o}}$ on the midplane

Coil L/R time constants are given in Table 9; they are noted to be relatively short, since NSTX is a small machine. This fact, in combination with the strong mutual coupling between the PF1a and PF1b coils with the $\mathrm{OH}$ coil presents a significant control challenge for the power supply system whose frequency response is limited by the input $\mathrm{AC}$ power frequency $\sim 60 \mathrm{~Hz}$. 
Table 9 - Coil L/R Time Constants

\begin{tabular}{|l|c|}
\hline \multicolumn{1}{|c|}{ Circuit } & $\begin{array}{c}\text { Time } \\
\text { Constant }\end{array}$ \\
\hline & (mS) \\
\hline OH & 133 \\
\hline PF1a & 134 \\
\hline PF1b & 194 \\
\hline PF2 & 477 \\
\hline PF3 & 624 \\
\hline PF4 & 455 \\
\hline PF5 & 707 \\
\hline TF & 640 \\
\hline
\end{tabular}

\subsection{Driving Voltage Requirements}

Detailed simulations [10,11] were performed of the $\mathrm{TF}$ and $\mathrm{OH}$ coil performance using the PSCAD (PSCAD/EMTDC Power Systems Simulation Software, Manitoba HVDC Research Center) simulation software. The models included the " $G$ " function calculation and the dynamic coil resistances, the resistances of the external cable and bus bar circuits, the commutation voltage drop behavior of the AC/DC converter power supplies, along with the D-site Motor Generator supply which delivers AC power to the power supplies at variable frequency as energy is extracted.

For the TF system it was found that a single power supply layer (one module in series $\mathrm{x}$ four modules in parallel) providing $1 \mathrm{kV}$ was adequate for both the $3 \mathrm{kG}$ and $6 \mathrm{kG}$ scenario; the $\int \mathrm{i}^{2}(\mathrm{t}) \mathrm{dt}$ due to the current rise was relatively small compared to flat top. Figure 20 shows the PSCAD simulated current waveforms for $3 \mathrm{kG}$ and $6 \mathrm{~kg}$ operation. 


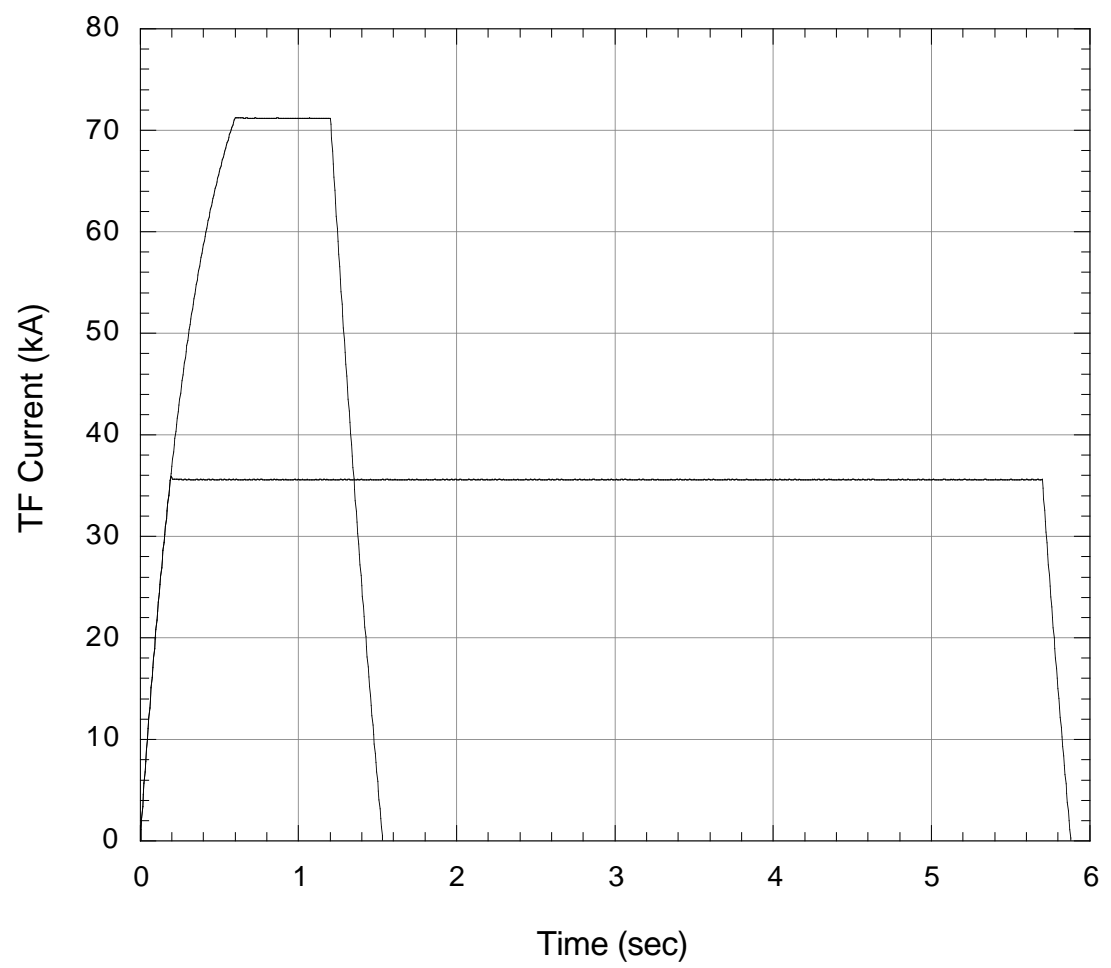

Figure 20 - TF Current Waveforms Simulated by PSCAD for 3kG (35.6kA) and $6 \mathrm{kG}(71.2 \mathrm{kA})$

The $\mathrm{OH}$ coil impedance was sized to match a four layer $(4 \mathrm{kV})$ power supply. However, as a conservative measure, it was decided to provide (and insulate to coil for) a $6 \mathrm{kV}$ system (the modules come in pairs of $1 \mathrm{kV}$ ) to ensure that sufficient loop voltage was provided during plasma initiation (NSTX relies fully on the power supplies and $\mathrm{I}^{*} \mathrm{R}$ drop in the $\mathrm{OH}$ coil winding to produce the breakdown loop voltage, i.e. DC circuit breakers and inserted resistors are not used). Figure 21 shows the PSCAD simulated current waveform for one of the 1MA design basis scenarios. 


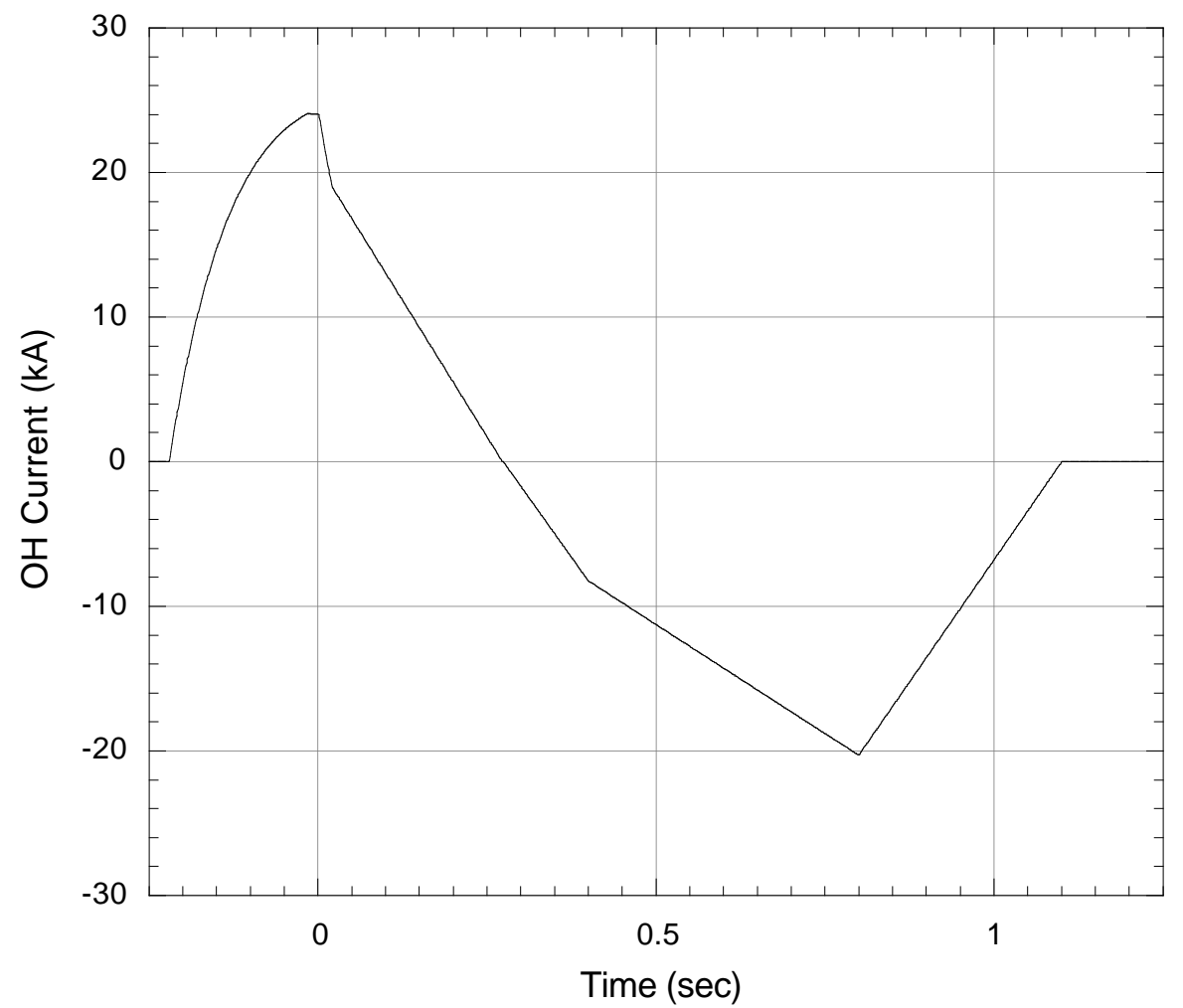

Figure 21 - OH Waveform Simulated by PSCAD

The PF coil driving voltage requirements were obtained by applying the linear breakpoint waveforms to the mutual inductance matrix and resistance vector. In general the requirements are below $1 \mathrm{kV}$. However, to ensure adequate voltage for plasma control, additional power supply layers were provided since they were readily available from the D-site inventory.

\subsection{Summary of Coil Ratings}

Coil ratings are summarized in Table 10. 
Table 10 -NSTX Coil Circuit Ratings

\begin{tabular}{|l|c|c|l|}
\hline Circuit & $\begin{array}{c}\text { Volts } \\
(+/-k V)\end{array}$ & $\begin{array}{c}\text { Peak } \\
\text { Amps } \\
(\mathrm{kA})\end{array}$ & $\begin{array}{l}\text { ESW@ } \\
\text { Peak Amps } \\
(\mathrm{sec})\end{array}$ \\
\hline TF & 1 & 35.6 & $\begin{array}{l}5.3 \\
(1.3)\end{array}$ \\
\hline OH & 6 & $+/ 2)$ & 0.525 \\
\hline PF1a Upper & 2 & 15 & 5 \\
\hline PF1a Lower & 2 & 15 & 5 \\
\hline PF1b & 2 & 20 & 1 \\
\hline PF2 Upper & 2 & 20 & 5 \\
\hline PF2 Lower & 2 & 20 & 5 \\
\hline PF3 Upper & 2 & 20 & 5 \\
\hline PF3 Lower & 2 & 20 & 5 \\
\hline PF4 Upper \& Lower in Series & 3 & 20 & 5 \\
\hline PF5 Upper \& Lower in Series & 3 & 20 & 5 \\
\hline
\end{tabular}

\subsection{Plasma Initiation and Field Null Creation}

A key function of the $\mathrm{OH}$ and PF system is the creation of sufficient loop voltage and field null region, for sufficient duration, for plasma initiation. To initiate Townsend avalance breakdown the required electric field and allowable stray poloidal field are a function of the toroidal field $\mathrm{B}_{\mathrm{T}}$ at the target breakdown radius. The required electric field is reduced, and the allowable stray field increased, if a means of pre-ionization (e.g. from Electron Cyclotron (EC) RF power) is used. For NSTX the requirement on the $\mathrm{OH}$ and $\mathrm{PF}$ system was to create conditions at $\mathrm{B}_{\mathrm{T}}=3 \mathrm{kG}$ where the stray field $|\mathrm{B}|$ and the loop voltage $\mathrm{V}$ satisfied the condition $|\mathrm{B}| \leq 1.3 \mathrm{~V} /\left(\pi \mathrm{R}^{2}\right)$ where $\mathrm{R}$ is the target breakdown radius $[12,13]$. This corresponds to the case of fully inductive breakdown without pre-ionization. On NSTX the EC preionization source was included to 1) provide additional insurance that NSTX would be able to achieve inductive breakdown and 2) to provide a noninductive plasma initiation source relevant to future ST operation without an $\mathrm{OH}$ coil (e.g. with CHI plasma start-up).

Field null and loop voltage creation on NSTX are complicated by the fact that the vacuum vessel forms a conducting shell, and the copper passive plates form an "n=0" toroidal loop, albeit broken by the gaps between the 12 gaps between the plates (a complete toroidal conducting path still exists 
through the stainless steel passive plate support brackets and vacuum vessel wall). Therefore, significant eddy currents flow as the external $\mathrm{OH}$ and $\mathrm{PF}$ coils are ramped, contributing to the stray field pattern, and a delay in the rise of the loop voltage within the vacuum vessel.

Several simulation codes were developed and used to study the initiation sequence and determine the $\mathrm{PF}$ and $\mathrm{OH}$ coil requirements, including the LRSIM code. These codes model the machine as an axisymmetric array of conducting filaments, some of which are driven (representing the coils and their associated power supplies), some of which are passive (representing the conducting metallic structures). The LRSIM model included approximately 100 filaments, beside the coils themselves, to represent the passive structure in each half plane. In addition, realistic power supply models (including finite time response and voltage drop under load) were included. LRSIM is also used by NSTX control system to test control waveform and gain settings programmed into the power supply real time controller, prior to their actual use.

It was found that a bias from the PF-3 coil set is necessary to null the initial stray vertical field from the $\mathrm{OH}$ coil ( 100 gauss), and that following the $\mathrm{OH}$ ramping to produce the main component of the loop voltage, a rapid response from the PF-3 and PF-5 coils is necessary to maintain field null conditions.

Figure 22 depicts a typical LRSIM result showing the field null structure.

The use of LRSIM to provide insight into this process and establish a starting point for coil current programming was a key ingredient to the rapid achievement of $1^{\text {st }}$ plasma on NSTX. 


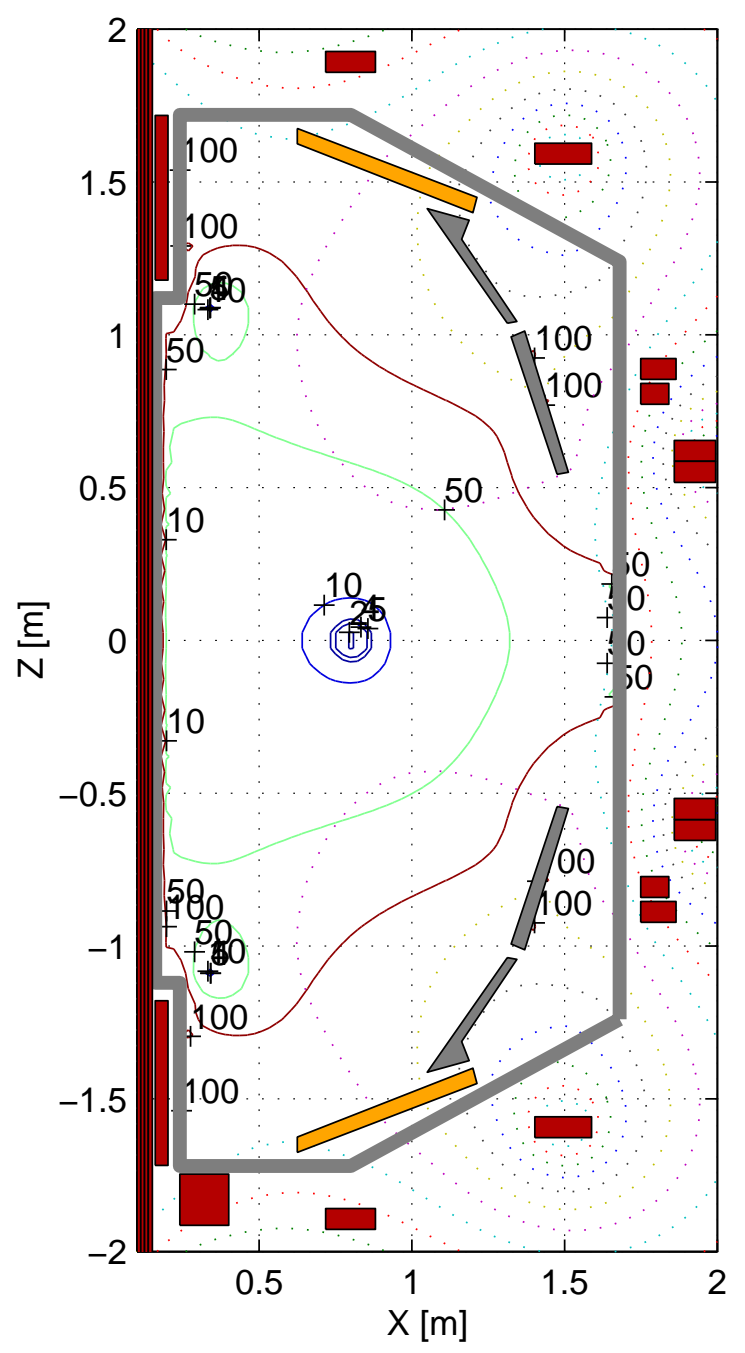

Figure 22 - Typical Field Null $(|\mathrm{B}|)$ and Flux Contours from LRSIM

Another issue related to initiation is the effect of eddy currents in the TF inner legs which occupy the bore of the $\mathrm{OH}$ coil. Analysis of this effect $[14,15]$ showed that the time constant of an individual TF inner leg conductor is of order $1 \mathrm{mS}$, which is not insignificant but still small relative to the $5-10 \mathrm{mS}$ plasma initiation transient period. 


\subsection{Plasma Disruption}

\subsubsection{Poloidal Forces due to Disruption Induced Toroidal Currents}

The SPARK and LRSIM codes were used to estimate disruption-induced toroidal currents in the internal hardware and vacuum vessel [16]. SPARK is a PPPL electromagnetic transient current/field/force analysis code which can handle toroidal geometries with non-axisymmetric elements. Two filaments located at $\mathrm{R}=\mathrm{R}_{\mathrm{o}}$ and $\mathrm{Z}=+/-0.6 \mathrm{~m}$ were used to account for the distribution of the plasma current over the plasma cross section. This approach was found to yield satisfactory results after experimentation with different representations using SPARK. The driving term was a current ramp from 1.0 MA to zero in $6 \mathrm{mS}$.

From a structural design point of view the primary forces of concern are those which pull the internal hardware away from the VV wall, toward the plasma (Figure 23).

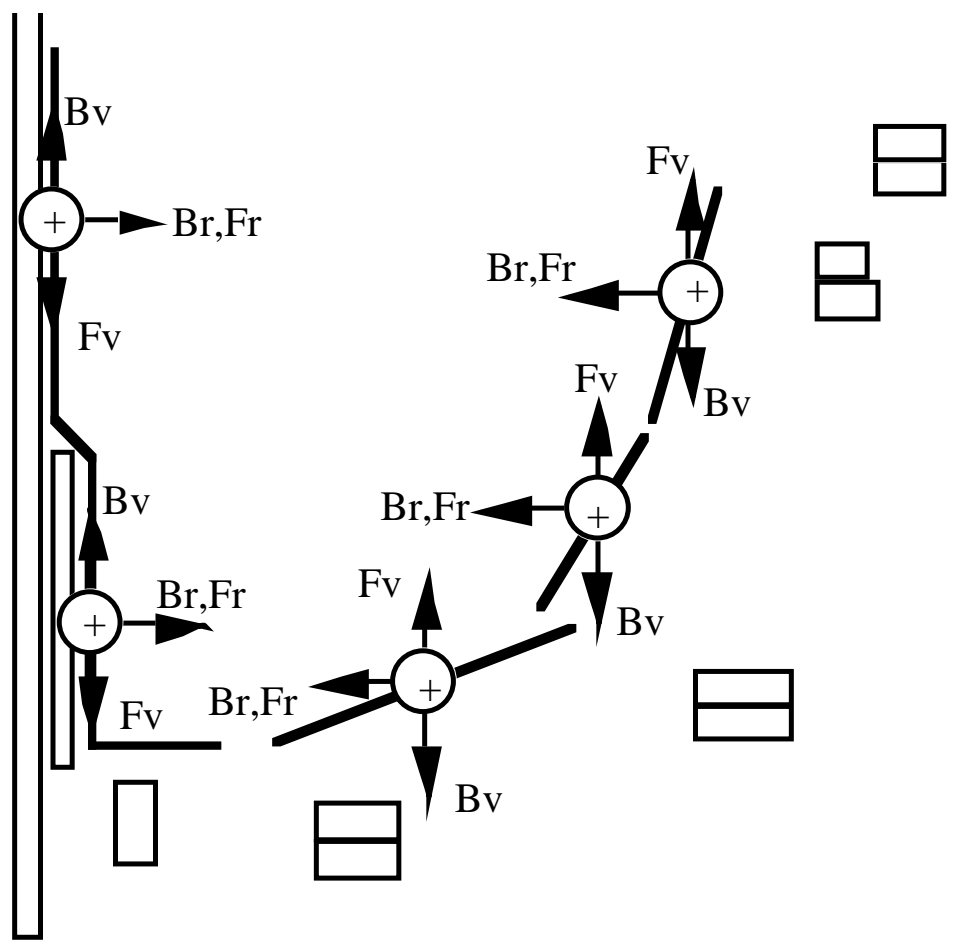

Figure 23 - Fields and Inward Forces on Internal Hardware 
To identify the worst case condition for each of the internal hardware structures (inner wall (IW) of center stack casing, OBD, SPP, and PPP), worst case coil current combinations were established [17] for each of the structures such that $\mathrm{J}_{\text {structure }} \times \mathrm{B}_{\text {coils }}$ (inward) was maximized. For each structure, coil currents were set to $0,(-)$, or (+) rating so as to maximize, separately, $B_{r}$ and $B_{z}$ at that structure. Coil current polarities were constrained where appropriate consistent with the reference plasma direction, but coils which are inherently bipolar or which might be used with either polarity for plasma shaping were allowed to take on either polarity. A total of nine coil current combinations were identified which define the worst case conditions for the structures. The background fields for these nine cases (including the contribution of the toroidal currents induced in the SPP and PPP) were computed and the worst case inward forces $F_{r}$ and $F_{z}$ taken to be the cross product of the disruption induced toroidal currents and these worst case background fields. An additional multiplying factor of 1.5 was applied to account for the possibility of a moving, non-centered plasma disruption scenario. Results are given in Table 11.

Table 11 - Summary of Poloidal Forces Due to Toroidal Disruption Currents

\begin{tabular}{|l|c|c|c|c|c|l|}
\hline & Inner Wall & IBD & OBD & SPP & PPP & \\
\hline Itoroidal & 35000.00 & 44100.00 & 44100.00 & 44100.00 & 105700.00 & Amp \\
\hline $\mathrm{Br}$ & 0.27 & 0.68 & 0.31 & 0.44 & 0.22 & $\mathrm{~T}$ \\
\hline $\mathrm{Bv}$ & 0.37 & 0.52 & 0.60 & 0.56 & 0.56 & $\mathrm{~T}$ \\
\hline $\mathrm{L}$ toroidal & 0.05 & 0.07 & 0.12 & 0.62 & 0.71 & $\mathrm{~m}$ \\
\hline $\mathrm{k}$ & 1.50 & 1.50 & 1.50 & 1.50 & 1.50 & \\
\hline Fradial/segment & 967.25 & 2516.10 & 4747.56 & 22790.53 & 62992.99 & $\mathrm{~N}$ \\
\hline & 217.44 & 565.62 & 1067.25 & 5123.31 & 14160.82 & $\mathrm{l}$ bs \\
\hline Fvertical/segment & 705.83 & 3290.29 & 2452.91 & 17906.84 & 24747.24 & $\mathrm{~N}$ \\
\hline & 158.67 & 739.66 & 551.41 & 4025.46 & 5563.18 & $\mathrm{lbs}$ \\
\hline
\end{tabular}

Although the approach described above is not rigorous it was found to be a practical and conservative one.

\subsubsection{Forces due to Disruption Induced Poloidal Halo Currents}

To calculate the halo driven forces, the toroidal field at the average radius of the element (based on $\mathrm{B}_{\mathrm{T}}=6 \mathrm{kG} @ \mathrm{R}_{\mathrm{o}}$ ) in question is multiplied by the current and by the poloidal length of the segment. This results in a poloidal force normal to the element. The division of current between the tiles and the 
backplates of the various elements will likely be such that the great majority of current will flow in the backplates rather than the tiles due the resistivity effects, except where the halo current enters or exits. Forces on the structures are given in Table 12 (in the case of the inner wall, on a per tile basis, assuming the full current flowing in the tile).

Table 12 - Summary of Poloidal Forces due to Halo Currents

\begin{tabular}{|l|c|c|c|c|c|l|}
\hline & $\begin{array}{c}\text { Inner } \\
\text { Wall* }\end{array}$ & IBD & OBD & SPP & PPP & \\
\hline Ip & $1.00 \mathrm{E}+06$ & $1.00 \mathrm{E}+06$ & $1.00 \mathrm{E}+06$ & $1.00 \mathrm{E}+06$ & $1.00 \mathrm{E}+06$ & Amp \\
\hline $\mathrm{k}$ & 0.10 & 0.10 & 0.10 & 0.10 & 0.10 & \\
\hline peaking & 2.00 & 2.00 & 2.00 & 2.00 & 2.00 & \\
\hline \#segment & 24.00 & 24.00 & 48.00 & 12.00 & 12.00 & \\
\hline Ipoloidal & 8333.33 & 8333.33 & 4166.67 & 16666.67 & 16666.67 & Amp \\
\hline Theta & -90.000 & -90.000 & -21.447 & -59.036 & -70.942 & degrees \\
\hline Ravg & 0.190 & 0.279 & 0.914 & 1.175 & 1.355 & $\mathrm{~m}$ \\
\hline Bt(Ravg) & 2.694 & 1.834 & 0.561 & 0.436 & 0.378 & $\mathrm{~T}$ \\
\hline L poloidal & 0.152 & 0.461 & 0.624 & 0.292 & 0.582 & $\mathrm{~m}$ \\
\hline Fnormal/segment & 3421.39 & 7045.35 & 1456.92 & 2118.99 & 3667.43 & $\mathrm{~N}$ \\
\hline & 769.13 & 1583.79 & 327.52 & 476.35 & 824.44 & $\mathrm{lbs}$ \\
\hline Fradial/segment & 769.13 & 1583.79 & 119.75 & 408.47 & 779.25 & $\mathrm{lbs}$ \\
\hline Fvertical/segment & 0.00 & 0.00 & 304.84 & 245.08 & 269.20 & $\mathrm{lbs}$ \\
\hline
\end{tabular}

*Note: Force given for Inner Wall is per tile

During the initial phase of the design, there was significant concern about the possibility of a large non-axisymmetric halo induced force on the center stack casing (CSC) due to the halo current toroidal peaking factor; the attractive force between the inner legs of the TF coil and the poloidal halo current flowing down the CSC would be non-symmetric (unbalanced) due to the peaking. The analysis $[18,19]$ showed that, due to the geometry of the CSC, halo current entering at a discrete point of injection quickly becomes toroidally symmetric as it flows from the point of entry to exit, owing to the fact that the impedance of the toroidal current path is comparable to that of the poloidal current path. As a result, unbalanced forces are small. This effect is depicted in Figure 24. 

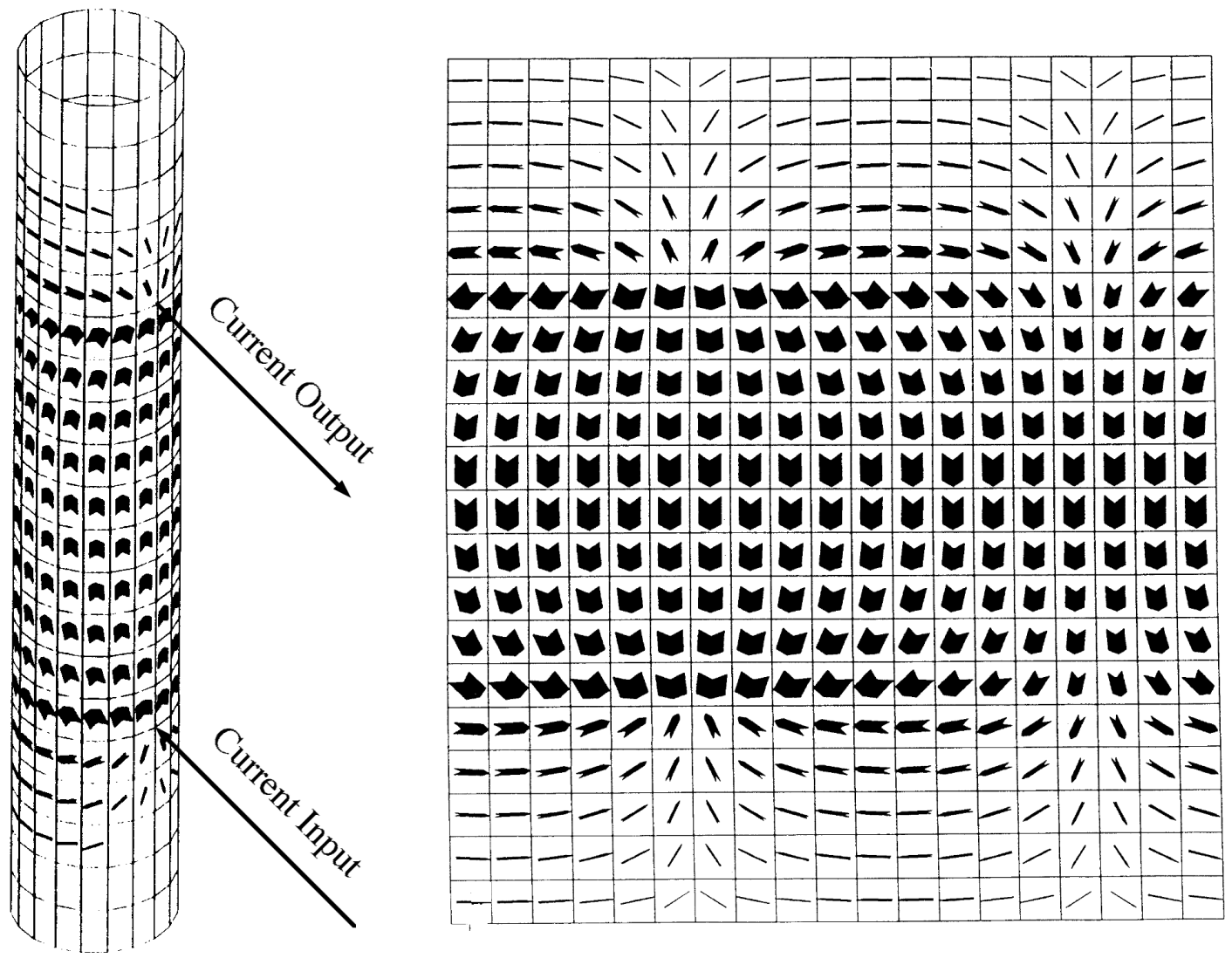

Figure 24 - Pattern of Halo Currents In Center Stack Casing (Width of Arrow Indicates Magnitude of Current)

It was found that the worst case force occur with the distance between entry and exit points $\sim 1 \mathrm{~m}$. Smaller separations lead to greater asymmetry but over a shorter length, hence a smaller force. The magnitude of the worst case force is very small (net radial force Fr less than $100 \mathrm{lbs}$.). This was an important finding be cause it allowed the use of the Microtherm layer between the $\mathrm{CSC}$ and $\mathrm{OH}$ coil, which although an excellent thermal insulator does not possess strong compressive strength.

\subsubsection{Plasma Disruption Induced Voltages}

In the case of a plasma disruption, an open circuited coil "i" will develop a measurable induced terminal voltage based on $\sum \mathrm{M}_{\mathrm{ij}}{ }^{*} \Delta \mathrm{I}_{\mathrm{j}} / \Delta \mathrm{t}$, while a coil connected to power supplies will act as if short circuited and experience a small change in current such that $\mathrm{L}_{\mathrm{i}} \Delta \mathrm{I}_{\mathrm{i}} \sim \sum \mathrm{M}_{\mathrm{ij}} * \Delta \mathrm{I}_{\mathrm{j}} / \Delta \mathrm{t}$. If a coil is connected 
to a power supply and carries current in the forward direction of the power supply then it is possible that the disruption induced current change could exceed the initial current in the opposite direction, in which case the current would be driven to zero and the power supply would become reverse biased and appear as an open circuit.

Based simply on the projected $\mathrm{dI}_{\mathrm{p}} / \mathrm{dt}$ of $1 \mathrm{MA} / 6 \mathrm{mS}$ and the direct mutual coupling between the coil circuits and the plasma, all circuits except PF-4 and PF-5 will experience less induced voltage than their normal rating. Further analysis taking into consideration the filtering effect of the passive plate and vacuum vessel structure, these coils also experience a voltage less than their rating in case of disruption.

When the power supply is connected, the induced current change is typically less than one or two kA except for PF-4 and PF-5 where it approaches 4kA.

\subsection{Coaxial Helicity Injection}

With CHI a power supply is connected across the two electrodes formed by the CSC and the outer VV, and up to $2 \mathrm{kV}$ is applied. The CHI power supply is rated to inject up to 50kA which is projected to produce up to 500kA of plasma current. An X-point poloidal field is formed by the driven plasma current and PF1b. As injected current flows around the poloidal perimeter it also flows around the toroidal circumference $q$ times, where $q$ is the value of the edge safety factor [3].

To allow for the CHI mode of operation, the NSTX machine proper was designed with a large number of dielectric breaks in addition to those which would normally be provided on a tokamak to interrupt eddy current loops. These serve to isolate the CSC and outer VV to a $5 \mathrm{kV}$ DC test level between each other and to ground. A schematic which identifies the main components of the machine at different potentials is given in Figure 25 and the voltages and dielectric breaks between these components are described in Table 13. 


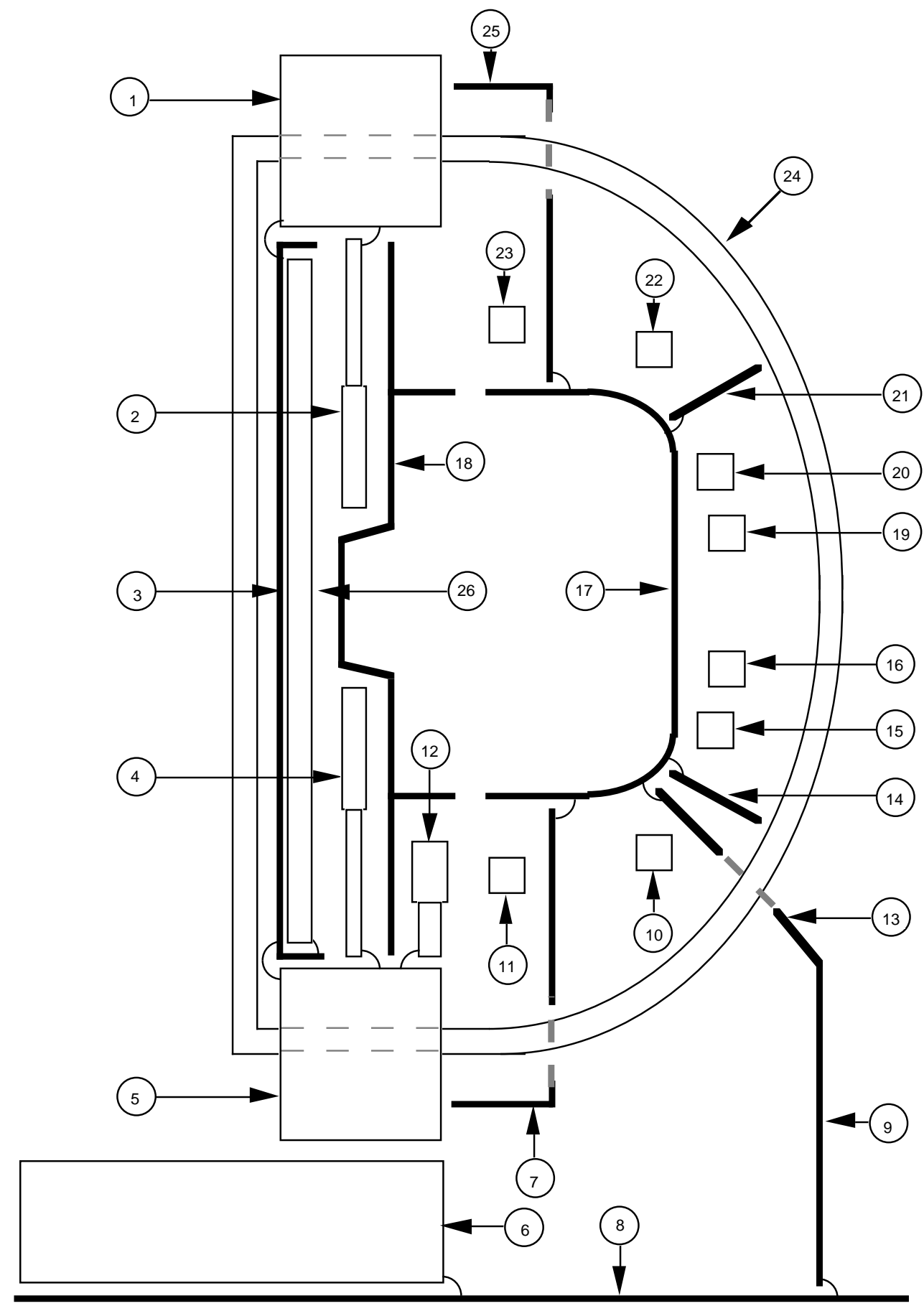

Figure 25 - NSTX Components at Different Electrical Potentials 
Table 13 - Dielectric Breaks for CHI Operation

\begin{tabular}{|c|c|c|c|c|}
\hline Gap & ID\#̈'s & $\begin{array}{l}\mathrm{Vmax} \\
(\mathrm{kV})\end{array}$ & $\begin{array}{l}\text { Hipot } \\
(\mathrm{kV})\end{array}$ & Comments \\
\hline CS Casing/Outer VV & $18 / 17$ & 2 & 5 & Ceramic insulators \\
\hline $\begin{array}{l}\text { CS Casing/OH Ground } \\
\text { Plane }\end{array}$ & $18 / 26$ & 2 & 5 & Microtherm in CS gap \\
\hline $\begin{array}{l}\text { CS Casing/PF1a Ground } \\
\text { Plane }\end{array}$ & $18 / 2,18 / 4$ & 2 & 5 & Microtherm in CS gap \\
\hline $\begin{array}{l}\text { CS Casing/PF1b Ground } \\
\text { Plane }\end{array}$ & $18 / 12$ & 2 & 5 & G-10/Kapton spacers \\
\hline $\begin{array}{l}\text { CS C a sing/Hub } \\
\text { Assembly }\end{array}$ & $18 / 1,18 / 5$ & 2 & 5 & G-10/Kapton spacers \\
\hline $\begin{array}{l}\text { OH Tension Tube/TF } \\
\text { Inner Leg }\end{array}$ & $3 / 24$ & 3 & 3 & $\begin{array}{l}\text { TF Inner Leg Ground } \\
\text { Insulation }\end{array}$ \\
\hline Hub Assembly/Umbrella & $1 / 25,5 / 7$ & 2 & 5 & $\begin{array}{l}\text { G-10 spline on top, turnbuckles } \\
\text { on bottom }\end{array}$ \\
\hline $\begin{array}{l}\text { L ow e r } \\
\text { Assembly/Pedestal }\end{array}$ & $5 / 6$ & 2 & 5 & G-10 spacer \\
\hline $\begin{array}{l}\text { Lower VV Leg/Upper } \\
\text { VV Leg }\end{array}$ & $9 / 13$ & 2 & 5 & G-10 spacer \\
\hline Umbrella/TF Coil & $7 / 24,25 / 24$ & 3 & 7 & $\begin{array}{l}\text { TF ground insulation plus } \\
\text { grouting under clamp attached } \\
\text { to leg }\end{array}$ \\
\hline TF Leg Supports/TF Coil & $\begin{array}{l}14 / 24 \\
21 / 24\end{array}$ & 3 & 7 & $\begin{array}{l}\text { TF ground insulation plus } \\
\text { grouting under clamp attached } \\
\text { to leg }\end{array}$ \\
\hline PF2/Outer VV & $\begin{array}{l}11 / 17,23 / 1 \\
7\end{array}$ & 6 & 13 & PF coil ground insulation \\
\hline PF3/Outer VV & $\begin{array}{l}10 / 17 \\
22 / 17\end{array}$ & 4 & 9 & PF coil ground insulation \\
\hline PF4/Outer VV & $\begin{array}{l}15 / 17 \\
20 / 17\end{array}$ & 4 & 9 & PF coil ground insulation \\
\hline PF5/Outer VV & $\begin{array}{l}15 / 17 \\
20 / 17\end{array}$ & 4 & 9 & $\begin{array}{l}\text { PF coil ground insulation plus } \\
\text { G-10/Kapton spacers }\end{array}$ \\
\hline
\end{tabular}

It was originally planned to bias the CSC up to $2 \mathrm{kV}$ while maintaining the $\mathrm{OH}$ coil ground plane and tension tube, along with the outer VV, near ground. However, concern about the small gap and entrained diagnostics in the space between the $\mathrm{OH}$ coil ground plane and the CSC led to the decision to tie the $\mathrm{OH}$ coil ground plane and tension tube to the same potential as the CSC. Along with this decision a corresponding decrease in the maximum allowable operating voltage of $\mathrm{CHI}$ to $1 \mathrm{kV}$ was imposed (based on feedback from first $\mathrm{CHI}$ experiments which were successful at $1 \mathrm{kV}$ ). Therefore the 
$\mathrm{OH}$ coil and TF inner leg ground insulation must withstand an additional $1 \mathrm{kV}$ compared to the original requirement. This extra stress is accepted in light of the necessity of protecting the aforementioned gap.

\section{Mechanical and Structural Design and Performance}

\subsection{Overview of Mechanical and Structural Design Approach}

The mechanical and structural design of NSTX responds to the following requirements:
(1) dead weight loads
(2) vacuum loads
(3) electromagnetic loads during normal operation
(4) thermal loads and displacements during normal operation and bakeout
(5) seismic loads
(6) feasibility of manufacture and assembly

Load paths and support schemes, working from the inside of the machine outward, are described in the following paragraphs.

\section{TF Inner Legs}

The TF inner legs, radial flags, and hub assemblies form an essentially monolithic structure. The radial flags are wedged via epoxy-glass (NEMA G-10) blocks into the hub assemblies, which are in turn fixed to the body of the inner legs via torque collars. The dead weight of this structure is supported by floor of the test cell via the pedestal. The joints between the TF inner and outer legs consist of de-mountable flexible connectors which allow for small axial growth of the inner legs due to thermal effects (the structure grows upwards since it is supported from the floor). The hub assemblies provide a reaction against torsional loads resulting from $\mathrm{J}_{\mathrm{tf}} \mathrm{x} \mathrm{B}_{\mathrm{oh}}$ which are oppositely directed top and bottom. The bottom hub assembly is fixed to the lower umbrella and pedestal, while the top is locked to the upper umbrella assembly through a G-10 spline, which allows the axial growth but not the twist. Thus the torsional loads are reacted between the two hub assemblies via the outer VV. The torque collar-to-hub assembly connection prevents the torsional load from being applied to the radial flags, which would otherwise have an adverse effect on the electrical conductance of the joints with the inner legs. 


\section{OH Coil}

The $\mathrm{OH}$ coil is wound on a "tension tube" spool piece. A gap exists between the inside of the tension tube and the TF coil inner legs, which allows for their independent axial growth. The bottom of the tension tube is attached to the lower hub assembly, but is not attached at the top. A layer of Teflon located between the tension tube and the adjoining $\mathrm{OH}$ coil groundwall insulation and first layer of the $\mathrm{OH}$ coil provides a slip plane which allows for axial growth of the $\mathrm{OH}$ coil due to its temperature rise during a pulse. The dead weight of the $\mathrm{OH}$ coil, in combination with compression washers which are react between the top flange of the tension tube and the top of the $\mathrm{OH}$ coil, hold it down against the bottom flange, even in the presence of "launching loads" which can occur due to the interaction between the $\mathrm{OH}$ and PF1b coils.

\section{Center Stack Casing}

The CSC is rigidly attached to the lower hub assembly which provides for dead load support down through the pedestal. The bellows assemblies top and bottom allow for relative axial displacement of the CSC and outer VV during operations $\left(\mathrm{CSC}\right.$ up to $600^{\circ} \mathrm{C}$ ) and bakeout. The gap between the $\mathrm{CSC}$ and $\mathrm{OH}$ coil groundplane, partially filled with Microtherm and magnetic diagnostics, so as to allow for independent axial thermal growth of the two structures.

\section{Umbrella Structures}

The upper and lower umbrella structures receive the torsional loads from the TF inner leg assembly and transmit them to the outer VV. In addition they secure the ends of the outer legs of the TF coils via cast aluminum clamps which are inserted into keyed openings on the umbrella structures.

\section{Outer Vacuum Vessel}

The outer VV provides support to the TF coil outer legs, outer PF coils, umbrella structures, and internal hardware (outboard divertor and passive plates), and also reacts the vacuum loads. To allow for radial expansion during bakeout the outer $\mathrm{VV}$ goes to $150^{\circ} \mathrm{C}$, the umbrella structures and outer PF coils are mounted to the outer VV via sliding supports. The TF coil 
outer legs are supported by turnbuckles which go slack as the outer VV expands.

\section{Legs and Support Columns}

The vacuum vessel and all components mounted thereto (total weight approximately 100,000 lbs.) is supported from the floor via four legs. The legs rest upon columns. The leg-to-column interface consists of a radial slide support, coated with a special low friction coefficient surface treatment ("Magnaplate"). This scheme allows for the axisymmetric radial expansion of the outer VV during bakeout. The legs and support columns receive, in addition to the dead weight load, some side loading due to the unbalance in vacuum forces, mainly due to the lack of same at the vacuum pumping and NBI ducts which are attached to the outer VV via flexible bellows assemblies. Additional struts are provide to react these loads to the floor. The welded connection of the legs to the outer VV, along with the sliding joints, are able to accommodate these additional side loads without excess stress, and without binding of the slides.

\subsection{Stress Allowable Criteria}

Based on the linear finite element analysis, the ASME code requires that the Tresca stress of the 2-D or 3-D element shall meet the following stress limits:

- General primary membrane stress shall not exceed $1.0 \mathrm{~K} \mathrm{~S}_{\mathrm{m}}$

- Local primary membrane stress shall not exceed $1.5 \mathrm{~K} \mathrm{~S}_{\mathrm{m}}$

- Primary membrane plus bending stresses shall not exceed $1.5 \mathrm{~K} \mathrm{~S}_{\mathrm{m}}$

- Total primary + secondary (thermal) stresses shall not exceed $3.0 \mathrm{~K} \mathrm{~S}_{\mathrm{m}}$

The $\mathrm{K}$ factor is 1.0 for normal operating conditions or 1.1 if case seismic force is involved. $\mathrm{S}_{\mathrm{m}}$ is the design stress intensity value defined in the ASME Boiler and Pressure Vessel code. Since the von Mises stress is generally more accurate than the Tresca stress in the representation of the equivalent one-dimensional stress and the difference between the two is small, it was used instead of the Tresca stress in determining the stress acceptance criteria. The design stress intensity value is set at $2 / 3$ of the minimum specified yield at temperature. For bolting material, the average 
tensile stress shall not exceed $1.0 \mathrm{~S}_{\mathrm{m}}$ and maximum direct tensile plus bending stress shall not exceed $1.5 \mathrm{~S}_{\mathrm{m}}$.

\subsection{Loads and Finite Element Stress Analysis}

\subsubsection{TF Coil System}

Torsional loads are generated in the inner leg bundle by the $\mathrm{OH}$ fields crossing the TF conductors, primarily the outer layer. This results in a torque of $\sim 24,000 \mathrm{~N}-\mathrm{m}$ on the $\mathrm{TF}$ inner leg bundle. Additional torsional loads are generated in the radial elements of the TF system (i.e., the flags, connectors, and outer legs) by the poloidal fields crossing these elements. Vertical loads are generated by the TF fields crossing over the TF flags, connectors, and outer legs. Additional downward vertical loads are generated by the dead weight of the structures. Radial loads are generated inwards on the inner legs due to the magnetic attraction between turns. Radial loads are generated outwards on the outer legs due to the magnetic force $\mathrm{J}_{\mathrm{TF}} \times \mathrm{B}_{\mathrm{T}}$. Ohmic heating of the $\mathrm{TF}$ bundle leg results in an overall growth in its length of $\sim 3 / 8$ " which, in turn, creates thermally induced loads.

The support system must react the aforementioned loads while maintaining stresses (e.g. inner leg turn-to-turn insulation shear) within allowables, and while preventing deformation and loss of contact pressure the critical inner leg to radial flag electrical joint.

The TF support structure, shown in Figure 26 provides the necessary features to react the loads. A stainless steel torque reaction collar is bonded to the outside of the TF inner leg bundle just above the ends of the $\mathrm{OH}$ tension cylinder via glass epoxy which acts in shear. A bolted flange connection transmits the torque from the collar to the hub portion of the restraint structure. Both "tiers" of flags are tightly shimmed in the vertical direction between the two discs in the hub portion of the restraint structure. In this manner, the entire circular array of radial flags clamped between upper and lower discs together form two tiers of thick discs. Vertical loads on the disc result in simple shearing loads across bolts of the joints. The bolts are shoulder bolts designed to act in shear and resist slippage at the joint. The shearing load is absorbed by a total of $36^{*} 4=144$ bolts. G-10 wedges are installed between the flags so the entire array of flags behaves as a solid disc. The resulting torque is reacted through the restraint structure to the umbrella structure and in turn to the outer VV. The connection between 
the restraint structure is free to move vertically (to permit free thermal expansion of the central bundle) but fixed in torsion. The TF inner leg bundle is supported from the floor via the support pedestal. This arrangement, in conjunction with the flexible connectors between the radial flags and the outer legs permits the bundle to freely expand upwards.

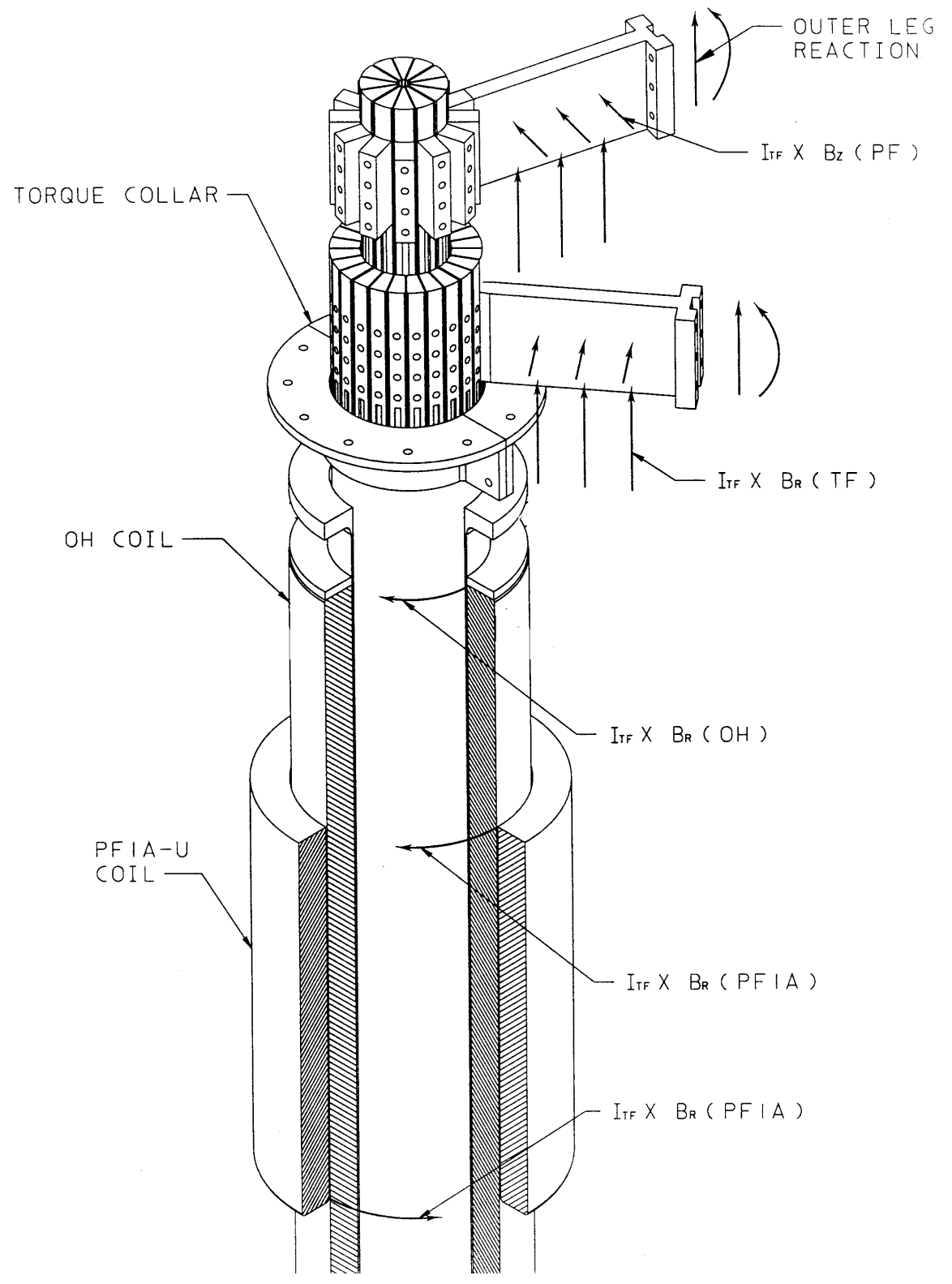

Figure 26 - TF Support Structure 
An ANSYS finite element model was generated to quantify the loads and the resulting stresses [20]. The model included one-quadrant of the TF coil system consisting of three outboard legs with three conductors each, nine inner core conductors and their turn insulation, the inner and outer TF flags and the de-mountable links between the inner conductors and the outer legs. Only the top half of the conductors were modeled with both the inner and outer conductors fixed at the midplane.

The analysis predicts a maximum torsoinal moment of $\sim 17,700 \mathrm{ft}-\mathrm{lb}$ for the case of $\mathrm{B}_{\mathrm{T}}=3 \mathrm{kG}, \mathrm{I}_{\mathrm{oh}}=24 \mathrm{kA}$, and $\mathrm{I}_{\mathrm{PF} 1 \mathrm{a}}=10 \mathrm{kA}$, occurring over the axial length between the center of the PF1a coil and the end of the bundle as it enters the hub assembly. This loading results in a von Mises stress of $4.20 \mathrm{ksi}$ in the copper, a maximum shear of $1.51 \mathrm{ksi}$ in the insulation in the vicinity of PF1a, and a torsional displacement of $0.1^{\text {". }}$. These results are presented as Model A in Table 14.

Table 14 - TF Inner Leg Stress Analysis

\begin{tabular}{|c|c|c|c|c|c|c|}
\hline & \multirow{2}{*}{$\begin{array}{l}\text { Copper } \\
\text { von Mises }\end{array}$} & \multicolumn{3}{|c|}{ Insulation } & \multirow[t]{2}{*}{ Disp. } \\
\hline & & & shear xy & shear yz & stress y & \\
\hline & & ksi & $\mathrm{ksi}$ & $\mathrm{ksi}$ & $\mathrm{ksi}$ & in \\
\hline \multirow[t]{2}{*}{ Model A } & Min. & & -0.64 & -0.8 & -1.03 & \\
\hline & Max. & 4.2 & 0.5 & 1.51 & 0.7 & 0.101 \\
\hline \multirow[t]{2}{*}{ Model B } & Min. & & -1.05 & -1.71 & -1.17 & \\
\hline & Max. & 4.98 & 0.23 & 0.54 & 1.3 & 0.011 \\
\hline \multirow[t]{2}{*}{ Model C } & Min. & & -1.59 & -1.67 & -1.02 & \\
\hline & Max. & 4.76 & 0.36 & 0.45 & 0.26 & 0.011 \\
\hline
\end{tabular}

Notes:

1) All models fixed at mid-plane, flags are coupled for vertical displacement

2) Model B has additional torsional constraints at flags

3) Model $\mathrm{C}$ has additional torsional constraints at flags and TF collar

The model was exercised in subsequent analyses to bracket the effect of the CS restraint structure. The first of these analyses, Model B, provided torsional constraints along the radial length of the flag. This boundary condition simulates the effect of the G-10 wedges which are installed between the flags. These wedges prevent bending along the length of the flag and transmit the torsional loads through the hub assembly to the 
umbrella structure of the vacuum vessel. For this set of constraints the maximum von Mises stress in the copper increases to $5.0 \mathrm{ksi}$ while the shear stress in the insulation increases to $1.7 \mathrm{ksi}$ at the top of the $\mathrm{OH}$ solenoid. The torsional displacement drops to 0.01". The second Model C added additional constraints to simulate the effect of the torque reaction collar. The result of these additional constraints was a slight reduction in the copper and insulation stresses and no change in the displacement.

The TF inner core is supported at its base and is allowed to grow/move freely in the vertical direction. This support arrangement creates no thermal stresses in the conductor but does create additional stress in the insulation of because of differences in the coefficients of thermal expansion between the copper and the insulation. A shear stress in the insulation of $<1 \mathrm{ksi}$ occurs.

The TF inner conductors are fabricated from quarter-hard CDA 107 copper with specified minimum yield strength of $30 \mathrm{ksi}$ (allowable stress at room temperature of $20 \mathrm{ksi}$ ). Shear strength of the selected insulation system is $\sim 6$ ksi. From these results it is concluded that the stresses in the TF inner core copper $(9.9 \mathrm{ksi}$ at $6 \mathrm{kG})$ is well below the allowable limits while the insulation shear stress $(3.4 \mathrm{ksi}$ at $6 \mathrm{kG})$ is challenging but acceptable.

\subsubsection{OH System}

The $\mathrm{OH}$ solenoid is supported from the test cell floor via the support pedestal. It is free to expand vertically upward independent from the TF bundle, tension tube and CSC. Outward radial J x B forces are generated by the current in each turn reacting against the self-field of the coil; the forces peak at the inner layer of the solenoid where the self-field is $\sim 8 \mathrm{~T}$. Additional radial $\mathrm{J} \times \mathrm{B}$ forces are generated by the current in each $\mathrm{OH}$ turn reacting against the stray field from other PF coils. Axial compressive forces are generated due to the attraction between $\mathrm{OH}$ turns. Additional axial forces are generated by the interaction of the $\mathrm{OH}$ current with the fields from nearby PF coils. PF1b has the greatest effect since it is located close to the end of the $\mathrm{OH}$ coil (PF1a is closer but its effect tends to cancel since $\mathrm{OH}$ turns exist both above and below its current center). PF1b operation is nominally of a polarity the same as that of the $\mathrm{OH}$ when it is operated, resulting in a downward force which is reacted through the common structure which supports both the $\mathrm{OH}$ and PF1b at the bottom. Care is taken in the protection systems to avoid large $\mathrm{OH}$ and $\mathrm{PF} 1 \mathrm{~b}$ currents in opposite directions which would cause a "launching load". The weight of the coil 
causes a vertical axial load. Additional loads are created as the "coolant wave" progresses through the winding after a pulse.

The $\mathrm{OH}$ solenoid is vertically constrained and preloaded via the tension tube with compression washers acting against the upper flange so that net axial loads do not result in tension between the solenoid turns but instead against the tension tube and its mounting.

To characterize the axial loads in the $\mathrm{OH}$ solenoid a series of finite element analyses were conducted whose outcome is summarized via the influence matrix shown in Table 15 which describes the effect of each PF coil on the $\mathrm{OH}$ coil. Each term in the matrix was developed by applying a unit current on the $\mathrm{OH}$ solenoid and on an individual PF coil bundle. The effect of the plasma was also included (two filaments at $R_{o}$ above and below the midplane).

For each row "i" in the table, $\mathrm{B}_{\text {sum }}$ (i) is the field per kA at the $\mathrm{OH}$ conductor center due the current in coil " $\mathrm{i}$ ". $\mathrm{F}_{\mathrm{z}}$ is the coefficient of axial force where:

$$
\mathrm{F}_{\mathrm{Zoh}}=\mathrm{I}_{\mathrm{oh}} * \sum \mathrm{F}_{\mathrm{z}}(\mathrm{i}) * \mathrm{I}(\mathrm{i})
$$

Similarly $F_{r}$ is the coefficient of radial force where:

$$
\mathrm{F}_{\mathrm{Roh}}=\mathrm{I}_{\mathrm{oh}} * \sum \mathrm{F}_{\mathrm{r}}(\mathrm{i}) * \mathrm{I}(\mathrm{i})
$$

In the case of $F_{\mathrm{r}}$ the summation represents the total "hoop stress". The large coupling to PF1b is evident from the Table. Six finite element cases were conducted using ANSYS to determine the stresses and deflections in the $\mathrm{OH}$ solenoid. The first examined the stresses and displacements under the 5000 lb. pre-load from the compression washers acting against the upper tension tube flange. The second examined the effect of electromagnetic (EM) loads only. The third set all conductors to the peak temperature at the end of a pulse, assuming adiabatic conditions. The fourth set the lower 45 turns of the coil at $14^{\circ} \mathrm{C}$ and the remaining turns at $83^{\circ} \mathrm{C}$ to simulate the effect of the cooling wave propagation through the coil. Cases 5 and 6 are combinations of the EM with the two thermal cases. In these analyses the OH, PF1a and PF1b coils were all assumed to be operating at their maximum current. The results of the analysis are given in Table 16. 
Table 15 - OH Coil Axial and Radial Force Coefficients

\begin{tabular}{|c|c|c|c|c|c|}
\hline Circuit & Bsum & Fz & Fr & Imax & $\begin{array}{c}\text { Max Axial } \\
\text { Load Fz }\end{array}$ \\
\hline & $($ Tesla/kA) & $\left(\mathrm{lbs/k \textrm {k } ^ { 2 } )}\right.$ & $\left(\mathrm{lbs} / \mathrm{kA}^{2}\right)$ & $(\mathrm{kA})$ & $(\mathrm{lbs})$ \\
\hline OH & 0.27768 & 0.000 & 22206.9 & 24 & 0 \\
\hline PF1a-u & 0.11917 & 12.489 & 2461.1 & 10 & 2997 \\
\hline PF1a-1 & 0.11917 & -12.489 & 2461.1 & 10 & -2997 \\
\hline PF1b-1 & 0.08837 & -110.252 & 1507.4 & 15 & -39691 \\
\hline PF2a-u & 0.01133 & 28.871 & 402.4 & 20 & 13858 \\
\hline PF2a-1 & 0.01133 & -28.871 & 402.4 & 20 & -13858 \\
\hline PF2b-u & 0.01133 & 27.403 & 438.4 & 20 & 13153 \\
\hline PF2b-1 & 0.01133 & -27.403 & 438.4 & 20 & -13153 \\
\hline PF3a-u & 0.00636 & 14.338 & 464.2 & 20 & 6882 \\
\hline PF3a-1 & 0.00636 & -14.338 & 464.2 & 20 & -6882 \\
\hline PF3b-u & 0.00636 & 13.633 & 482.0 & 20 & 6544 \\
\hline PF3b-1 & 0.00636 & -13.633 & 482.0 & 20 & -6544 \\
\hline PF4a-u & 0.00177 & 1.727 & 187.3 & 20 & 829 \\
\hline PF4a-1 & 0.00177 & -1.727 & 187.3 & 20 & -829 \\
\hline PF4b-u & 0.00282 & 2.424 & 302.1 & 20 & 1164 \\
\hline PF4b-1 & 0.00282 & -2.424 & 302.1 & 20 & -1164 \\
\hline PF4c-u & 0.00315 & 2.360 & 342.1 & 20 & 1133 \\
\hline PF4c-1 & 0.00315 & -2.360 & 342.1 & 20 & -1133 \\
\hline PL-u & 0.00067 & 0.072 & 47.6 & 1000 & 1727 \\
\hline PL-1 & 0.00067 & -0.072 & 47.6 & 1000 & -1727 \\
\hline
\end{tabular}

Table 16 - OH Stress Analysis for $\mathrm{OH}=24 \mathrm{kA}, \mathrm{PF} 1 \mathrm{a}=15 \mathrm{kA}, \mathrm{PF} 1 \mathrm{~b}=20 \mathrm{kA}$

\begin{tabular}{|c|c|c|c|c|c|c|c|c|c|}
\cline { 3 - 10 } \multicolumn{2}{c|}{} & \multicolumn{2}{c|}{ Copper Stress } & \multicolumn{4}{c|}{ Insulation Stress } & \multicolumn{2}{c|}{ Displacement } \\
\hline Case & Load & $\begin{array}{c}\text { von } \\
\text { Mises } \\
(\mathrm{ksi})\end{array}$ & $\begin{array}{c}\text { Sy } \\
(\mathrm{ksi})\end{array}$ & $\begin{array}{c}\text { Sy } \\
(\mathrm{ksi})\end{array}$ & $\begin{array}{c}\text { Sz } \\
(\mathrm{ksi})\end{array}$ & $\begin{array}{c}\text { Sxy } \\
(\mathrm{ksi})\end{array}$ & $\begin{array}{c}\text { Sxz } \\
(\mathrm{ksi})\end{array}$ & $\begin{array}{c}\text { Dmax } \\
(\mathrm{in})\end{array}$ & $\begin{array}{c}\text { Dz } \\
(\mathrm{in})\end{array}$ \\
\hline 1 & Preload & 0.15 & 0.03 & -0.042 & -0.119 & 0.002 & 0.010 & 0.011 & 0.011 \\
\hline 2 & EM & 22.88 & 19.80 & 0.732 & -6.436 & 0.198 & 0.175 & 0.101 & -0.101 \\
\hline 3 & Maximum Temp. & 2.27 & -2.46 & 1.499 & -1.196 & 0.106 & 0.327 & 0.246 & 0.245 \\
\hline 4 & $\begin{array}{c}\text { Temp. at 15.5 } \\
\text { sec. }\end{array}$ & 8.23 & 8.01 & 2.134 & -5.366 & 0.096 & 0.959 & 0.217 & 0.217 \\
\hline 5 & Case 2+3 & 23.20 & 19.91 & 1.978 & -7.248 & 0.290 & 0.416 & 0.148 & 0.147 \\
\hline 6 & Case 2 +4 & 23.20 & 19.93 & 2.210 & -7.142 & 0.280 & 0.823 & 0.119 & 0.119 \\
\hline
\end{tabular}


The maximum tensile ("hoop") stress $\sigma_{\mathrm{y}}$ in the $\mathrm{OH}$ copper is $\sim 20 \mathrm{ksi}$ while the maximum shear stress in the insulation is less than $1 \mathrm{ksi}$. The hoop stress of $19.8 \mathrm{ksi}$ due to EM alone, compared to the theoretical value of $17.8 \mathrm{ksi}$ for hoop stress in an infinite solenoid of the same radial dimensions and current density, reflects the additional contribution of field from the other PF coils.

The $\mathrm{OH}$ conductor is fabricated from half-hard CDA 10700 copper with specified minimum yield strength of $36 \mathrm{ksi}$ (allowable stress at room temperature of $24 \mathrm{ksi}$ ). Shear strength of the selected insulation system is $\sim 3$

ksi.. From these results it is concluded that the stress in the $\mathrm{OH}$ copper is near the allowable limit while the insulation shear stress $(<1 \mathrm{ksi})$ is well within the allowable. Based on available fatigue data (for CDA 10400 copper), and the tensile stress $\sigma_{\mathrm{y}} \sim 20 \mathrm{ksi}$, the cycles to failure is of order 400,000. Therefore with the double swing of the $\mathrm{OH}$ current (two stress cycles per pulse) a failure might be expected after 200,000 pulses at the full rating. A traditional design rule for fatigue allowables, namely that the range of stress should be less than $1 / 2$ of the stress to failure at the design cycle life and less than the stress to failure at 20 times the design cycle life suggests, based on the CDA 10400 data, that the latter criteria may be limiting, however. This would imply a lifetime of $200,000 / 20=10,000$ pulses at full rating. While this falls somewhat short of the total number of pulses planned for NSTX, it is considered acceptable based the conservative nature of the design rule and the necessity for an aggressive design approach.

\subsubsection{Outer PF Coils}

The outer PF coils experience radial and axial forces due to their mutual $\mathrm{J} x$ $B$ interaction. To characterize these loads a series of finite element analyses were conducted whose outcome was a pair of influence matricies shown in Tables 17 and 18 which describe the effect of each PF coil on the radial and axial load of the other PF coils. The effect of the plasma was also included (two groups of filaments "PLA" which carries $63 \%$ of $I_{p}$ and "PLB" which carries 36\%). For each column " $\mathrm{j}$ " in the table the entries in the "i" rows contain the force coefficients which describe the effect of $1 \mathrm{kA}$ of current in coil "i" on coil " $\mathrm{j}$ ". Therefore:

$$
\mathrm{F}_{\mathrm{z}}(\mathrm{j})=\mathrm{I}(\mathrm{j}) * \sum \mathrm{F}_{\mathrm{z}}(\mathrm{i}, \mathrm{j}) * \mathrm{I}(\mathrm{i})
$$

Similarly $F_{r}$ is the coefficient of radial force where: 


$$
F_{R}(j)=I(j) * \sum F_{r}(i, j) * I(i)
$$

In the case of Fr the summation represents the total "hoop stress".

Table 17 - PF Coil Axial Force Coefficients

\begin{tabular}{|l|r|r|r|r|r|r|r|r|r|r|r|r|r|r|}
\hline & OH & PF1AU & PF1AL & PF1BL & PF2U & PF2L & PF3U & PF3L & PF4U & PF4L & PF5U & PF5L & PLA & PLB \\
\hline OH & 0 & -9.6 & 9.6 & 53.3 & -54.1 & 54.1 & -27.7 & 27.7 & -4.6 & 4.6 & -5.9 & 5.9 & 0 & 0 \\
\hline PF1AU & 9.6 & 0 & 0.05 & 0.05 & -24.2 & 0.26 & -2.55 & 0.96 & 3.06 & 1.56 & 3.51 & 2.2 & 0.13 & 0.09 \\
\hline PF1AL & -9.6 & -0.05 & 0 & 97.2 & -0.26 & 24.2 & -0.96 & 2.52 & -1.56 & -3.06 & -2.2 & -3.51 & -0.13 & -0.09 \\
\hline PF1BL & -53.3 & -0.05 & -97.2 & 0 & -0.29 & 17.9 & -1.1 & -7.16 & -1.84 & -4.87 & -2.72 & -5.81 & -0.11 & -0.07 \\
\hline PF2U & 54.1 & 24.2 & 0.26 & 0.29 & 0 & 1.7 & 99.0 & 6.56 & 33.0 & 11.1 & 40.29 & 16.72 & 0.54 & 0.35 \\
\hline PF2L & -54.1 & -0.26 & -24.2 & -17.9 & -1.7 & 0 & -6.6 & -99.0 & -11.08 & -33.0 & -16.7 & -40.3 & -0.54 & -0.35 \\
\hline PF3U & 27.7 & 2.5 & 0.96 & 1.1 & -99.0 & 6.6 & 0 & 26.0 & 165.1 & 44.9 & 204.6 & 69.6 & 1.5 & 0.95 \\
\hline PF3L & -27.7 & -0.96 & -2.5 & 7.2 & -6.6 & 99.0 & -26.0 & 0 & -44.9 & -165.1 & -69.6 & -204.6 & -1.5 & -0.95 \\
\hline PF4U & 4.6 & -3.06 & 1.6 & 1.8 & -33.0 & 11.1 & -165.1 & 44.91 & 0.01 & 89.8 & 189.4 & 138.0 & 1.27 & 0.39 \\
\hline PF4L & -4.6 & -1.6 & 3.1 & 4.9 & -11.1 & 33.0 & -44.9 & 165.1 & -89.8 & -0.01 & -138.0 & -189.4 & -1.27 & -0.39 \\
\hline PF5U & 5.9 & -3.5 & 2.2 & 2.71 & -40.3 & 16.7 & -204.6 & 69.6 & -189.4 & 138.0 & 0 & 225.9 & 1.31 & 0.42 \\
\hline PF5L & -5.9 & -2.2 & 3.5 & 5.81 & -16.7 & 40.3 & -69.6 & 204.6 & -138.0 & 189.4 & -225.9 & 0 & -1.31 & -0.42 \\
\hline PLA & 0 & -0.13 & 0.13 & 0.11 & -0.54 & 0.54 & -1.5 & 1.5 & -1.27 & 1.27 & -1.31 & 1.31 & 0 & 0 \\
\hline PLB & 0 & -0.09 & 0.09 & 0.07 & -0.35 & 0.35 & -0.95 & 0.95 & -0.39 & 0.39 & -0.42 & 0.42 & 0 & 0 \\
\hline
\end{tabular}

Table 18 - PF Coil Radial (Hoop) Force Coefficients

\begin{tabular}{|c|c|c|c|c|c|c|c|c|c|c|c|c|c|c|}
\hline & OH & PF1AU & PF1AL & PF1BL & PF2U & PF2L & PF3U & PF3L & PF4U & PF4L & PF5U & PF5L & PLA & PLB \\
\hline OH & 23112.1 & -33.8 & -33.8 & -57.7 & -18.9 & -18.9 & -15.2 & -15.2 & -10.5 & -10.5 & -14.1 & -14.1 & -0.4 & -0.2 \\
\hline PF1AU & 2493.8 & 439.1 & 0.5 & 0.33 & -7.14 & 0.71 & -8.69 & 1.14 & -1.27 & 0.72 & -1.65 & 0.74 & 0.08 & 0.04 \\
\hline PF1AL & 2493.8 & 0.5 & 439.1 & 22.7 & 0.71 & -7.14 & 1.14 & -8.69 & 0.72 & -1.27 & 0.74 & -1.65 & 0.08 & 0.04 \\
\hline PF1BL & 1283.1 & 0.57 & 210.1 & 302.4 & 0.88 & -56.5 & 1.52 & -14.59 & 1.21 & -0.15 & 1.43 & -0.57 & 0.11 & 0.06 \\
\hline PF2U & 942.3 & 180.4 & 3.41 & 2.44 & 387.2 & 5.5 & -110.4 & 9.7 & 4.1 & 8.4 & 1.5 & 10.3 & 0.67 & 0.4 \\
\hline PF2L & 942.3 & 3.41 & 180.4 & 290.9 & 5.5 & 387.2 & 9.7 & -110.4 & 8.4 & 4.1 & 10.3 & 1.5 & 0.67 & 0.4 \\
\hline PF3U & 1007.4 & 151.3 & 13.3 & 9.68 & 447.9 & 21.9 & 515.4 & 40.1 & 44.7 & 37.6 & 24.7 & 47.0 & 2.64 & 1.63 \\
\hline PF3L & 1007.4 & 13.3 & 151.3 & 150.9 & 21.9 & 447.9 & 40.1 & 515.4 & 37.6 & 44.7 & 47.0 & 24.7 & 2.64 & 1.63 \\
\hline PF4U & 667.4 & 53.8 & 20.9 & 14.9 & 92.4 & 33.3 & 166.1 & 59.0 & 184.4 & 56.8 & -899.0 & 57.5 & 4.28 & 2.48 \\
\hline PF4L & 667.4 & 20.9 & 53.8 & 40.4 & 33.3 & 92.4 & 59.0 & 166.1 & 56.8 & 184.4 & 57.5 & -899.0 & 4.28 & 2.48 \\
\hline PF5U & 903.8 & 70.7 & 32.3 & 23.7 & 130.0 & 54.0 & 264.1 & 100.2 & 1284.3 & 111.8 & 395.1 & 127.9 & 5.8 & 3.2 \\
\hline PF5L & 903.8 & 32.3 & 70.7 & 55.0 & 54.0 & 130.0 & 100.2 & 264.1 & 111.8 & 1284.3 & 127.9 & 395.1 & 5.8 & 3.2 \\
\hline PLA & 31.0 & 0.97 & 0.97 & 0.52 & 0.9 & 0.9 & 0.76 & 0.76 & -0.74 & -0.74 & -1.07 & -1.07 & 0.08 & 0.04 \\
\hline PLB & 17.2 & 0.62 & 0.62 & 0.33 & 0.56 & 0.56 & 0.39 & 0.39 & -0.52 & -0.52 & -0.61 & -0.61 & 0.04 & 0.03 \\
\hline
\end{tabular}


The above forces are relevent primarily to the design of the coil supports and the outer VV which supports the outer PF coils.

\subsubsection{Center Stack Casing}

To the extent that the halo current is axi-symmetric it results in a uniform inward pressure on the wall of the CSC. The non-axisymmetric component causes a net radial load of less than $100 \mathrm{lbs}$, which, since the casing is fixed to the support structure only at the bottom, produces a bending moment reacted at the bottom flange. The maximum von Mises stress occurs at the flange connection to the shell and is $8.6 \mathrm{ksi}$. At the midplane the maximum bending stress is $2.6 \mathrm{ksi}$ and the maximum displacement is $<0.02$ ".

\subsubsection{Outer Vacuum Vessel}

The outer VV is loaded by the following forces:

1) dead weight

2) vacuum

a. balanced

b. unbalanced

3) thermal

a. normal operation

b. bakeout

4) electromagnetic

a. normal operation

b. plasma disruption

5) seismic

Except for 2)b. and 5), an ANSYS finite element 3-D model was used to analyze the loads and stresses [22]. As shown in Figure 27 the model was limited to one toroidal quadrant of the NSTX machine with one NBI port and two 24 " circular midplane ports. The model also includes the upper and lower domes, reinforcing ribs, dome ports, umbrella structures, passive plates and outboard divertor internal hardware structures and their supports, and one leg support assembly. In some cases the sliding joint features are modeled explicitly, in others their effect is simulated by suitable adjustment of material properties. 

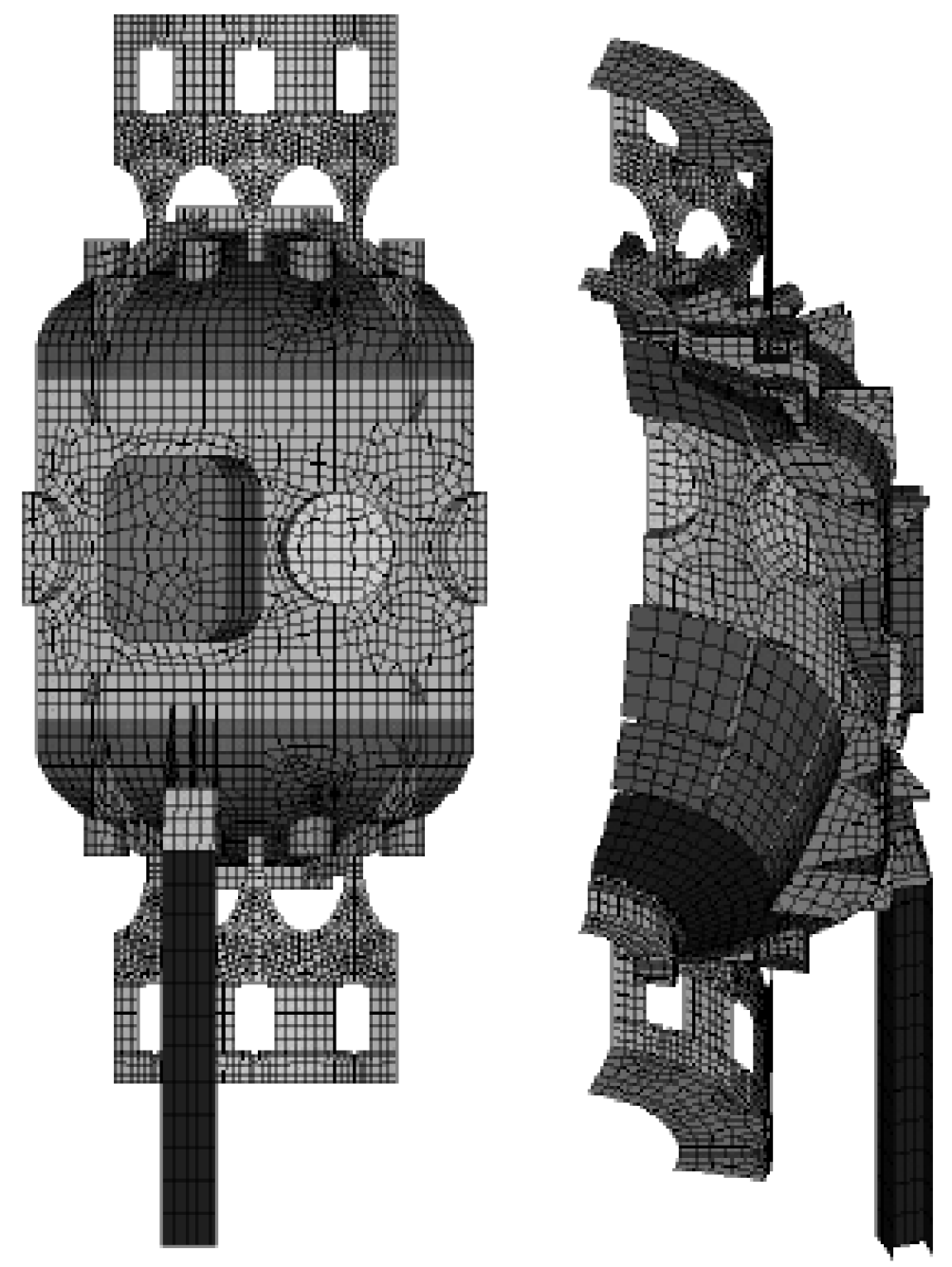

Figure 27 - Quarter Section Finite Element Model of Vacuum Vessel

Tables 19 (normal operations at $50^{\circ} \mathrm{C}$ ) and 20 (bakeout operations with outer $\mathrm{VV}$ at $150^{\circ} \mathrm{C}$ and internal hardware $350^{\circ} \mathrm{C}$ ) summarize the results of the analysis. In order to elucidate the results separate rows are included which exclude the divertor, and which include the vessel only, leg support only, and torque frame only in the scan for minima and maxima. Also given are the applicable allowables at the given temperatures, based on a maximum stress intensity for 304 stainless steel of $20 \mathrm{ksi} @ 50^{\circ} \mathrm{C}$ and $18.7 \mathrm{ksi} @$ $200^{\circ} \mathrm{C}$. The finite element analysis proved an invaluable tool in identifying weak spots in the design and confirming corrective measures. The above results reflect the evolved design after various corrections such as inclusion of ribs, increase in material thicknesses, increases in welds, inclusion of sliding joints, and measures to avoid large thermal gradients. 
Table 19 -Vacuum Vessel Stresses and Deflections, Normal Operation

\begin{tabular}{|c|c|c|c|c|c|c|}
\hline & 1 & 2 & 3 & 4 & 5 & 6 \\
\hline Loading & $\begin{array}{c}\text { Tem } \\
\text { p. }\end{array}$ & EM & Vacuum & Dead Load & $\begin{array}{c}\text { T+EM+DL+ } \\
\text { Vac }\end{array}$ & $\mathrm{EM}+\mathrm{DL}+\mathrm{Vac}$ \\
\hline Max. Svm (ksi) & 16.97 & 21.76 & 10.94 & 7.31 & 22.92 & 21.90 \\
\hline Membrane Svm (ksi) & 3.21 & 21.32 & 6.83 & 4.99 & 21.76 & 21.61 \\
\hline Max. U (in) & 0.080 & 0.054 & 0.021 & 0.016 & 0.088 & 0.056 \\
\hline Max. Ux (in) & 0.045 & 0.025 & 0.006 & 0.009 & 0.050 & 0.025 \\
\hline Min. Ux (in) & 0.000 & -0.013 & -0.021 & -0.010 & 0.006 & -0.027 \\
\hline Max/Min Uy (in) & 0.004 & -0.047 & -0.007 & -0.005 & -0.048 & -0.049 \\
\hline Max/Min Uz (in) & 0.080 & 0.020 & 0.014 & -0.016 & 0.072 & -0.030 \\
\hline w/o Divertor Svm (ksi) & 16.97 & 21.76 & 10.94 & 7.31 & 22.92 & 21.90 \\
\hline Vessel only Svm (ksi) & 16.97 & 11.43 & 10.94 & 3.76 & 18.13 & 13.56 \\
\hline Leg Support Svm (ksi) & 4.89 & 2.10 & 1.61 & 7.31 & 8.21 & 7.82 \\
\hline $\begin{array}{l}\text { Torque Frame max. } \\
\text { Svm (ksi) }\end{array}$ & 3.29 & 21.76 & 0.53 & 0.63 & 22.92 & 21.90 \\
\hline $\begin{array}{l}\text { Bending + Membrane } \\
\text { Allowable } @ 50^{\circ} \mathrm{C}\end{array}$ & & & & & 60.00 & 30.00 \\
\hline $\begin{array}{l}\text { General/Local } \\
\text { Membrane Allowable } \\
@ 50^{\circ} \mathrm{C}\end{array}$ & & & & & & $20.0 / 30.0$ \\
\hline
\end{tabular}

Table 20 -Vacuum Vessel Stresses and Deflections, Bakeout

\begin{tabular}{|l|c|c|c|c|c|}
\hline Load Case & 1 & 2 & 3 & 4 & 5 \\
\hline Loading & Temp. & Vacuum & Dead Load & $\begin{array}{c}\text { Vacuum+ Dead } \\
\text { Load }\end{array}$ & $\begin{array}{c}\text { BT+DL+ } \\
\text { Vacuum }\end{array}$ \\
\hline Max. Svm (ksi) & 38.87 & 10.94 & 7.31 & 11.66 & 39.74 \\
\hline Membrane Svm (ksi) & 15.23 & 6.83 & 4.99 & 6.89 & 16.83 \\
\hline Max. U (in) & 0.315 & 0.021 & 0.016 & 0.023 & 0.306 \\
\hline Max. Ux (in) & 0.194 & 0.006 & 0.009 & 0.007 & 0.182 \\
\hline Min. Ux (in) & 0.000 & -0.021 & -0.010 & -0.021 & 0.000 \\
\hline Max/Min Uy (in) & 0.015 & -0.007 & -0.005 & -0.008 & 0.012 \\
\hline Max/Min Uz (in) & 0.300 & 0.014 & -0.016 & -0.022 & 0.282 \\
\hline w/o Divertor Svm (ksi) & 38.87 & 10.94 & 7.31 & 11.66 & 39.74 \\
\hline Vessel only Svm (ksi) & 38.87 & 10.94 & 3.76 & 11.66 & 39.74 \\
\hline Leg Support Svm (ksi) & 23.93 & 1.61 & 7.31 & 4.84 & 26.40 \\
\hline Torque Frame Svm (ksi) & 15.52 & 0.53 & 0.63 & 0.81 & 15.38 \\
\hline $\begin{array}{l}\text { Bending Plus Membrane } \\
\text { Allowable @ 200 }\end{array}$ & & & & 28.10 & 56.10 \\
\hline $\begin{array}{l}\text { General/Local Membrane } \\
\text { Allowable @ 200 }{ }^{\circ} \mathrm{C}\end{array}$ & & & & $18.7 / 28.1$ & \\
\hline
\end{tabular}




\section{Thermal and Hydraulic Design and Performance}

\subsection{Normal Operation}

\subsubsection{Coil Cooling Water}

De-ionized cooling water is supplied at $10^{\circ} \mathrm{C}$ with resistivity $\geq 1 \mathrm{M} \Omega-\mathrm{cm}$. Cooling water flow and pressure drop is described in Table 21 [7,9]. $\mathrm{OH}$ numbers refer to layer numbers 1-4, each of which as two winding $X$ and $Y$ in hand. Nominal $\mathrm{OH}$ flow rates are designed to minimize the temperature difference between layers during cool-down. TF reflects each inner leg turn in series with each outer leg turn.

Table 21 - Cooling Water Flow

\begin{tabular}{|c|c|c|c|c|c|}
\hline Coil & $\begin{array}{l}\text { Flow/ } \\
\text { Circuit }\end{array}$ & Velocity & No. of Circuits & Flow & $\Delta \mathrm{P}$ \\
\hline & (GPM) & $(\mathrm{m} / \mathrm{s})$ & & (GPM) & (PSI) \\
\hline $\mathrm{OH} 1 \mathrm{X}$ & 0.64 & 2.3 & 1 & 0.6 & 207.3 \\
\hline $\mathrm{OH} 1 \mathrm{Y}$ & 0.64 & 2.3 & 1 & 0.6 & 207.8 \\
\hline $\mathrm{OH} 2 \mathrm{X}$ & 0.71 & 2.5 & 1 & 0.7 & 266.3 \\
\hline $\mathrm{OH} 2 \mathrm{Y}$ & 0.71 & 2.5 & 1 & 0.7 & 266.3 \\
\hline $\mathrm{OH} 3 \mathrm{X}$ & 0.76 & 2.7 & 1 & 0.8 & 329.7 \\
\hline $\mathrm{OH} 3 \mathrm{Y}$ & 0.76 & 2.7 & 1 & 0.8 & 331.8 \\
\hline $\mathrm{OH} 4 \mathrm{X}$ & 0.82 & 2.9 & 1 & 0.8 & 400.0 \\
\hline $\mathrm{OH} 4 \mathrm{Y}$ & 0.82 & 2.9 & 1 & 0.8 & 400.0 \\
\hline PF1a & 6.15 & 3.0 & 2 & 12.3 & 100.0 \\
\hline PF1b & 3.10 & 3.1 & 1 & 3.1 & 100.0 \\
\hline PF2a & 5.38 & 2.6 & 2 & 10.8 & 100.0 \\
\hline PF2b & 5.38 & 2.6 & 2 & 10.8 & 100.0 \\
\hline PF3a & 3.62 & 1.8 & 2 & 7.2 & 100.0 \\
\hline PF3b & 3.62 & 1.8 & 2 & 7.2 & 100.0 \\
\hline PF4b & 4.66 & 2.3 & 2 & 9.3 & 100.0 \\
\hline $\mathrm{PF} 4 \mathrm{c}$ & 4.34 & 2.1 & 2 & 8.7 & 100.0 \\
\hline PF5a & 3.59 & 1.7 & 2 & 7.18 & 100.0 \\
\hline PF5b & 3.59 & 1.7 & 2 & 7.18 & 100.0 \\
\hline $\mathrm{TF}$ & 3.20 & 1.0 & 36 & 115.2 & 94.8 \\
\hline & & Totals & 61.0 & 202.7 & \\
\hline
\end{tabular}


Heat loads are given in Table 22 for the three modes of NSTX operation. TF losses are the same in all three modes $\left(\mathrm{B}_{\mathrm{T}}=0.6 \mathrm{~T}\right.$ assumed in short flat top, inductive mode).

Table 22 - Heat Loads to Cooling Water System

\begin{tabular}{|l|c|c|c|c|c|c|}
\hline \multicolumn{1}{|c|}{ Mode } & OH ESW & PF ESW & TF ESW & $\begin{array}{c}\text { Pulsed } \\
\text { Loss }\end{array}$ & $\begin{array}{c}\text { Rep } \\
\text { Period }\end{array}$ & Avg. Loss \\
\hline & $(\mathrm{sec})$ & $(\mathrm{sec})$ & $(\mathrm{sec})$ & $(\mathrm{MJ})$ & $(\mathrm{sec})$ & $(\mathrm{kW})$ \\
\hline Inductive & 0.525 & 1.0 & 1.5 & 75.1 & 600.0 & 125.2 \\
\hline $\begin{array}{l}\text { Partial } \\
\text { Inductive }\end{array}$ & 0.238 & 5.0 & 6.0 & 104.5 & 300.0 & 348.2 \\
\hline $\begin{array}{l}\text { Non- } \\
\text { Inductive }\end{array}$ & 0.000 & 5.0 & 6.0 & 96.3 & 300.0 & 321.1 \\
\hline
\end{tabular}

\subsubsection{Vacuum Vessel and Internal Hardware Heating and Cooling}

Machine temperature is regulated at $50^{\circ} \mathrm{C}$ using a heating/cooling skid which circulates pressurized water through stainless steel piping networks, one external to the machine and welded to the outer VV, the other internal to the machine and brazed into the copper backing plates of the divertors and passive plate. Auxiliary heating power input of up to $6 \mathrm{MW}$ for 5 seconds, once every 300 seconds (average power $100 \mathrm{~kW}$ ) must be removed from the machine by the skid. The center stack casing is not actively cooled, and heat deposited thereon is mainly removed by radiation outward to the divertor and passive plates. Inward heat flow is minimized by the Microtherm insulation. For fully rated ohmic, RF and NBI heating power input it is anticipated that the center stack casing may ratchet to a temperature as high as $600^{\circ} \mathrm{C}$.

\subsubsection{Heat Loads on PFC tiles}

The heat loads specified by Physics [23] for the PFC tiles are given in Table 23 for the three plasma configurations. The design requirement is to limit tile temperatures below $1200^{\circ} \mathrm{C}$ to avoid sublimation.

Heat flux on the divertors is assumed to impinge over a region beginning at the strike point and ending at a distance of equal to the power flux width $(\Delta)$ given in the Table. The peak heat flux occurs at the strike point. The heat 
flux (q) along the power flux width is assumed equal to $\mathrm{q}(\mathrm{x})=\mathrm{q}_{\mathrm{peak}} * \varepsilon^{-\mathrm{x} / \Delta}$ where $\mathrm{x}=0$ occurs at the strike point.

Extensive analysis of the thermal performance of the various NSTX tile designs was performed, including the center stack carbon fiber composite (CFC) tiles and the graphite tiles used on the center stack, divertors, and passive plates [24]. Both 1D and 3D analysis using P-THERMAL was used in the studies.

Table 23 -Heat Loads on Plasma Facing Components

\begin{tabular}{|c|c|c|c|c|c|c|c|c|}
\hline \multirow[t]{2}{*}{ Scenario } & \multirow[t]{2}{*}{ Parameter } & \multicolumn{2}{|c|}{ Inner Div } & \multicolumn{2}{|c|}{ Outer Div } & \multirow{2}{*}{$\begin{array}{l}\text { Inner } \\
\text { Wall } \\
\end{array}$} & \multirow[t]{2}{*}{ Total } & \\
\hline & & Upper & Lower & Upper & Lower & & & \\
\hline \multirow{5}{*}{$\begin{array}{l}\text { Natural } \\
\text { Divertor }\end{array}$} & Total Power & & & & & & 6.0 & MW \\
\hline & Radiated Power & & & & & & 1.8 & MW \\
\hline & Non-Radiated Power & 0.0 & 0.0 & 1.1 & 1.1 & 2.1 & 4.2 & MW \\
\hline & Power Flux Width & 0.000 & 0.000 & 0.094 & 0.094 & 2.000 & & $\mathrm{~m}$ \\
\hline & Peak Flux & 0.0 & 0.0 & 4.3 & 4.3 & 1.9 & & $\mathrm{MW} / \mathrm{m}^{\wedge} 2$ \\
\hline \multirow{5}{*}{$\begin{array}{l}\text { Double } \\
\text { Null }\end{array}$} & Total Power & & & & & & 6.0 & MW \\
\hline & Radiated Power & & & & & & 1.8 & MW \\
\hline & Non-Radiated Power & 0.4 & 0.4 & 1.7 & 1.7 & 0.0 & 4.2 & MW \\
\hline & Power Flux Width & 0.038 & 0.038 & 0.038 & 0.038 & 2.000 & & $\mathrm{~m}$ \\
\hline & Peak Flux & 5.1 & 5.1 & 17.1 & 17.1 & 0.0 & & $\mathrm{MW} / \mathrm{m}^{\wedge} 2$ \\
\hline \multirow{5}{*}{$\begin{array}{l}\text { Single } \\
\text { Null }\end{array}$} & Total Power & & & & & & 6.0 & MW \\
\hline & Radiated Power & & & & & & 1.8 & MW \\
\hline & Non-Radiated Power & 0.0 & 1.4 & 0.0 & 2.8 & 0.0 & 4.2 & MW \\
\hline & Power Flux Width & 0.000 & 0.092 & 0.000 & 0.100 & 2.000 & & $\mathrm{~m}$ \\
\hline & Peak Flux & 0.0 & 7.0 & 0.0 & 10.8 & 0.0 & & $\mathrm{MW} / \mathrm{m}^{\wedge}$ \\
\hline
\end{tabular}

Main conclusions of the PFC thermal analysis were that:

- For 5 second pulsing, thermal penetration is limited to $\sim 0.5$ " such that increased tile thickness is not beneficial in terms of thermal absorption;

- Without divertor sweeping, the maximum power flux with a peak temperature allowable of $1200^{\circ} \mathrm{C}$ is $6 \mathrm{MW} / \mathrm{m} 2$; 
- In order to receive power with flux in excess of $6 \mathrm{MW} / \mathrm{m} 2$ (as is required for a limited number of cases) without exceeding the temperature allowable, divertor sweeping will be required.

\subsection{Bakeout}

The ANSYS finite element 3-D, 1/4 section model used to analzye the vacuum vessel stresses was also used to estimate the heat flow during bakeout, with the internal hardware PFC tiles at $350^{\circ} \mathrm{C}$ and the outer $\mathrm{VV}$ at $150^{\circ} \mathrm{C}$ [24]. Heat flow is summarized in Table 24.

Table 24 - Heat Flow During Bakeout

\begin{tabular}{|l|l|}
\hline HEAT INPUTS & \\
\hline Passive Plate and Divertor Heating & $86.7 \mathrm{~kW}$ \\
\hline Center Stack Ohmic Heating & $5.3 \mathrm{~kW}$ \\
\hline Total Input & $74 \mathrm{~kW}$ \\
\hline HEAT OUTPUTS & \\
\hline Outward to Cooling System on Outer VV & $60.0 \mathrm{~kW}$ \\
\hline Inward from Center Stack to OH coil & $5.3 \mathrm{~kW}$ \\
\hline Outward through Outer VV insulation and port covers and ducts & $8.7 \mathrm{~kW}$ \\
\hline
\end{tabular}

It should be noted that these results are highly dependant on assumed conductivites and emissivities.

For the ohmic heating a DC power supply is used which is capable of delivering $4 \mathrm{kA}$ to the center stack casing, which has a resistance of $830 \mu \Omega$ at $350^{\circ} \mathrm{C}$. Therefore the available ohmic heat input is $4 \mathrm{kA} 2 * 830 \mu \Omega=$ $13.3 \mathrm{~kW}$.

For the internal hardware heating, the original design called for the use of a high temperature heat transfer fluid to be circulated in the stainless steel tubing network both inside and outside the vessel. However, concerns over flammability, and pollution of the inside of the vacuum vessel in case of a leak, have ruled out the use of this or any other complex compounds. Therefore at this time the Project is considering alternative methods (including superheated steam and compressed air). Until a decision is taken on an alternative scheme the system's operation is limited to $150^{\circ} \mathrm{C}$ using pressurized water. 


\section{Fabrication Features}

\subsection{TF and $\mathrm{OH}$ Coils}

$\mathrm{TF}$ and $\mathrm{OH}$ coils were manufactured by Everson Electric Co., Bethlehem, PA.

\subsubsection{Conductors}

All TF and $\mathrm{OH}$ conductors utilize Copper Development Association (CDA) alloy 10700 (silver bearing oxygen free copper) with 100\% IACS conductivity, "quarter hard" for TF and "half hard" for $\mathrm{OH}$. The two TF inner leg conductor shapes were extruded and then machined to provide 1) electrical joint bolt holes with threaded inserts, 2) precision electrical joint contact surfaces and 3) milled groove for insertion and soldering of water cooling tube. The TF outer leg conductors were roll-formed, then milled grooves added for soldering of the water tube. The $\mathrm{OH}$ conductors are extruded with a central cooling hole. The extruded cross section of the $\mathrm{OH}$ conductor is slightly non-rectangular to compensate for the "keystone" effect, such that after winding into the relatively small radius, the deformed shape becomes closer to rectangular. Since each of the four layers has a different radius whereas only one conductor extrusion was made, the final selected shape is a compromise and none of the layers are perfectly rectangular.

\subsubsection{Electrical Insulation}

Preliminary design work indicated the need for a high shear strength turn-toturn insulation in the TF inner leg bundle with a relatively low voltage withstand requirement, but quite the opposite in the $\mathrm{OH}$ system where the shear stress is low and the voltage much higher. In the TF coil the first and last of the 36 turns are adjacent to one another, but the voltage is only $1 \mathrm{kV}$. In the $\mathrm{OH}$ coil the maximum voltages which appears between turns in the same layer and between layers are $25 \%$ and $75 \%$ of the total terminal voltage, respectively, resulting in turn to turn voltage as high as $4.5 \mathrm{kV}$. Early investigations also addressed the relative merits of a B-staged insulation system versus a Vacuum Pressure Impregnation (VPI). Based on discussions with coil manufacturers and insulation suppliers along with some R\&D [25] it was decided that a B-staged system was feasible and would be less 
expensive than VPI. A B-staged material was identified which could meet the TF requirements for high shear strength and, with the addition of a layer of Kapton, the $\mathrm{OH}$ requirements for dielectric strength, albeit with a reduction in shear strength.

Final selected insulation material for the B-stage epoxy-glass component is a product supplied by Insulating Materials, Inc. (IMI) of Schenectedy, NY, consisting of a glass tape with a TGDM type epoxy supplied to IMI by Composite Technology Development (CTD) of Boulder, Co. R\&D performed by Cryogenic Materials, Inc., Boulder, Co., on the TF inner leg and $\mathrm{OH}$ versions of the insulation consisted of lap shear and shear/compression), shear compression fatigue, and DC hipot. Results are summarized in Table 25. Selected temperatures for shear tests are based on projected temperature at time of peak shear stress. All conductors were grit blasted, solvent wiped, and then primed with Ciba Geigy DZ80-1. This is an essential step in achieving the requisite shear strength.

Details of the TF inner leg and OH insulation systems are given in Table 26.

Table 25 - Insulation R\&D Results

\begin{tabular}{|l|c|c|}
\hline & TF Inner Leg & OH \\
\hline $\begin{array}{l}\text { Bi-axial shear @ 600lbs } \\
\text { compression (avg. psi } \\
\text { failure) }\end{array}$ & $\begin{array}{c}6062 \mathrm{psi} @ 60^{\circ} \mathrm{C}, 8 \\
\text { samples }\end{array}$ & $\begin{array}{c}3710 \mathrm{psi} @ 100^{\circ} \mathrm{C}, 10 \\
\text { samples }\end{array}$ \\
\hline $\begin{array}{l}\text { Fatigue test @ 600lbs } \\
\text { compression (test w/o } \\
\text { failure, 1e6 cycles) }\end{array}$ & $\begin{array}{c}2400 \mathrm{psi} @ 60^{\circ} \mathrm{C}, 6 \\
\text { samples }\end{array}$ & $\begin{array}{c}1000 \mathrm{psi} @ 100^{\circ} \mathrm{C}, 6 \\
\text { samples }\end{array}$ \\
\hline DC Hipot (avg. kV failure) & $\begin{array}{c}16 \mathrm{kV}(420 \text { volt } / \mathrm{mil}), 16 \\
\text { samples }\end{array}$ & \begin{tabular}{c} 
Not tested \\
\hline
\end{tabular}
\end{tabular}


Table 26 - NSTX Insulation Design Details

\begin{tabular}{|c|c|c|}
\hline & TF Inner Leg & $\mathrm{OH}$ \\
\hline \multicolumn{3}{|l|}{ Turn Insulation } \\
\hline Epoxy-glass & IMI 2258XS & IMI 2258XS \\
\hline Thickness (10\% compression) & $0.0054 ”$ & $0.0054 ”$ \\
\hline Number of Layers & 3 half lapped & 1 half lapped \\
\hline Epoxy-glass/Kapton & n.a. & IMI 2259XS \\
\hline Thickness (10\% compression) & n.a. & $0.008 ”$ \\
\hline Number of Layers & n.a. & 1 half lapped \\
\hline Total Build & $0.032 "(0.064 "$ turn-turn $)$ & $0.026(0.0525 "$ turn-turn $)$ \\
\hline Voltage Stress & 15.6 volts/mil @ 1kV & 85.7 volts $/ \mathrm{min} @ 4.5 \mathrm{kV}$ \\
\hline \multicolumn{3}{|l|}{ Ground Insulation (Outer) } \\
\hline Epoxy-glass & 3M Scotchply \#1003 & 3M Scotchply \#1003 \\
\hline Number of Layers & 2 half-lapped & 3 half-lapped \\
\hline Thickness (10\% compression) & $0.009 ”$ & $0.009 ”$ \\
\hline Total Build & $0.036 "$ & $0.054 "$ \\
\hline Ground Insulation (Inner) & n.a. & \\
\hline Teflon & n.a. & $0.002 "$ \\
\hline Number of Layers & n.a. & 2 half-lapped \\
\hline Epoxy-glass & n.a. & IMI 2258XS \\
\hline Thickness (10\% compression) & n.a. & $0.0054 ”$ \\
\hline Number of Layers & n.a. & 3 half-lapped \\
\hline Total Build & n.a. & $0.036 "$ \\
\hline
\end{tabular}

\subsubsection{OH Layer to Layer Joints}

A crucial feature of the $\mathrm{OH}$ coil is the layer to layer joint. As part of the $R \& D$ work several configurations were investigated and tested for ultimate strength prior to selecting a scheme consisting of a 4" overlap of the two conductors to be joined, soldered together with $96 \%$ tin/4\% silver soft solder, then secured using Sil-Fos TIG braze tack welds at the ends of the two overlapping sections. Tests of this configuration, shown in Figure 28, had an average stress to failure at $37.4 \mathrm{ksi}$ ( 8 samples). Fatigue tests were performed on 3 samples at 20ksi cyclic loading and failures occurred after $300 \mathrm{k}, 420 \mathrm{k}$, and $555 \mathrm{k}$ cycles, in all cases in the conductor, not the joint. 


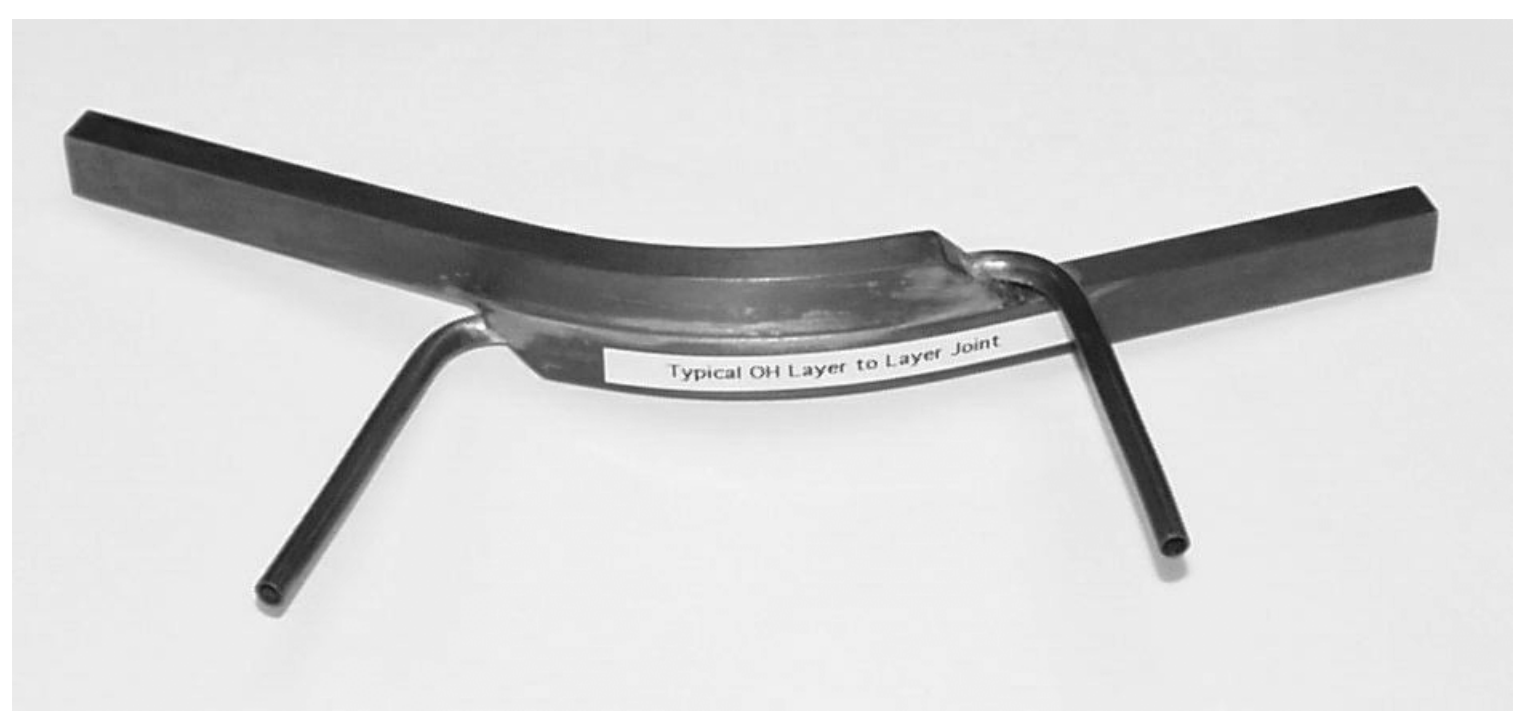

Figure 28 - Prototype OH Layer to Layer Joint

\subsubsection{TF Bundle Fabrication}

A significant fabrication challenge was presented by the TF inner legs: how to assemble the 36 insulated turns into a bundle with sufficient precision to fit within the inner diameter of the $\mathrm{OH}$ tension tube, allowing only a small nominal gap to permit sliding, while at the same time providing the required radial restraint. And, aside from the assembly considerations, the fact that the TF inner legs form the axis of the plasma places additional importance on its precision. The TF inner leg assembly, approximately 18 feet in length, was required to be formed to a tolerance of $+/-0.015$ inches deviation from the ideal cylindrical shape. In order to accomplish this, the following procedure was developed:

1) The assembly was divided into 4 quadrants, each of which was first press-cured in a precision steel mold, which included a special alignment fixture to secure the positions of the ends of the inner legs at their electrical joint contact surface;

2) The quadrants were then brought together, a groundwall insulation applied, and the completed assembly bonded together in a second presscure operation using a final sizing and curing mold;

3 ) The surface of the groundwall insulation was precision machined to achieve the final desired tolerance. 
The TF Inner Leg bundle fabrication process is depicted in Figure 29.

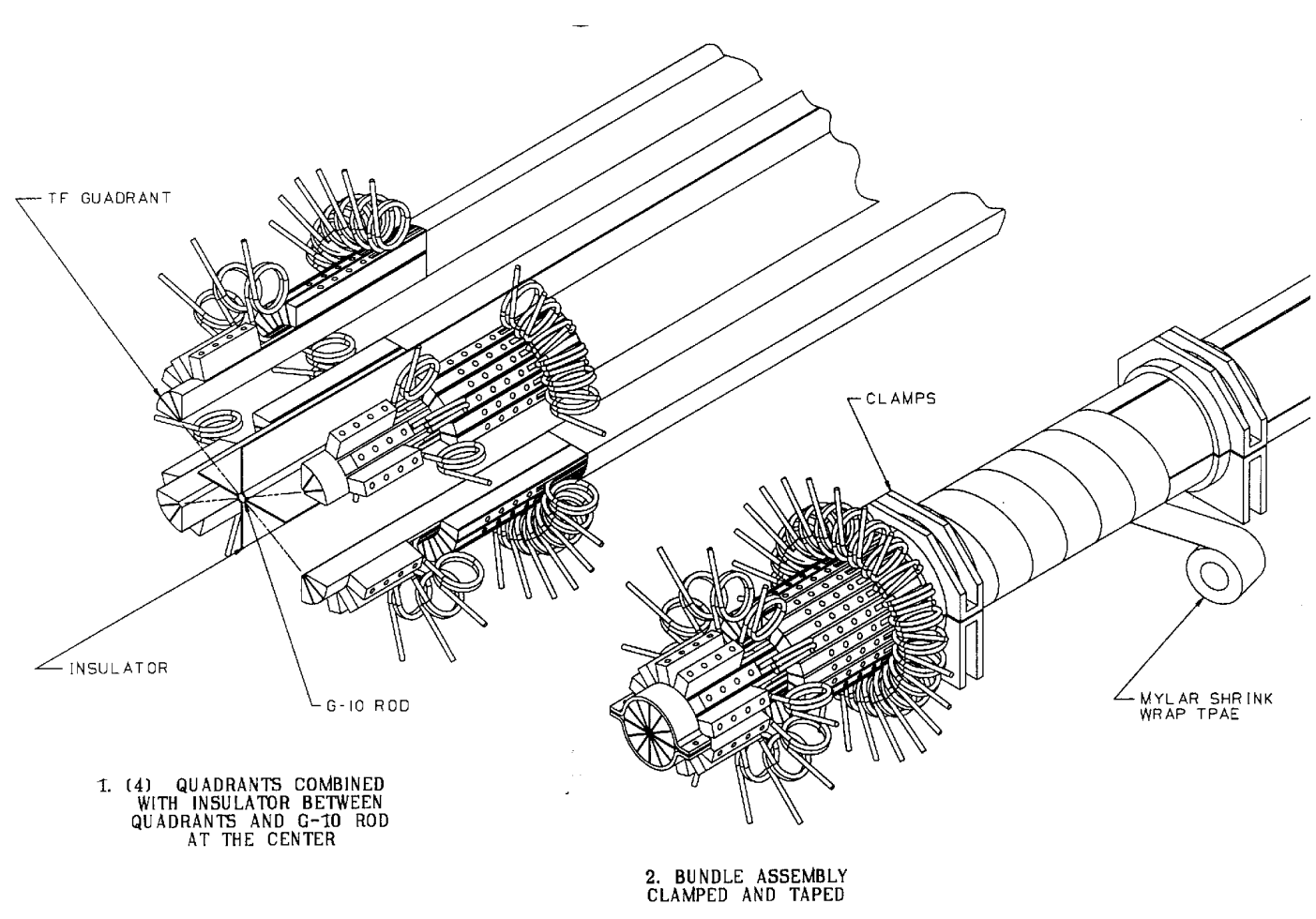

Figure 29 - TF Inner Leg Fabrication Procedure

\subsubsection{TF Inner Leg to Radial Flag Joints}

A crucial feature of the TF coil system is the joint between the inner legs and the radial flags, which operates at high current density. The NSTX joint was designed with a nominal contact pressure of 2000 psi, beyond which little is gained in terms of joint conductance vs. mechanical load. The joint is silver plated to enhance conductivity and to promote stable contact resistance. In addition to contact resistance effects, local joint heating is influenced by the variation in current density as the current leaves the vertical inner leg and enters the radial flag; the current concentrates on the inside of the turn. The outer layer turns present the worst case since the current path transitions from vertical to radial immediately at the joint interface, whereas on the inner layer a short length of radial conductor is present prior to the joint. 
Based on preliminary joint resistance measurements and 2-D transient electrical/thermal simulations, the silver plated joint provides the required conductivity to limit the local heating to $\leq 140^{\circ} \mathrm{C}$. Worst case conditions result from the $\mathrm{B}_{\mathrm{T}}=0.6 \mathrm{~T}$ case, where the pulse time is much shorter than the $0.3 \mathrm{~T}$ case and less time is available for heat diffusion away from the joint.

Although the hub assembly is designed to minimize the variation in pressure on the joint under thermal/mechanical load, $R \& D$ measurements were performed to determine what level of axial and torsional forces are required to produce a measurable variation in contact resistance from the allowable of $2 \mu \Omega /$ in $^{2}$. Vertical loads of up to 1800 in-lbs were applied without measurable change in joint resistance while horizontal loads were found to degrade the joint beginning at that level.

The joint is constructed using four 5/16", A286 bolts, with their length extending the full length of the flag, provide elastic pre-load on the joint which will track thermal expansions and variations in axial loads. The bolts are "body bound" (i.e., tight fitting) at the joint interface so they react shear loads without slippage. They are torqued to provide a pre-load of 2000 psi. Stainless steel threaded inserts are used to provide a hardened bolt interface with improved pull-out strength. Tests indicate a pull-out strength of $\sim 6000$ lbs. The torque restraint structure, in conjunction with the body bound bolts, keeps the joint fixed and clamped under constant pressure throughout the operating cycle. Table 27 lists the major features of the bolted joint.

\section{Table 27 - TF Bolted Joint Features}

\begin{tabular}{|l|l|}
\hline Feature & Description \\
\hline Size \& Number of Bolts & $(4) 5 / 16 "$ bolts \\
\hline Bolt Material & A286 \\
\hline Bolt Length & $11 \mathrm{in}$. \\
\hline Nominal Joint Pressure & $2000 \mathrm{psi}$ \\
\hline Allowable Contact Resistance & $2 \mu \Omega / \mathrm{in}^{2}$ \\
\hline Cross Sectional Area & $5.0 \mathrm{in}^{2}$ \\
\hline Average Current Density @ 71.6kA & $14.3 \mathrm{kA} / \mathrm{in}^{2}$ \\
\hline Load per Bolt & $2500 \mathrm{lb}$ \\
\hline Axial Stress in Bolts & $43000 \mathrm{psi}$ \\
\hline Shear Stress in Bolts & $2300 \mathrm{psi}$ \\
\hline Pullout Yield Load for Insert & $5000 \mathrm{lb}$ \\
\hline Factor of Safety for Pullout & 2 \\
\hline
\end{tabular}


A photograph of the radial leg is shown in Figure 30.

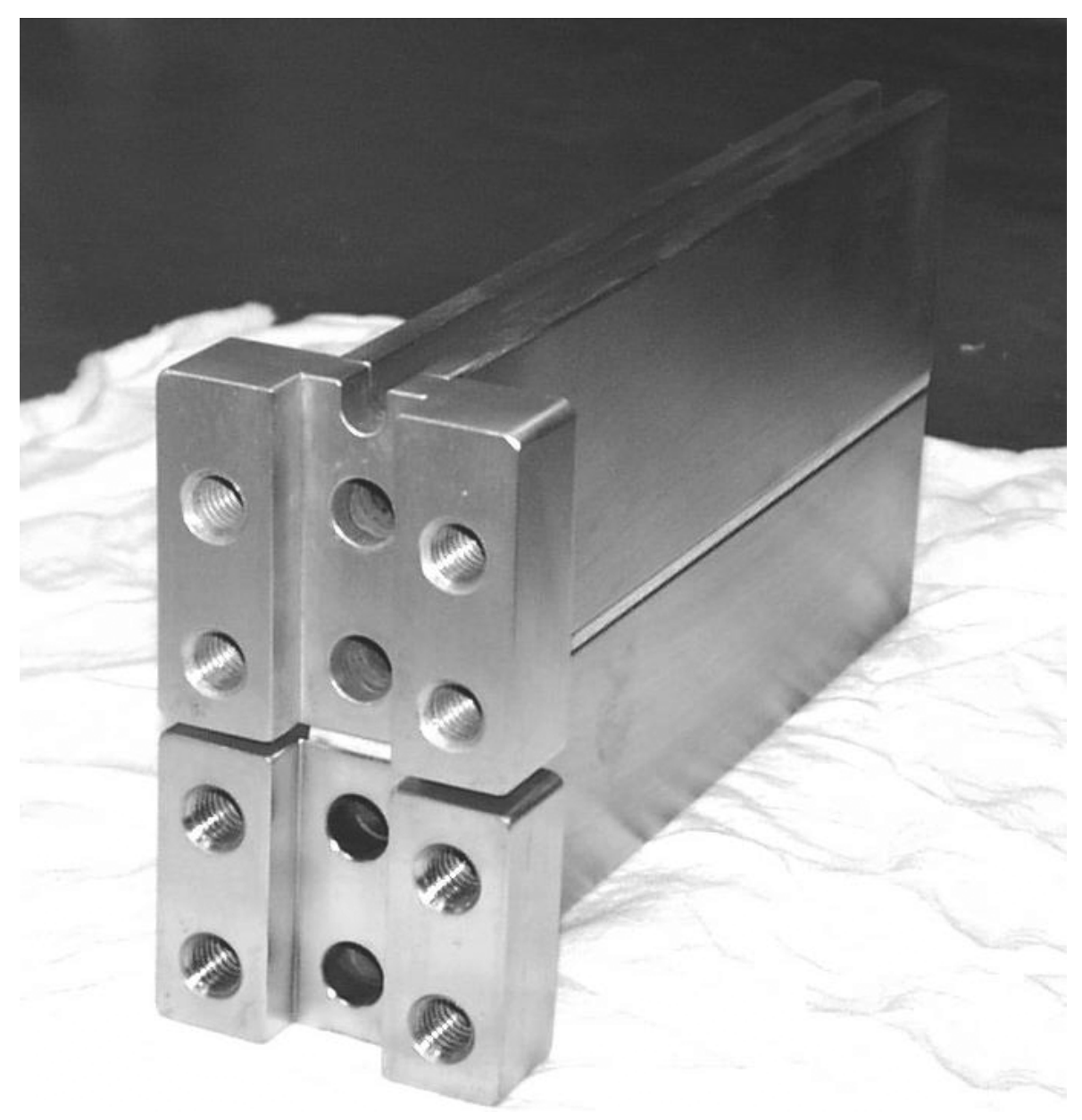

Figure 30 - TF Radial Flag

The flags are designed with a radial split. This feature facilitates fit-up, provides a degree of redundancy, and permits the measurement of joint resistance with relative ease (ohmmeter probes placed on upper and lower sections, current passes in and out of the contact area with the inner leg). 


\subsection{Plasma Facing Components}

The PFC tiles in NSTX consist of 3760 individual tiles of 60 unique designs [26]. The various generic types and their main features are listed in Table 28.

Table 28 - PFC Construction Features

\begin{tabular}{|l|l|l|l|l|l|l|l|l|}
\hline Component & $\begin{array}{l}\text { Tile } \\
\text { Mat'l }\end{array}$ & $\begin{array}{l}\text { Tile } \\
\text { Thick. } \\
\text { (inch) }\end{array}$ & $\begin{array}{l}\text { Back- } \\
\text { plate } \\
\text { Thick. } \\
\text { (inch) }\end{array}$ & $\begin{array}{l}\text { Mount } \\
\text { Method }\end{array}$ & $\begin{array}{l}\text { Surface } \\
\text { Contour } \\
\text { Plasma } \\
\text { Side }\end{array}$ & $\begin{array}{l}\text { Surface } \\
\text { Contour } \\
\text { Back } \\
\text { Side }\end{array}$ & $\begin{array}{l}\text { Tile } \\
\text { Overlap } \\
\text { Toroidal }\end{array}$ & $\begin{array}{l}\text { Tile } \\
\text { Overlap } \\
\text { Poloidal }\end{array}$ \\
\hline $\begin{array}{l}\text { CSC Rail } \\
\text { Tiles }\end{array}$ & CFC & 0.55 & n.a. & rail & cylinder & cylinder & yes & yes \\
\hline $\begin{array}{l}\text { CSC Basic } \\
\text { Tiles }\end{array}$ & Graphite & 0.55 & n.a. & rail & cylinder & cylinder & yes & yes \\
\hline $\begin{array}{l}\text { IBD/ } \\
\text { Conical } \\
\text { Section }\end{array}$ & Graphite & 0.75 & n.a. & bar & conical & conical & yes & yes \\
\hline $\begin{array}{l}\text { IBD/ } \\
\text { Vertical } \\
\text { Section }\end{array}$ & Graphite & 1.0 & n.a. & T-bar & cylinder & cylinder & yes & yes \\
\hline $\begin{array}{l}\text { IBD } \\
\text { Horizontal } \\
\text { Section }\end{array}$ & Graphite & 2.0 & n.a. & T-bar & flat & flat & yes & yes \\
\hline OBD & Graphite & 1.0 & 1.0 & T-bar & flat & flat & yes & yes \\
\hline SPP & Graphite & 1.0 & 0.5 & T-bar & flat & flat & no & yes \\
\hline PPP & Graphite & 1.0 & 0.5 & T-bar & flat & flat & no & yes \\
\hline
\end{tabular}

\section{Notes:}

1) Carbon Fiber Composite (CFC) material manufactured by Allied Signal Corp. (865-19-4)

2) Graphite material manufactured by Union Carbide Corp. (type ATJ)

Except for the CSC tiles, the configuration, material, and application of the tiles follows conventional practice for fusion devices. The CSC tiles are of a unique design driven by the severe constraints on radial build of the center stack; a radial build of only 0.55 " is allocated to the CSC tiles and their mounts. The CSC tiles consist of alternating columns of "rail tiles" and "captured" tiles, the latter which are locked into place by the former. A unique design for mounting the rail tiles to the CSC was developed which 
utilizes drift (shear) pins and Inconel brackets. Installation is accomplished via hidden fasteners accessed through very small holes in the tile faces.

Assuming full current flow in the CSC tiles (and not in the underlying casing), halo current loads can produce a force approaching 100 psi per tile. Although most events are anticipated to result in an inward force on the tile, the possibility of an outward "pull-out" force is assumed to remain. This force is transmitted as a shear load through the drift pins, up to $\sim 300 \mathrm{lbs}$ per pin.In addition the tiles must withstand up to $2 \mathrm{MW} / \mathrm{m} 2$ for 5 seconds, with the underlying $\mathrm{CSC}$ ratcheted up in temperature to $600^{\circ} \mathrm{C}$.

The baseline rail tile design is shown in Figure 31. The rail tile assembly is attached to the CSC by Inconel weld studs and captured allen head nuts. The nuts are tightened through small 0.150 " access holes in the face of the tiles. The design utilizes four, 0.125 " diameter, Inconel drift pins to retain the tile. A step in the rail tile permits lapping adjacent captured tiles and serves to retain them, thereby halving the total number of mounting studs required. Wave springs under the captured tiles serve multiple functions; they pre-load the captured tiles to the rail tiles, cushion them against disruption loads, and permit thermal expansion. Radiation shields are used behind the captured tiles to prevent excessive heat transfer to the center stack column.

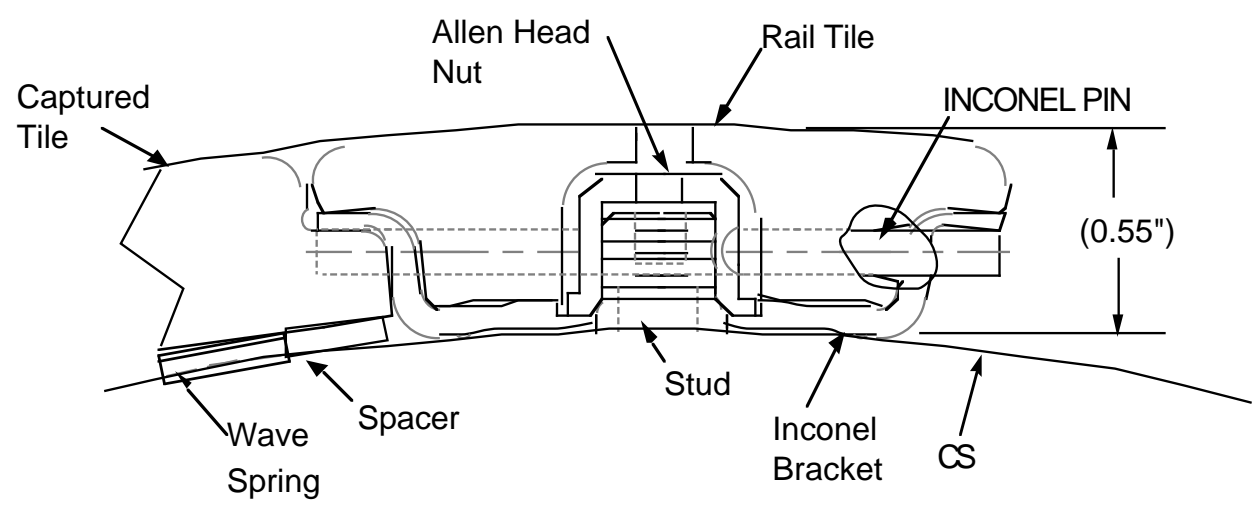

Figure 31 - Center Stack Casing Rail Tile Design

The CSC tile implementation on NSTX was greatly facilitated by the availability of a 2-D carbon fiber composite (CFC) material from Allied Signal Corp. (type 866-19-4). This material was relatively inexpensive, 
available within a reasonable time ( $\sim 6$ months), and possessed the required performance in terms of mechanical strength, thermal conductivity, and thermal performance as evidenced by pull-out and high heat flux tests [28].

\subsection{Magnetic Diagnostics}

Implementation of magnetic diagnostics on the center stack of NSTX was extremely challenging due to the very small available space and the high temperature. The Rogowski loops, which measure the plasma current and must encircle the entire vacuum vessel poloidally, passing through the central stack annular space between the $\mathrm{OH}$ coil groundwall and the Microtherm insulation, are unique [28]. Two are implemented on NSTX, each 34' in length, 0.135" radial thickness, 77 turns per inch. Since the center stack casing is removable, the Rogowskis must be designed to be opened and coiled up without damage. Figure 32 shows a photograph of the Rogowski during the insertion of the $\mathrm{OH}$ coil assembly into the center stack.

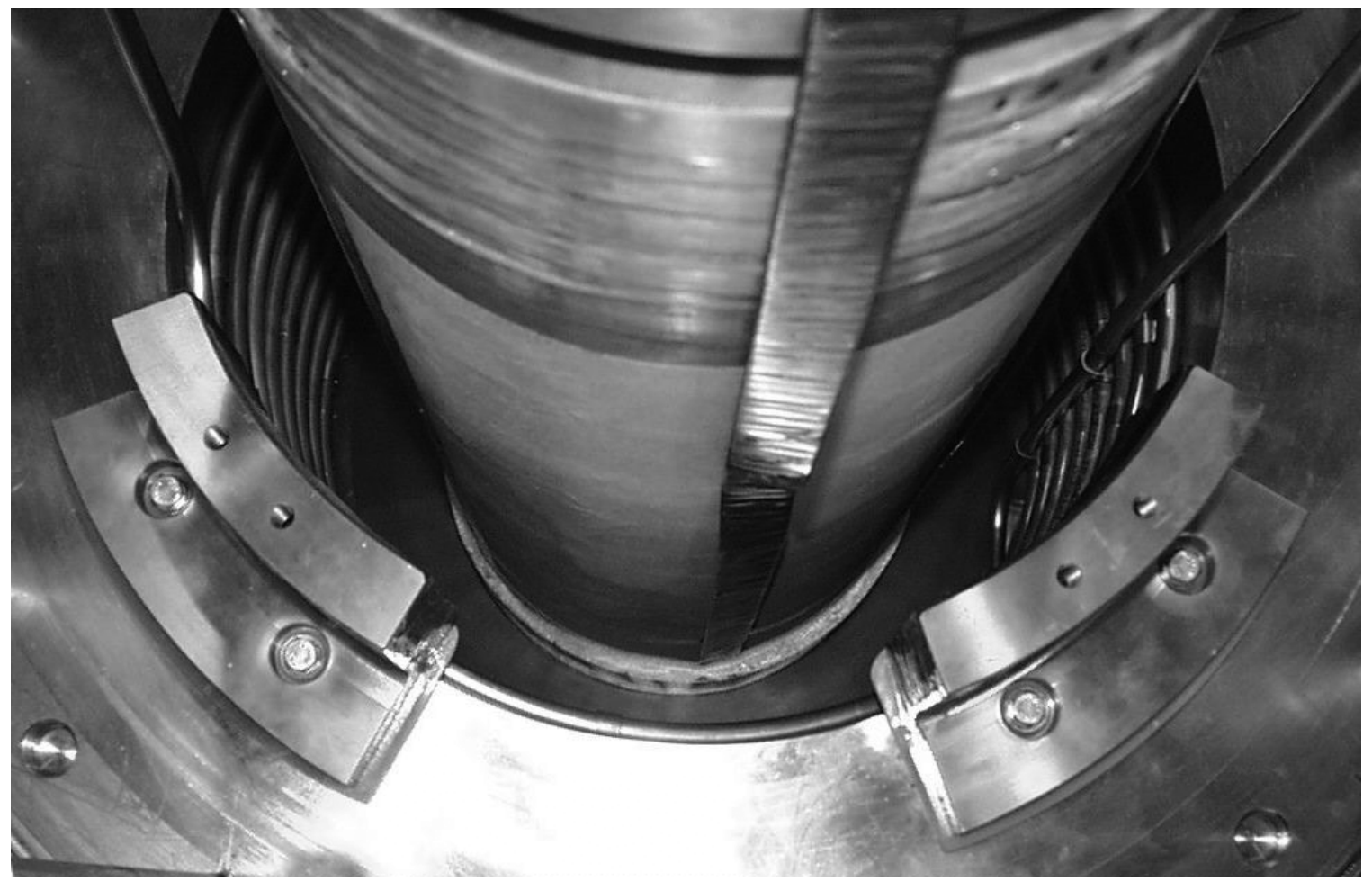

Figure 32 - Plasma Current Rogowski Loop 


\subsection{Magnetic Permeability}

NSTX utilizes a large number of stainless steel components in the vacuum vessel and other structures which are worked, machined, and welded. During the execution of the NSTX Project it was found necessary to advise manufacturers on material selection and processing techniques, and to expand on the definition of magnetic permeabilty allowables, in order that a minimum of field-perturbing components were present on the machine while at the same time reasonable and practical manufacturing procedures could be followed.

Wrought austenitic stainless steels (i.e. plate, pipe, forgings) are typically non-magnetic in the as-rolled condition $\left(\mu_{\mathrm{r}} \leq 1.02\right)$. Thermal processing, welding, cutting, etc., can result in some level of ferrite which increases the permeability. Chemical composition is a key predictor of magnetic characteristics. Chromium, molybdenum, silicon, and columbium promote ferrite while carbon, manganese, and nickel promote austenite. Some limited amount of ferrite is beneficial to stainless steel welds and castings as it prevents micro-fissuring and resistance to stress corrosion cracking. Certain stainless steels such as Type 316 (16Cr 10Ni 2Mo typ.) will contain less ferrite and better magnetic permeability than other such as Type 304 (18Cr 8 Ni typ.). Since most NSTX usage is of Type 304, certain guidelines were followed to minimize permeability such as 1) hot formed steel should be purchased, with the forming method clearly documented by the material certification and 2) when the chemical composition can be reviewed prior to purchase, the choice of a material with lower $\mathrm{Cr}, \mathrm{Mo}, \mathrm{Si}$, and $\mathrm{Cb}$ and higher $\mathrm{C}, \mathrm{Mn}$, and Ni should be preferred, 3) rough cutting of materials used water jet methods where possible. The choice of welding filler material needs to consider ferrite content, expressed as the Ferrite Number (FN). FN between 2 and 4.5 typically produce welds with acceptable permeability which also resist cracks and corrosion. A common weld filler for Type 304 is ER308 which is difficult to find with $\mathrm{FN}$ in the desired range. An alternate is ER316. In some cases the use of a high nickel allow filler (FN 0) may be acceptable if mechanical requirements are not demanding. Careful annealing is another option to reduce permeability.

For NSTX, the allowables were set to $\mu_{\mathrm{r}} \leq 1.05$ for base material, $\mu_{\mathrm{r}} \leq 1.2$ for machined/formed parts, and $\mu_{\mathrm{r}} \leq 2.0$ for welded parts. These numbers represent a considerable increase over the allowables specified at the outset of the project. 


\section{Summary and Conclusions}

NSTX is a proof-of-principle experiment aimed at exploring the physics of the spherical torus configuration. The low aspect ratio decreases the available cross sectional area through the center of the torus for toroidal and poloidal field coil conductors, vacuum vessel wall, plasma facing components, etc., thus increasing the need to deploy all components within the "center stack" in the most efficient manner possible. Therefore careful engineering of this region of the machine, utilizing materials up to their engineering allowables, has been key to meeting the desired objectives. The design and construction of the machine has been accomplished in a rapid and cost effective manner thanks to the availability of extensive facilites, a strong experience base from the TFTR era, and good cooperation between institutions.

\section{References}

[1] M. Peng, Spherical Torus Pathway to Fusion Power, Journal of Fusion Energy, Vol. 17, No. 1, 1998

[2] S. Kaye, M. Ono, Physics Design of the National Spherical Torus Experiment, Fusion Technology, Vol. 36, July 1999

[3] T. Jarboe, Formation and Steady-State Sustainment of a Tokamak by Coaxial Helicity Injection, Fusion Technology, Vol. 15, January 1989

[4] S. Kaye, Inductive Discharge Scenarios, NSTX Memo 72-970129-SMK01

[5] S. Kaye, Disruption Modeling, NSTX Memo 72-970206-SMK-01

[6] S. Kaye, Disruption Forces Due To Halo Currents, Technical Note, February 1998

[7] C. Neumeyer, TF Coil Parameters, NSTX Calculation No. 13-2

[8] C. Neumeyer, OH Coil Thermal Behavior, NSTX Calculation No. 13-3 
[9] C. Neumeyer, PF Coil Parameters, NSTX Calculation No. 13-1

[10] C. Neumeyer, TF Electrical Performance, NSTX Calculation No. 52-1

[11] C. Neumeyer, OH Electrical Performance, NSTX Calculation No. 53-1

[12] S. Kaye, Plasma Initiation, NSTX Memo 72-970129-SMK-02

[13] R. Hatcher et. al., NSTX Plasma Startup Simulations, APS Meeting, 1998

[14] R. Colchin, Eddy Currents in the Toroidal Field Conductors of the Low-Aspect Ratio Tokamak START, Fusion Technology, Vol. 29, May 1996

[15] J. Bialek, Eddy Currents in TF Cross Section, NSTX Memo 13-970214JMB-01

[16] I. Zatz, SPARK Plasma Disruption Simulation, NSTX Calculation No. 11-1.

[17] C. Neumeyer, Internal Hardware Force Calculation, NSTX Calculation No. 11-2

[18] J. Bialek, J. Spitzer, Estimate of Halo Loads for Inner Leg of the Vacuum Vessel, NSTX Memo 13-961010-JMB-01

[19] N. Pomphrey, J. Bialek, W. Park, Modeling of the Toroidal Asymmetry of Poloidal Halo Currents in Conducting Structures, Nuclear Fusion, Vol. 38, No. 3, 1998

[20] H.M.Fan, TF Coil Stress Analysis, NSTX Calculation No. 13-12

[21] H.M.Fan, OH Coil Stress Analysis, NSTX Calculation No. 13-11

[22] H. M. Fan, Vacuum Vessel Stress Analysis for NSTX Plasma Disruption Loads, Technical Note

[23] S. Kaye, NSTX Divertor Heat Flux Estimates, PPPL Memo October 24, 1996 
[24] B. Nelson, Thermal Analysis of NSTX Center Stack and Outboard Divertor Tiles, NSTX Calculation No. 11-5

[25] A. Brooks, H.M.Fan.Update of VV Bakeout Heating Requirements, NSTX Memo 13-980511-AWB-01

[26] J. Chrzanowski, Center Stack R\&D Final Report, NSTX No. 13970430-JHC

[27] P. Goranson, et.al., Design of the Plasma Facing Components for NSTX, Proceedings $18^{\text {th }}$ SOFE 1999

[28] R. Nygren, et. al., High Heat Flux Tests of Carbon Composites for KSTAR and NSTX, Proceedings $18^{\text {th }}$ SOFE 1999

[29] B. McCormack, et. al., Rogowski Loop Designs for NSTX, Proceedings $18^{\text {th }}$ SOFE 1999 
The Princeton Plasma Physics Laboratory is operated by Princeton University under contract with the U.S. Department of Energy.

\author{
Information Services \\ Princeton Plasma Physics Laboratory \\ P.O. Box 451 \\ Princeton, NJ 08543
}

Phone: 609-243-2750

Fax: 609-243-2751

e-mail: pppl_info@pppl.gov

Internet Address: http://www.pppl.gov 